\section{orn}

OAK RIDGE

NATIONAL

LABORATORY

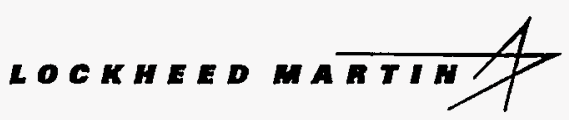

MANAGED BY

LOCKHEED MARTIN ENERGY SYSTEMS, INC.

FOR THE UNITED STATES

DEPARTMENT OF ENERGY

DEC 281995 DOE-HUD INITIATIVE

OSTI Impact Evaluation of the Energy Retrofits Installed in the Margolis High-Rise Apartment Building, Chelsea Housing Authority

M. M. Abraham

H.A. McLain

J.M. MacDonald

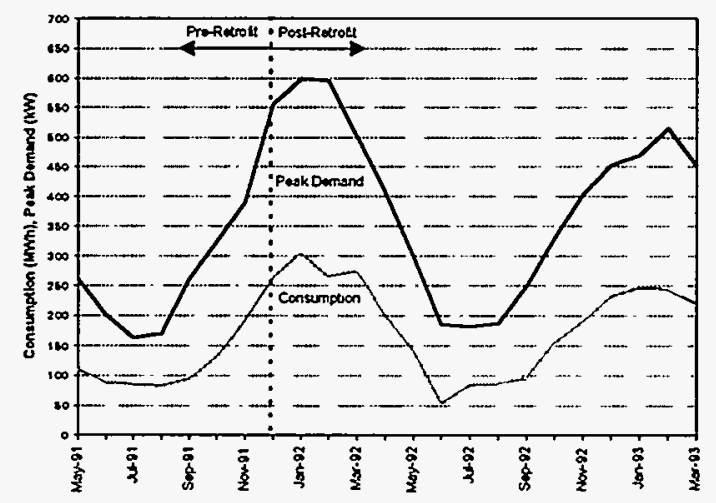

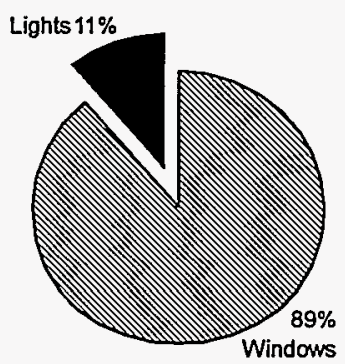

Consumption Savings Contributions

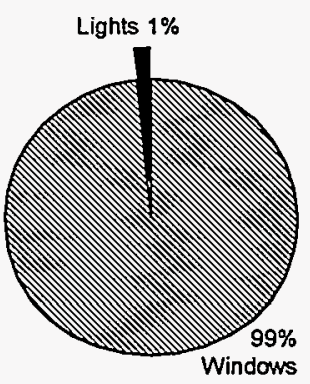

Peak Demand Savings Contributions
DISTRIBUTION OF THIS DOCUMENT IS UNLIMITED BS

Prepared for the

Office of Buildings Technology

Existing Buildings Energy Research Program

U.S. Department of Energy under contract No. DE-AC05-84OR21400

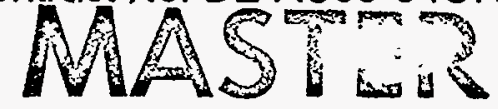


This report has been reproduced directly from the best available copy.

Available to DOE and DOE contractors from the Office of Scientific and Technical Information, P.O. Box 62, Oak Ridge, TN 37831; prices available from (615) 576-8401, FTS 626-8401.

Available to the public from the National Technical Information Service, U.S. Department of Commerce, 5285 Port Royal Rd., Springfield, VA 22161.

This report was prepared as an account of work sponsored by an agency of the United States Government. Neither the United States Government nor any agency thereof, nor any of their employees, makes any warranty, express or implied, or assumes any legal liability or responsibility for the accuracy, completeness, or usefulness of any information, apparatus, product, or process disclosed, or represents that its use would not infringe privately owned rights. Reference herein to any specific commercial product, process, or service by trade neme, trademark, manufacturer, or otherwise, does not necessarily constitute or imply its endorsement, recommendation, or favoring by the United States Government or any agency thereof. The views and opinions of authors expressed herein do not necessarily state or reflect those of the United States Government or any agency thereof. 
DOE-HUD INITIATIVE

Impact Evaluation of the

\title{
Energy Retrofits Installed in the Margolis High-Rise Apartment Building, Chelsea Housing Authority
}

M. M. Abraham

H.A. McLain

J.M. MacDonald

March 1995

\author{
Prepared for the \\ Office of Buildings Technology \\ Existing Buildings Energy Research Program \\ U.S. Department of Energy
}

Prepared by the

OAK RIDGE NATIONAL LABORATORY

Oak Ridge, Tennessee 37831

Managed by

LOCKHEED MARTIN ENERGY SYSTEMS, INC.

for the

U.S. DEPARTMENT OF ENERGY

under contract DE-AC05-840R21400 


\section{CONTENTS}

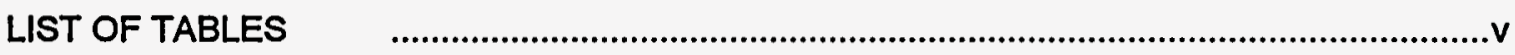

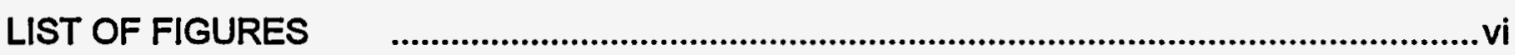

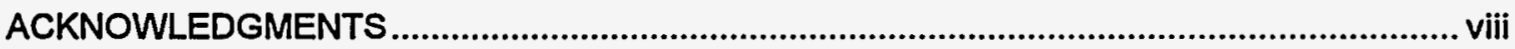

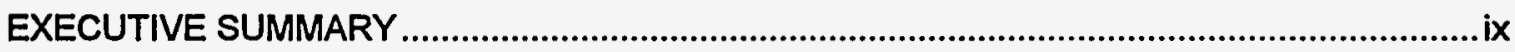

ABSTRACT

1. INTRODUCTION

1.1 SELECTION OF THE DEMONSTRATION SITE ..............................................

1.2 PARTICIPANT MOTIVATION AND CONTRIBUTIONS ...................................4

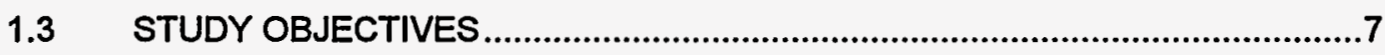

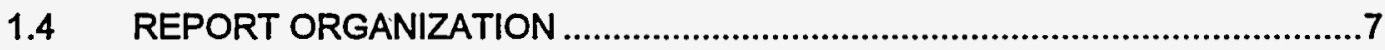

2. MARGOLIS APARTMENT BUILDING AND CONSERVATION MEASURES .......................8

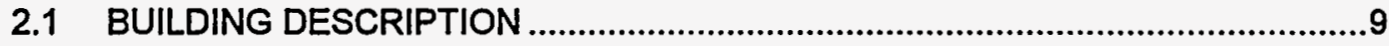

2.1.1 Design and Construction ......................................................................9

2.1.2 Occupancy and Use ..................................................................10

2.1.3 Local Climate ..............................................................................10

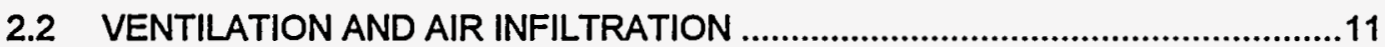

2.2.1 Building Ventilation System..........................................................11

2.2.2 Building Infiltration .........................................................................12

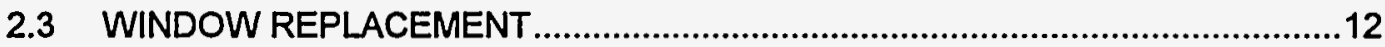

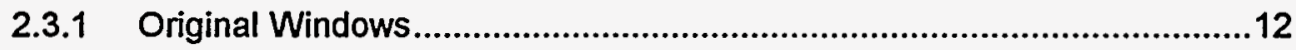

2.3.2 Replacement Windows ...................................................................13

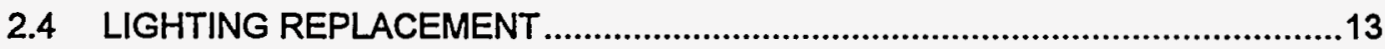

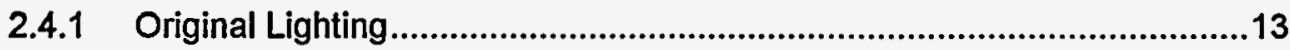

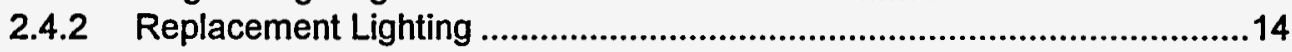

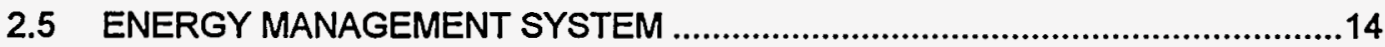

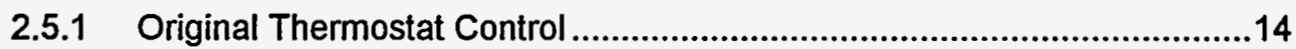

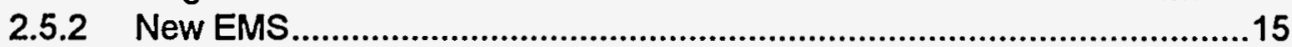

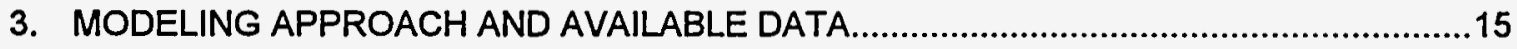

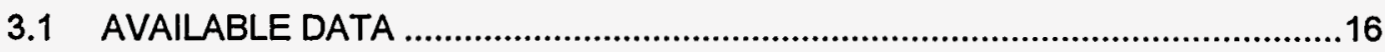

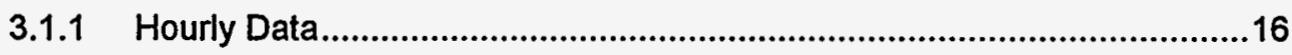

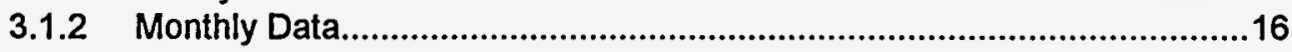




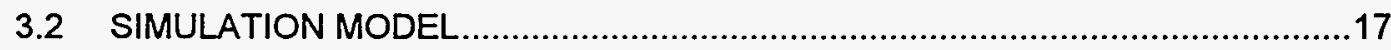

E.3 ENERGY AND COST SAVINGS CALCULATIONS ......................................18

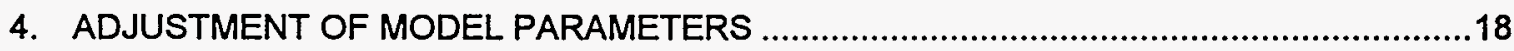

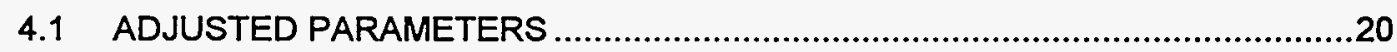

4.2 MONTHLY BILLING PERIOD COMPARISONS .......................................27

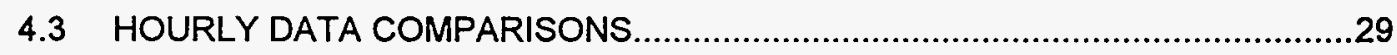

5. CONSERVATION MEASURES: ENERGY AND COST SAVINGS ................................30

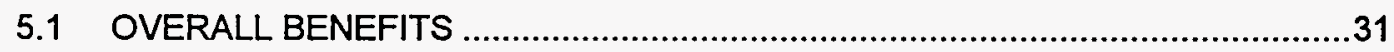

5.1.1 Energy and Peak Demand Savings..................................................31

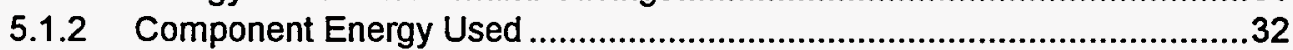

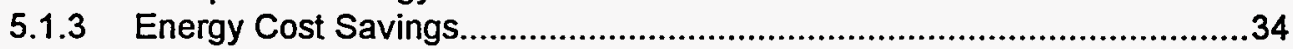

5.2 COST/BENEFITS OF THE INDIVIDUAL MEASURES .....................................35

5.2.1 Monthly Benefit Contributions ..........................................................36

5.2.2 Additional Savings by Implementing Controls ....................................38

6. DISCUSSION OF RESULTS

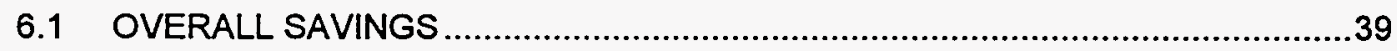

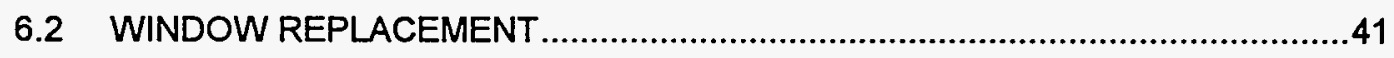

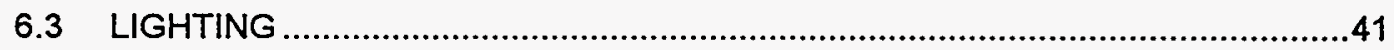

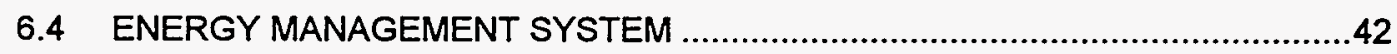

6.5 PREDICTED ENERGY AND COST SAVINGS BY MEASURE.............................43

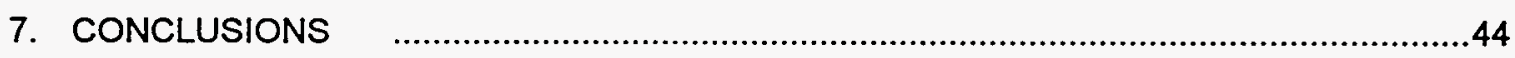

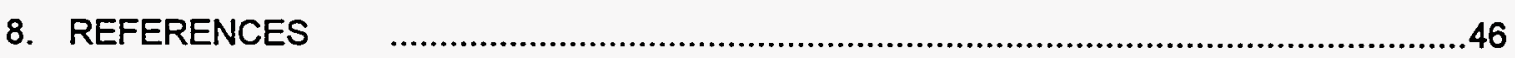

APPENDIX A: DOE-2.1D Pre-Retrofit Input File ............................................................. A-1

APPENDIX B: DOE-2.1D Post-Retrofit Input File ..............................................................

APPENDIX C: Margolis Building COMIS Results ..............................................................

APPENDIX D: Margolis Building BECo Utility Costs ........................................................ 


\section{LIST OF TABLES}

S.1 Components of energy consumption for the Margolis building, as determined by normalized simulation model

S.2 Summary of annual consumption, demand and utility costs for the Margolis building. xiii

4.1 Significant parameters utilized in the Margolis building pre-retrofit model .20

4.2 Significant parameters used in the Margolis building post-retrofit model .21

5.1 Components of energy consumption for the Margolis building, as determined by normalized simulation model

5.2 Reduction in annual heating load, by retrofit scenario .33

6.1 Summary of annual consumption and demand scenarios for the Margolis building .40

6.2 Summary of measure costs, utility costs and simple payback for the Margolis building ....40

6.3 Costs, and energy and cost savings, by measure 


\section{LIST OF FIGURES}

S.1 Normalized monthly on-peak energy consumption ....................................................

S.2 Normalized monthly off-peak energy consumption .........................................................

S.3 Normalized monthly peak demand for normalized model ............................................ xii

S.4 Monthly consumption costs for normalized model ..................................................... xii

2.1 Margolis apartment building, located in Chelsea, Massachusetts....................................8

2.2 Peak and off-peak consumption and peak demand profiles for Margolis Building, from monthly utility bills, (BECO 1993) .......................................................................................

2.3 Typical floor plan for floor in Margolis apartment building .........................................10

4.1 Pre-retrofit comparison of DOE-2.1D and whole-building hourly data, July $1992 \ldots \ldots \ldots \ldots . .22$

4.2 Post-Retrofit comparison of DOE-2.1D model and monthly utility data, $1993 \ldots \ldots \ldots \ldots \ldots . . .23$

4.3.a Hourly weather data for January $15-21,1992$, (NCDC, 1992) ....................................25

4.3.b Comparison of Crack Method hourly consumption models with actual data .....................25

4.4 Comparison of Air-Change Method hourly consumption models with actual data ............26

4.5 Comparisons of monthly consumption and peak demand for

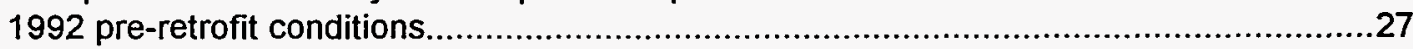

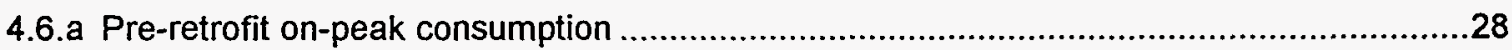

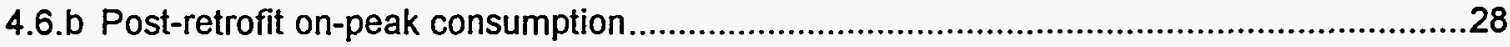

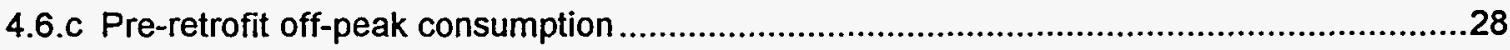

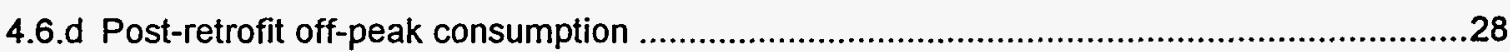

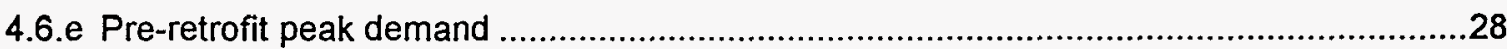

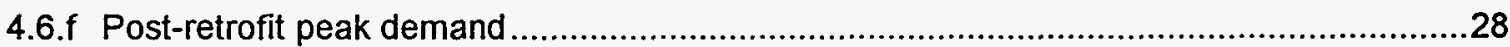

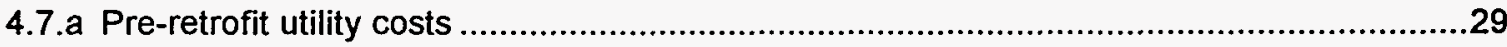

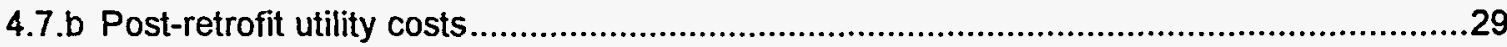

4.8 Pre-retrofit hourly comparison of simulation model and actual data, January 22-31, 1992

4.9 Post-retrofit hourly comparison of simulation model and actual data, January 22-31, 1993 
5.1.a Normalized monthly on-peak energy consumption

5.1.b Normalized monthly off-peak energy consumption ....................................................32

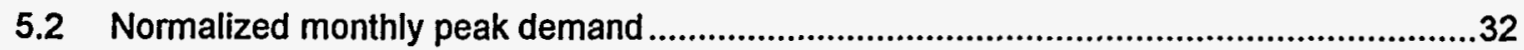

5.3 Monthly consumption costs, pre- and post-retrofit, for normalized model.........................34

5.4 Monthly demand costs, pre- and post-retrofit, for normalized model.............................35

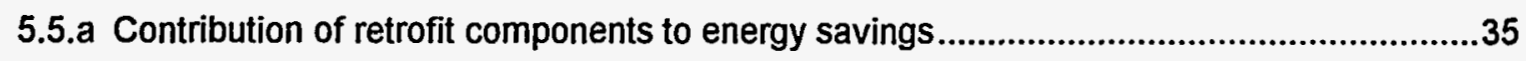

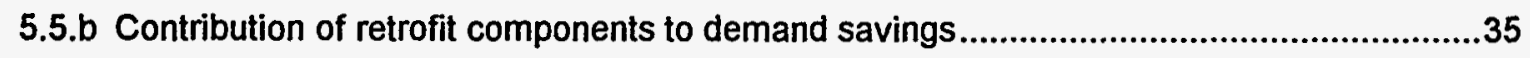

5.6 Consumption savings of retrofit models relative to pre-retrofit conditions ..........................36

5.7 Peak demand savings of retrofit models relative to pre-retrofit conditions .......................36

5.8 Monthly utility cost savings of retrofit models over pre-retrofit conditions ........................37

5.9 Consumption savings of retrofit model over pre-retrofit conditions ..............................38

5.10 Demand savings of retrofit model over pre-retrofit conditions.......................................38 


\section{ACKNOWLEDGMENTS}

The authors gratefully acknowledge the information provided by staff of the Citizens Conservation Corporation concerning the retrofits installed at the Margolis building and the history of events concerning the retrofits. The Boston Edison Company provided the energy use data from the Margolis building used in this analysis. Members of the Project Working Group are acknowledged for their important efforts in arranging the overall demonstration project, as described in the report. Special recognition must also be given to staff of the Energy and Environment Division at Lawrence Berkeley Laboratory, who helped track events and analyzed the air infiltration at the Margolis building, and helped shepherd this report to completion. 


\section{EXECUTIVE SUMMARY}

\section{S.1 OBJECTIVE AND SCOPE}

The objective of this study was to investigate the benefits of several energy conservation retrofits installed in the Margolis apartment building. This retrofit project was taken on by DOE, HUD, the Chelsea public housing authority, and the local electrical utility (Boston Edison, BECo) to demonstrate the use of shared technical and financial resources for achieving energy savings in public housing. The effects of lighting, window, and energy management retrofits were examined to determine energy, demand, and cost saving benefits. The study analyzed the contribution of each of these measures on the overall reduction in electric demand and consumption. The effects of the energy conservation retrofits were analyzed using hourly and monthly consumption data and a calibrated hourly energy simulation model. By using the calibrated model, the individual contributions of the retrofits could be more readily distinguished.

\section{S.2 MARGOLIS APARTMENT BUILDING AND MEASURES}

The Margolis apartment building is a thirteen story, all electric, residential high-rise, located in Chelsea, Massachusetts. The $101,000 \mathrm{ft}^{2}$ foot building contains 150 apartment units, a lobby, a laundry facility and a community room. Low-income elderly and handicapped tenants occupy the units. The building is heated with electric baseboard heat and cooled mainly with natural ventilation through open windows. Electrical consumption and peak demand during the twelve months prior to retrofit were $2,156 \mathrm{MWh}$ and $599 \mathrm{~kW}$, at a cost of $\$ 162,000$. Post-retrofit consumption was reduced by $325 \mathrm{MWh}$, peak demand by $100 \mathrm{~kW}$, and utility costs by $\$ 28,000$. The total cost of the retrofit installation was $\$ 372,000$.

The lighting retrofit reduced existing lighting illumination levels and power densities by replacing old incandescent fixtures with energy efficient fluorescent fixtures. Apartment lighting 
power levels were reduced from $0.8 \mathrm{~W} / \mathrm{ft}^{2}$ to $0.46 \mathrm{~W} / \mathrm{ft}^{2}$. Exterior and common area lighting power levels were also reduced as mercury vapor and incandescent fixtures were replaced with low-wattage, high-pressure sodium fixtures.

Windows throughout the building were replaced with new energy-efficient windows. Small slider windows in apartments and stairwells were replaced with double-pane windows, for a

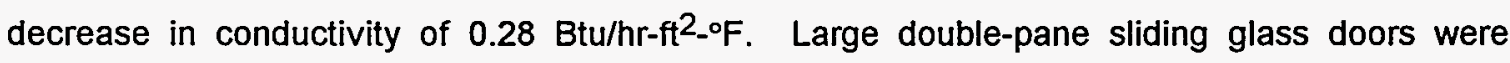
replaced with double-pane argon-filled doors, which decreased conductivity by $0.43 \mathrm{Btu} / \mathrm{hr}-\mathrm{ft}^{2}{ }^{\circ}{ }^{\circ} \mathrm{F}$. In addition, building infiltration loads were estimated to be reduced by $15 \%$ with the new windows.

An energy management system (EMS) was installed to control the thermostats located in the apartments. The EMS was originally programmed to reduce nighttime setpoint temperatures by $4^{\circ} \mathrm{F}$, in the apartments. Unfortunately, the setback approach appears to increase electric costs under the time-of-day rate schedule for this building. The system is not presently implementing setbacks, and thus the energy savings from this measure have been insignificant.

\section{S.3 MODELING APPROACH AND AVAILABLE DATA}

The energy simulation model of the Margolis building was developed using DOE-2.1D energy simulation software. The model was put together with information obtained from site-visit reports, and from architectural and mechanical drawings. DOE-2.1D results include building loads and consumption and demand profiles, on hourly and monthly bases. The weather data used in the calibration model were recorded at Boston's Logan International airport, which is located approximately two miles south of the actual building.

Both hourly and monthly consumption data were available for the Margolis building and were key elements in the calibration of the simulation model. The low-level availability of airconditioning equipment allowed hourly data to be used to estimate lighting, appliance, and 
occupant-related loads, during the summer months. Hourly data helped in the determination of infiltration loads, which were strong during the colder months. A site-report and subsequent model quantifying the infiltration flows in the building were also used to replicate infiltration loads. Monthly utility data were used to match consumption in months where hourly data were unavailable, and to match utility costs.

Once the calibrated model had been developed, a weather-normalized model was run to determine the average effects of the retrofits. This model used weather representing a typical meteorological year, drawn statistically, from thirty years of local weather data. The contribution of each retrofit component was determined using this normalized model.

\section{S.4 RETROFIT MEASURES BENEFITS}

Figures $\mathbf{S . 1}$ through $\mathrm{S.4}$ show the pre- and post-retrofit results of the simulation model for on- and off-peak consumption, peak demand, and utility costs for a weather-normalized year. Total annual consumption is reduced by $325 \mathrm{MWh}$ while monthly peak demand is reduced, on average, by $61 \mathrm{~kW}$. Over $60 \%$ of the total energy savings occur during utility off-peak hours and is largely due to the reduction in window conductivity resulting from the retrofit.

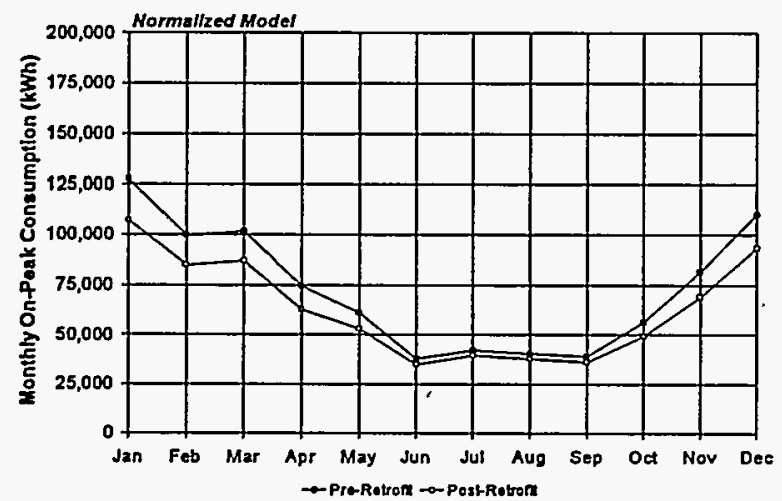

Figure S.1 Normalized monthly on-peak energy consumption

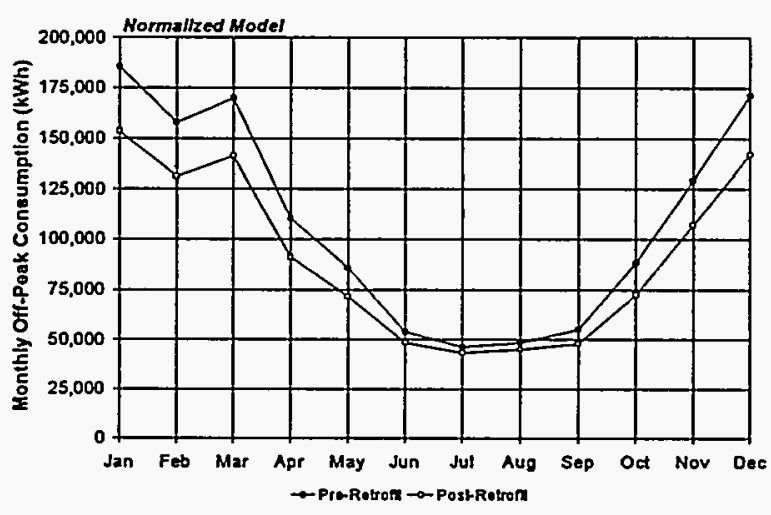

Figure S.2 Normalized monthly off-peak energy consumption 


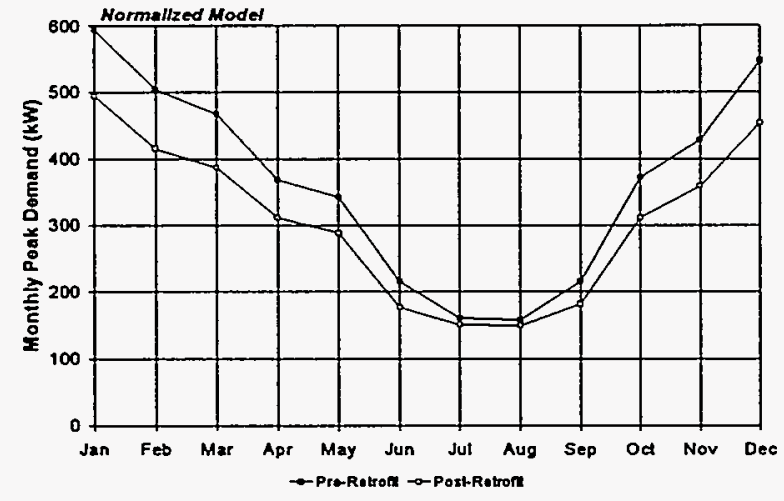

Figure S.3 Normalized monthly peak demand

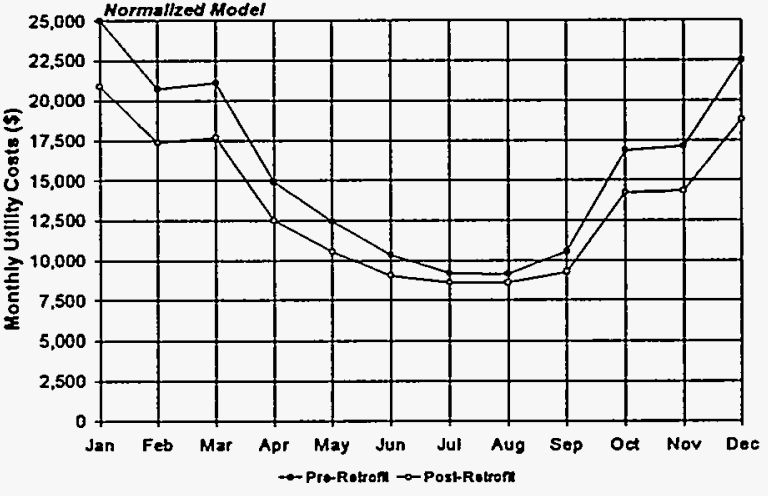

Figure S.4 Monthly consumption costs for normalized model

Major components of electrical energy consumption are shown in Table S.1, for pre- and post-retrofit models. The largest consumer of energy for this building is in space heating. A significant reduction in space heat consumption was achieved with the retrofit, however the potential for further conservation still exists in this category.

\begin{tabular}{|c|c|c|}
\hline Component & $\begin{array}{c}\text { Pre-Retrofit Consumption } \\
\left(\mathrm{kWh} / \mathrm{ft}^{2} / \mathrm{yr}\right)\end{array}$ & $\begin{array}{c}\text { Post-Retrofit Consumption } \\
\left(\mathrm{kWh} / \mathrm{ft}^{2} / \mathrm{yr}\right)\end{array}$ \\
\hline Space Heating & 11.10 & 8.54 \\
Space Cooling & 0.04 & 0.04 \\
Domestic Hot Water & 2.07 & 2.06 \\
Lights & 3.65 & 2.97 \\
Elevator & 0.695 & 0.695 \\
Misc. Equipment & 4.08 & 4.08 \\
\hline Total & 21.63 & 18.38 \\
\hline
\end{tabular}

note: total area $=101,000 \mathrm{ft}^{2}$

Table S.1 Components of energy consumption for the Margolis building, as determined by normalized simulation model 
Table S.2 presents a summary of the normalized energy and cost savings of each measure, along with full pre- and post-retrofit models. Again, the window retrofit was the most successful with energy savings of $291 \mathrm{MWh}$, demand savings of $98 \mathrm{~kW}$ and corresponding cost savings of over $\$ 25,000$. The annual energy savings from the lighting retrofit was $31 \mathrm{MWh}$, with a demand savings of only $1 \mathrm{~kW}$. Also included in Table S.2 is the potential energy, demand and cost savings that would occur if the EMS is brought back on-line. Note that while an additional energy savings of $32 \mathrm{MWh}$ would occur, demand savings would be reduced by $40 \mathrm{~kW}$. This increase in electrical demand is attributed to the increase in demand for space heat needed at the end of the setback period. The increase in morning demand is penalized by the utility rate structure and thus cost savings for the EMS setback are reduced by $\$ 2,500$.

\begin{tabular}{|c|c|c|c|c|c|c||}
\hline Scenario & $\begin{array}{c}\text { Energy } \\
(\mathrm{MWh})\end{array}$ & $\begin{array}{c}\text { Energy } \\
\text { Savings } \\
(\mathrm{MWh})\end{array}$ & $\begin{array}{c}\text { Demand } \\
(\mathrm{kW})\end{array}$ & $\begin{array}{c}\text { Demand } \\
\text { Savings } \\
(\mathrm{kW})\end{array}$ & $\begin{array}{c}\text { Utility } \\
\text { Cost } \\
(\$)\end{array}$ & $\begin{array}{c}\text { Utility Cost } \\
\text { Savings } \\
(\$)\end{array}$ \\
\hline Pre-Retrofit & 2,174 & & 594 & & 189,882 & \\
\hline Post-Retrofit & 1,849 & $\begin{array}{c}325 \\
(15 \%)\end{array}$ & 494 & $\begin{array}{c}100 \\
(16.8 \%)\end{array}$ & 161,883 & $\begin{array}{c}27,999 \\
(14.6 \%)\end{array}$ \\
\hline Lighting & 2,143 & $\begin{array}{c}31 \\
(1.5 \%)\end{array}$ & 593 & $\begin{array}{c}1 \\
(0.2 \%)\end{array}$ & 187,328 & $\begin{array}{c}2,554 \\
(1.2 \%)\end{array}$ \\
\hline Windows & 1,883 & $\begin{array}{c}291 \\
(13.4 \%)\end{array}$ & 496 & $\begin{array}{c}98 \\
(16.5 \%)\end{array}$ & 164,475 & $\begin{array}{c}25,407 \\
(13.4 \%)\end{array}$ \\
\hline $\begin{array}{c}\text { Post- } \\
\text { w/ Setbacks }\end{array}$ & 1,817 & $\begin{array}{c}357 \\
(16.4 \%)\end{array}$ & 534 & $\begin{array}{c}60 \\
(10.1 \%)\end{array}$ & 164,394 & $\begin{array}{c}25,488 \\
(13.3 \%)\end{array}$ \\
\hline
\end{tabular}

Table S.2 Summary of annual consumption, demand and utility costs for the Margolis building

\section{S.5 CONCLUSIONS}

The Margolis apartment building underwent improvements in energy efficiency as part of a joint effort to demonstrate the technical and financial benefits to public housing from 
cooperation amongst DOE, HUD, and the local utility, BECo. Retrofits of lighting, windows and energy management controls were installed in late 1992. The impacts of these retrofits are documented in this report.

A DOE-2.1D based energy simulation model was built to determine the effects of the retrofit measures, on an individual and combined basis. Drawings and site-reports were used to build the initial model, while hourly and monthly consumption and demand data were used in the calibration. Calibrated parameters included lighting capacity, appliance and occupant-related loads, and infiltration. The final model had good results, however a better understanding of building infiltration is desirable.

Energy savings from window retrofits were the most substantial for the total retrofit package. The new windows contributed to $90 \%$ of the total annual energy savings of $325 \mathrm{MWh}$ and to $99 \%$ of the total cost savings of $\$ 28,000$. The reason: window retrofits were most effective in reducing space heating loads, the largest energy consumer in the building. Lighting retrofits actually increased the space heating requirement as the installed lighting capacity was reduced. This resulted in a reduction in the overall energy and demand savings that could be attributed to the new lights.

The EMS is not used currently to set back temperatures and is not saving the Margolis building any energy. The simulation model was used to determine the potential for energy and demand savings if the EMS were operated with the originally intended setbacks. While energy consumption would decrease by $32 \mathrm{MWh}$, substantial increases in demand are penalized enough by the utility rate structure to reduce cost savings by $\$ 2,500$. 


\title{
Impact Evaluation of the Energy Retrofits
}

Installed in the Margolis High-Rise Apartment Building,

Chelsea Housing Authority

M.M. Abraham

H.A. McLain

J.M. MacDonald

\begin{abstract}
As part of a joint demonstration effort involving HUD, DOE, a local public housing authority and Boston Edison, an evaluation of energy and demand saving retrofits was conducted for a tall, residential, low-income building located in Boston. The thirteen story building underwent window, lighting, and heating system control renovations in December, 1992. The success of these retrofits was determined using monthly and hourly whole-building consumption data along with a calibrated DOE-2.1D energy simulation model.

According to the model developed, post-retrofit conditions showed reductions in annual energy consumption of $325 \mathrm{MWh}$ and in peak demand of $100 \mathrm{~kW}$. These savings resulted in an annual energy cost savings of $\$ 28,000$. Over ninety percent of energy and cost savings were attributed to the window retrofit. Interaction of the reduction in lighting capacity with the building's electric resistance heating system reduced the potential for energy and demand savings associated with the lighting retrofit. Results from the hourly simulation model also indicate that night setbacks controlled by the energy management system were not implemented. An additional $32 \mathrm{MWh}$ in energy savings could be obtained by bringing this system on-line, however peak demand would be increased by $40 \mathrm{~kW}$ as the morning demand for space heat is increased, with a net loss in cost savings of $\$ 2,500$.
\end{abstract}




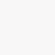




\section{INTRODUCTION}

The Federal government owns and operates hundreds of thousands of housing units and provides financial support to millions of other units. However, housing authorities lack financial resources, appropriate management incentives, and technical expertise to improve energy efficiency in these dwellings. In order to deal with this issue, the Department of Energy (DOE) and the Department of Housing and Urban Development (HUD) developed a joint initiative during FY 1990 to improve energy efficiency in public housing and other types of Federally aided housing.

In April, 1991, the DOE Boston Support Office (BSO) organized a meeting of headquarters staff of DOE and HUD, and local agencies and utilities that were likely participants in the demonstration. A Project Working Group was organized from those attending and their input was used to develop a Conceptual Description of the project.

In general, Paul King of the BSO was the project field manager and primary contact. Owners and funding agents, who needed first approval of planned actions, included the local housing authority (PHA), Boston Edison Company (BECo), HUD, and DOE. ORNL worked closely with the PHA and the local utility, BECo, to collect data and review energy assessments. Other members of the Working Group received summary information and interim plans to review and had the option of becoming more closely involved with any phase of the project. Periodic meetings were held in the Boston area to review project progress and special issues or developments. Members included the active participants in the project plus other interested agencies that may assist in future replication of the concept. Members of the Working Group included the following:

Paul J. King, Chairman

E. C. Freeman, Jr.

Bernie Manheimer

Carl Byers

Robert McLaughlin

Thomas P. Malone

Robert Ovagimian
DOE Boston Region Support Office

$\mathrm{DOE} / \mathrm{HQ}$

HUD/HQ

HUD Boston Office of Public Housing

HUD Boston Office of Public Housing

HUD Regional Environmental Officer

HUD Regional Office 
Richard Kluck

Terry Civic

Robert Nason

Barry McDonough

Robert P. O'Brien

William R. Mixon

Rick Diamond

Steve Morgan
HUD Boston Office of Public Housing

Massachusetts Division of Energy Resources

Executive Director, Chelsea Housing Authority

Boston Edison Company

New England Power Service

Oak Ridge National Laboratory

Lawrence Berkeley Laboratory

Citizens Conservation Corporation

The overall objectives of this DOE-HUD Initiative on Energy Efficiency are to:

- Make housing more affordable and comfortable through energy efficiency improvements in HUD programs,

- Apply existing technical information on energy efficiency to HUD-assisted housing construction and retrofit activities,

- Reduce Federal outlays for utility expenditures, and

- Demonstrate strategies that use the financial and technical resources of both the public and private sectors and that provide substantial benefits to all parties.

The impact evaluation reported here provides technical feedback to the project developers. The results from this project are intended to benefit all public housing authorities in the Boston region and also to provide benefits to all participants.

The project was intended to determine if such a collaborative effort would fit within the institutional structure of each participant, lead to increased energy efficiency and load reductions, change total project costs or the distribution of costs, reduce time for implementation, or enhance benefits for each participant. Participation by the different organizations demonstrated the benefits of developing organizational infrastructures and how barriers and examples of solutions can be identified. The energy saving impacts of the project are documented here to promote replication of this general process.

\subsection{SELECTION OF THE DEMONSTRATION SITE}

The demonstration building was chosen from a list of public housing buildings, within the Boston Edison Company's service territory, that were identified by the HUD Boston Regional Office (HBRO) as receiving grants for modernization and meeting project criteria. Project 
criteria were that the building(s) shall contain 100 to 150 dwelling units, be electrically heated, and be eligible for BECo's electric efficiency program.

The site selected was the Chelsea Housing Authority's (CHA) Margolis Apartment building. This site was chosen based upon: (1) HBRO recommendation; (2) on-site inspection of the building by ORNL, BECo, and DOE/BSO; (3) an assessment of other eligible buildings of the Boston Housing Authority; and (4) the interest and commitment of the Chelsea Housing Authority.

The Margolis Apartment building is an all electric, thirteen story, 150 unit, elderly- and handicapped-occupied high-rise. The building has two elevators, electric baseboard heat, and circulating domestic hot water heating systems on each floor. The total building electricity cost exceeded $\$ 150,000\left(\$ 1.48 / \mathrm{ft}^{2}\right)$ in 1992 , with $40 \%$ of this cost incurred during the three month period from January through March.

The CHA received approval from the HBRO to expend $\$ 628,000$ in "development" funds in four areas on the Margolis building:

1. Roof replacement (which has been completed),

2. Masonry sealing and repair and window replacement,

3. Elevator repair, and

4. Miscellaneous repairs and modifications.

The CHA submitted a Fiscal Year 1991 application for Comprehensive Improvements Assistance Program (CIAP) funding in the amount of $\$ 3,700,000$ for additional improvement projects, however the development funds had to be depleted before CIAP funds would be considered.

The local electric utility participant, BECo, has included this building in its Public Housing Electric Efficiency Program. The energy conservation measures installed under the program included efficient lighting in individual apartments and community room(s), replacement of bedroom and community room glazing with high efficiency glazing units, insulation of domestic water heaters, and an energy management control system. A number of other energy efficiency 
measures have been recommended and may be completed in the future with HUD development and/or CIAP funds.

\subsection{PARTICIPANT MOTIVATION AND CONTRIBUTIONS}

U.S. Department of Energy (DOE) The DOE Headquarters (HQ) offices of Building Technologies, Utility Technologies, and Financial and Technical Assistance, and their participating National Laboratories, are interested in transferring the results of their research to practical use, in order to significantly increase the level of energy efficiency achieved through rehabilitation. In addition, they are interested in documenting the actual benefits achieved from multifamily efficiency improvements, and in developing and refining tools for selecting measures to be performed based on cost effectiveness.

Funding from the DOE-HUD Initiative provided the technical assistance and expertise of DOE National Laboratories that have been active in the Existing Buildings Research Program and in the Weatherization Assistance Program. The Oak Ridge National Laboratory (ORNL) and Lawrence Berkeley Laboratory (LBL) assisted DOE and the DOE Regional Support Office in their efforts to organize and plan the project. The laboratories also served as technical resources to all participants during project implementation.

DOE Regional Support Office The ten DOE regional offices have been assigned significantly increased responsibility to serve as a technical resource within their region and to transfer DOE developed technologies and innovations to practice. They continue to administer DOE grant funds to states for low income weatherization assistance programs, but are becoming much more proactive in the promotion of regional energy efficiency.

DOE Boston Regional Support Office (BSO) The BSO provided overall field management for the site selected and coordinated participants. This included providing leadership in identifying 
participating organizations, formulating the project, ensuring continued coordination and cooperation among participants during implementation, and maintaining communications of project status and issues. This office served as the local project contact and as the technical interface with ORNL.

U.S. Department of Housing and Urban Development (HUD) HUD/HQ offices, together with DOE, are committed to meeting objectives of the DOE-HUD Initiative. Both HUD/HQ and the HUD Boston Regional Office of Public Housing (HBRO) are interested in demonstrating how HUD programs can be linked to private-sector and other public-sector programs to make federally-aided housing more energy efficient. Both technical and financial linkages are of interest. This demonstration focused on public housing, and the coordinated application of HUD, utility, and other resources to achieve cost-effective energy efficiency within an overall comprehensive modernization concept.

Boston Regional Office of Public Housing Administration of the Comprehensive Improvements Assistance Program (CIAP), for each of the six New England states, is handled by this office. Under this program, public housing authorities apply to HUD for grant funds for comprehensive rehabilitation and modernization of public housing. Qualified candidates must have had an energy audit and must update it periodically. Energy efficiency improvements are sometimes incorporated into the comprehensive construction if they are shown to have a simple payback period of at least 15 years.

Chelsea Housing Authority (CHA) The CHA is an organization created by local government to administer HUD programs and to own and manage public housing projects. It receives direct payments from HUD to develop and operate housing for low-income families, including the CIAP funds for correcting physical deficiencies. Each PHA that receives CIAP grant funds is responsible for awarding and overseeing the modernization construction contracts. 
The CHA was responsible for the housing project selected for this demonstration. The CHA reviewed and agreed upon energy efficient measures proposed by the Boston Edison Company. CHA also coordinated and integrated work to be completed by the utility with the comprehensive modernization work funded by CIAP. All on-site activities were coordinated through a designated representative of the $\mathrm{CHA}$.

Boston Edison Company (BECo) The BECo Public Housing Electric Efficiency Program installs electric efficiency measures in buildings owned and managed by PHAs. The program targets high use electrically heated buildings, although non-electrically heated buildings are also eligible to participate. Each building in the program receives a technical assessment by a BECo Contractor to identify electrical energy conservation opportunities (e.g., space heating and cooling, domestic water heating, and lighting). The Contractor prepares specifications of BECo approved measures and presents the cost and savings analysis to the participating PHA.

After approval by the CHA the Contractor arranged for subcontractors to install all approved measures, with the full cost to be paid by BECo, with the exception of cost-sharing with the PHA for replacement windows. The Contractor inspected the completed installation to verify the quality of work, integrity of measures, and projected electrical savings. Training was provided for PHA maintenance and/or property management staff on the proper operation and maintenance of electrical equipment. Assistance was also provided in educating residents on energy efficient practices.

The BECo objective was to build a cooperative framework with DOE and HUD to facilitate the identification and installation of energy efficient measures in Federally aided housing. BECo is interested in implementing their electric efficiency program on PHA buildings chosen for the demonstration and would apply in-house expertise and experience to achieve maximum savings, improve affordability and comfort, and educate building operators and residents. Improved understanding of measure performance will help BECo to conduct their 
program more effectively in the future. BECo assisted in the evaluation of the demonstration by providing energy consumption information and collecting required field data.

- The New England Power Service (NEPS) NEPS completed a Phase I R\&D Program in July, 1991, which featured installation of efficiency measures in 730 units of electrically heated multifamily buildings, both privately and publicly owned. NEPS fully funded measures which were estimated to be cost-effective, based on the value of avoided energy and capacity benefits, and expected to save approximately $2,200 \mathrm{kWh} /$ year for each dwelling unit. Upon completion of the detailed evaluation of the first phase, the Company expected to expand the Multifamily Retrofit Program with the goal of reaching approximately 10,000 units in the first four years. This particular DOE-HUD Initiative demonstration project was organized at a time that NEPS was between phases and not available for active participation. However, NEPS would still benefit from the understanding of measure performance obtained from this effort.

\subsection{STUDY OBJECTIVES}

This report of the impact evaluation of energy and energy cost savings and cost effectiveness is important to the participants in this effort. Research questions to be addressed by the impact evaluation include the following:

- What is the actual change in energy consumption and electric demand, normalized to standard weather conditions, due to installation of the energy conservation measures (ECMs)?

- What was the installed cost of each ECM?

- What was the estimated overall cost effectiveness of ECMs installed?

\subsection{REPORT ORGANIZATION}

This report contains eight sections, and in addition, an abstract, executive summary and appendices. This section presented a brief background on the project, including participants, site 
selection and project objectives. Section two describes the building studied, including details on pre- and post-retrofit conditions. Sections three and four present detailed information on the development of the energy simulation model for the Margolis building. Analysis and results of the energy simulation model are presented in section five, including utility cost savings estimates. The effectiveness of the individual retrofits are discussed in section six. Finally, project conclusions and references are presented in sections seven and eight, respectively.

\section{MARGOLIS APARTMENT BUILDING AND CONSERVATION MEASURES}

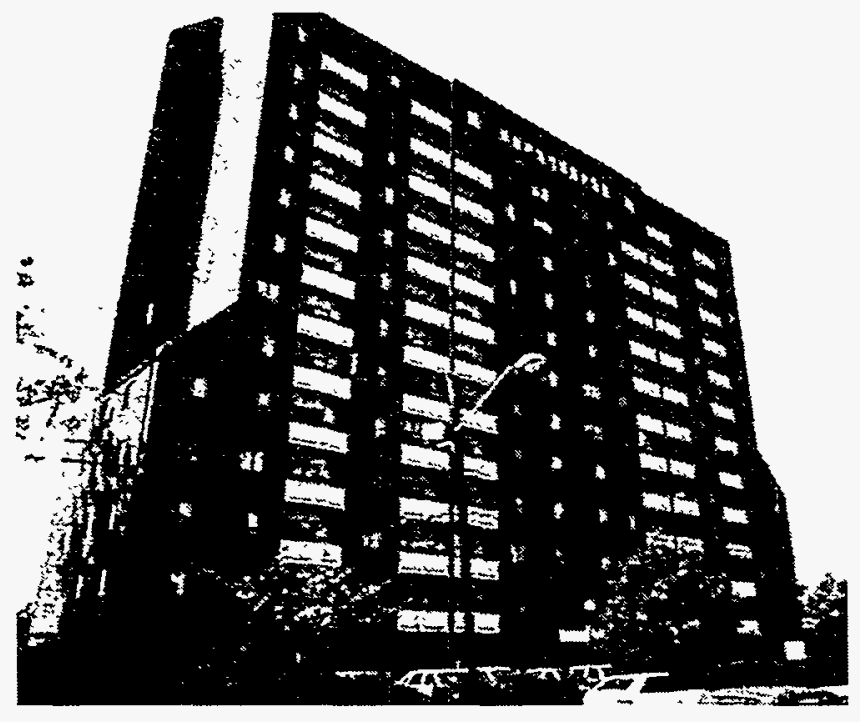

Figure 2.1 Margolis apartment building, located in Chelsea, Massachusetts
The Margolis apartment building, built in 1974 and located in Chelsea, Massachusetts, (Figure 2.1), is served by the Boston Edison Electric Company (BECo). The building is an all electric, thirteen story, 150 unit residential dwelling for the handicapped and elderly. The building underwent lighting, window, and control retrofits in December, 1992. Peak and off-peak consumption and peak demand profiles are shown in

Figure 2.2, for pre- and post-retrofit months. Electrical utility costs for 1991 and 1992 were $\$ 147,000$ and $\$ 161,700$, respectively. In late 1992, window, lighting and control retrofits were implemented. During the first nine months after retrofit, (December 1992 - August 1993) the peak demand was reduced by $41 \mathrm{~kW}$, with a total consumption savings of $317 \mathrm{MWh}$ compared to the same months in 1992 . Installation costs were around $\$ 370,000$, with anticipated energy cost savings of $\$ 35,000$ per year, (BECo $1993 a$ ). 

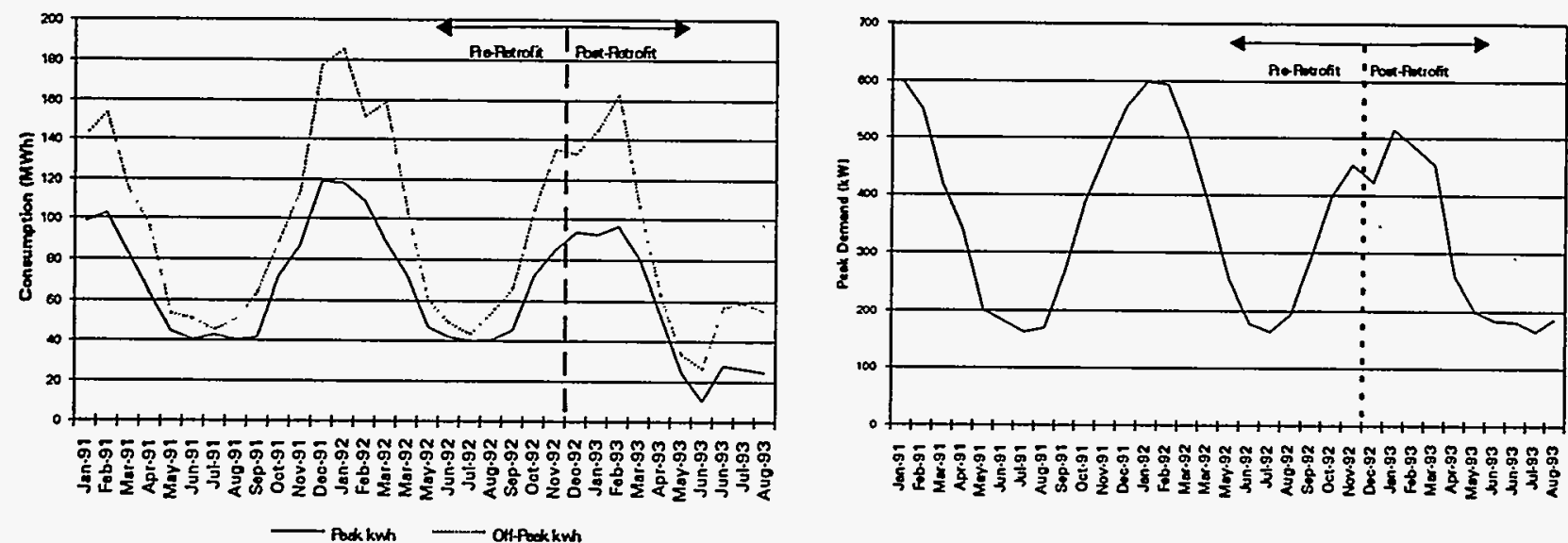

Figure 2.2 Peak and off-peak consumption and peak demand profiles for Margolis building, from monthly utility bills, (BECo 1993a)

\subsection{BUILDING DESCRIPTION}

\subsubsection{Design and Construction}

The total floor area of the Margolis apartment building is $101,000 \mathrm{ft}^{2}$. The first story contains carports for eleven automobiles and a main lobby with post boxes. The remaining tweive floors are comprised of 142 one bedroom units $\left(586 \mathrm{ft}^{2}\right)$ and 8 two bedroom units (883 $\mathrm{ft}^{2}$ ), with 'a laundry room and an 'activity area on the thirteenth floor. Eighteen units are handicapped equipped. In addition to the bedroom(s), each apartment contains a kitchen, living room, full bathroom and dining area. A typical floor plan is shown in Figure 2.3. Apartments are heated via electric resistance baseboard heaters. While a few tenants have installed small airconditioners, the majority must cool via natural ventilation through open windows.

The pre-retrofit building envelope contained external walls with 4 " bricks on 6" concrete blocks with 2" of rigid insulation and interior gypsum sheets for a total conductivity of 0.094 $\mathrm{Btu} / \mathrm{hr}-\mathrm{ft}^{2}{ }^{\circ} \mathrm{F}$. The roof was built-up roofing with air space and the equivalent of $\mathrm{R}-25$ insulation 


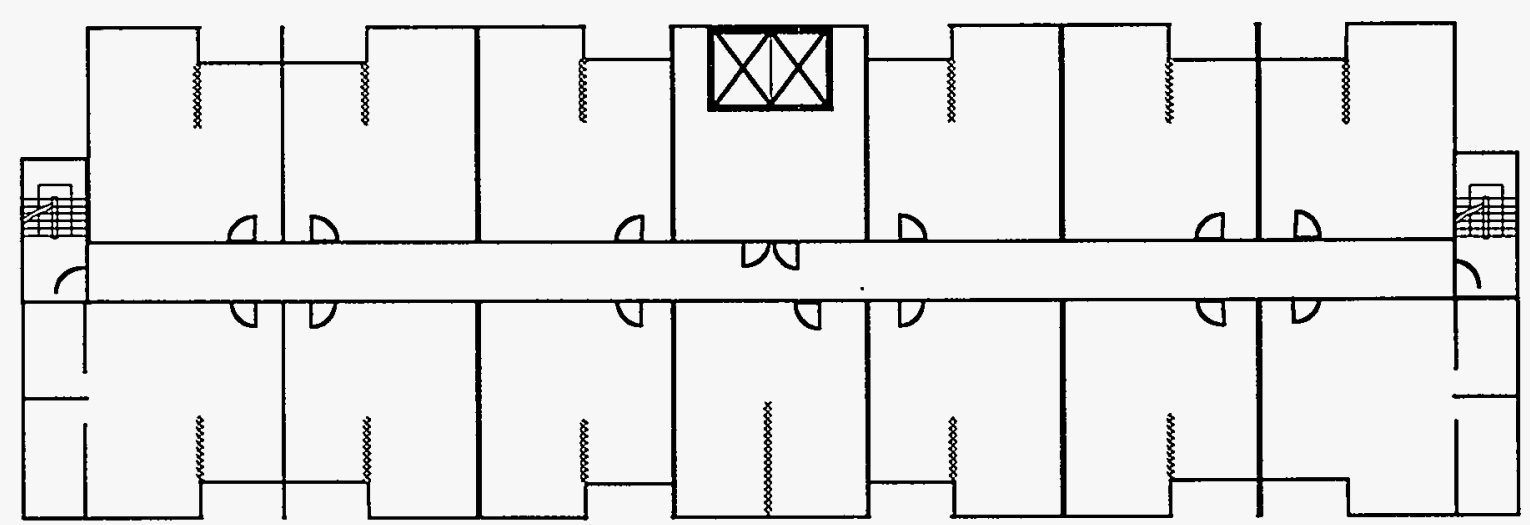

Figure 2.3 Typical floor plan for floor in Margolis apartment building

for a total U-value of $0.036 \mathrm{Btu} / \mathrm{hr}^{-} \mathrm{ft}^{2} \mathrm{-}^{\circ} \mathrm{F}$. Double-pane windows and sliding glass doors had a

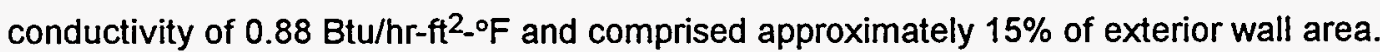

\subsubsection{Occupancy and Use}

Approximately 160 tenants occupy this low-income apartment building. The majority of the tenants are elderly and a small percentage are handicapped. The daily occupant-dependent components of building consumption exhibit typical residential dual-peak profiles. Peaks tend to occur around 9:00 a.m. and 5:00 p.m. and rarely vary on weekends and holidays. Apartment equipment, including a refrigerator, television, and range, provides an estimated equipment load of $1.0 \mathrm{~W} / \mathrm{ft}^{2}$.

\subsubsection{Local Climate}

Due to a high building surface to volume ratio, location, and immediate surroundings, the Margolis building has exhibited weather dependent consumption profiles in the winter months. The building is completely unshielded due to the lack of neighboring high-rise buildings. The 
occupant-dependent profile is distorted on days when low temperatures are combined with highspeed winds out of the northwest.

\subsection{VENTILATION AND AIR INFILTRATION}

\subsubsection{Building Ventilation System}

A site visit was made in June 1992 to determine infiltration and ventilation conditions within the building (LBL 1992). The supply air system for the Margolis building was designed to provide $7,000 \mathrm{cfm}$ of air to the main corridors, with electric resistance heating when needed. In addition, the supply air was also designed to enter the individual apartment via a small gap under the corridor door. This supply system has been inoperable since 1989 due to the failure of the filter drive for the air-cleaning system. When the supply fan was turned on, during the site visit, actual air-flow was $5,000 \mathrm{cfm}$. It was determined, however, that little of this supply air actually reached the apartments since the door gaps were too small.

The exhaust system contains 29 roof-mounted fans which remove stale apartment air from kitchen and bathroom exhaust risers. Upon inspection, all of these fans were found to be inoperable due to either broken motors or V-belts. Bathroom and kitchen roof exhaust fans were designed at 720 and $480 \mathrm{cfm}$ and, when operated, actually only produced 450 and $290 \mathrm{cfm}$, respectively. Also, the filters in apartment bathroom and kitchen exhaust fans were found to be filthy.

Ventilation rates were determined using tracer gas measurements in two "typical" apartments. With operation of the supply fan alone, the apartment ventilation rate was approximately $0.2 \mathrm{ACH}$. When roof exhaust fans were operated along with the supply fan, as intended, the ventilation rate increased to $0.44 \mathrm{ACH}$. 


\subsubsection{Building Infiltration}

During the site visit, blower door measurements were made to determine apartment air leakage. The average effective leakage area for one- and two-bedroom apartments was 31 in $^{2}$ and $39 \mathrm{in}^{2}$, respectively. Seventy-five percent of the air leakage was through the exterior wall. Worn double-pane windows and sliding glass doors were found to be the major source of exterior leakage. The site visit report also notes that these measurements were taken under extremely windy conditions and may not represent precise measurements.

The infiltration audit also found other areas of the building, besides apartments, to be major sources of infiltration. Specifically, elevator shafts and stairwells were found to be extremely drafty. When the doors to these areas are allowed to remain open, further infiltration into conditioned areas occurs. Site visit reports indicated that the tenants often left the doors open.

Data gathered from the ventilation/infiltration audit were used to develop a computer model to simulate the air-flow into and throughout the building (Feustel 1993). The model provided infiltration information as a function of wind velocity and building height. The results were then used to represent infiltration behavior in the whole-building energy simulation model.

\subsection{WINDOW REPLACEMENT}

\subsubsection{Original Windows}

Double-pane sliding glass windows and doors are used throughout the building. Each apartment has a slider window, approximately $16 \mathrm{ft}^{2}$, and a sliding glass door, approximately 40 $\mathrm{ft}^{2}$, on the exterior wall. Both slider windows and doors are double-pane glass and have

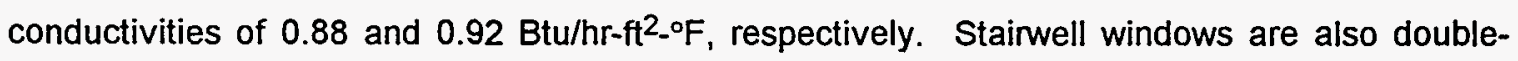
pane sliders with an area of $16 \mathrm{ft}^{2}$ and estimated conductivity of $0.88 \mathrm{Btu} / \mathrm{hr}-\mathrm{ft}^{2}-{ }^{\circ} \mathrm{F}$. A majority of 
these windows and doors were found to have leakage problems, evident by the existence of condensation between the panes.

\subsubsection{Replacement Windows}

In December 1992, new windows were installed in apartments and in stairwells. The double-pane slider windows were replaced with double-pane, argon-filled windows. The conductivity of the new windows is $0.60 \mathrm{Btu} / \mathrm{hr}-\mathrm{ft}^{2}-{ }^{\circ} \mathrm{F}$. By request of the tenants, sliding glass doors were not replaced with conventional wood or metal doors with windows. Instead, the exterior doors were replaced with double-pane argon-filled sliding glass doors. The conductivity

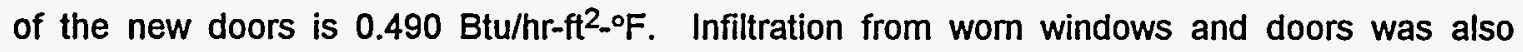
expected to decrease with the installation of the new windows.

\subsection{LIGHTING REPLACEMENT}

\subsubsection{Original Lighting}

As designed, the building contained an abundance of inefficient lighting fixtures and several opportunities existed for retrofit of interior and exterior lighting. The original lighting capacity installed in the apartments was $0.8 \mathrm{~W} / \mathrm{ft}^{2}$. Apartment lamps were almost entirely incandescent with an average fixture size of $75 \mathrm{~W}$. Corridor and stairwell fluorescent lighting power levels were at 1.0 and $0.3 \mathrm{~W} / \mathrm{ft}^{2}$. The corridor connecting the garage area to the main lobby and elevators had 13,120W mercury vapor fixtures. Exterior lighting included ten, 120W mercury vapor fixtures, located in carports, and seven $150 \mathrm{~W}$ incandescent parking lot fixtures. 


\subsubsection{Replacement Lighting}

The high incandescent illumination and power levels in apartments were reduced by replacement with smaller, energy efficient compact fluorescents. The apartment lighting retrofit reduced installed apartment lighting capacity to $0.46 \mathrm{~W} / \mathrm{ft}^{2}$. As an illustration, $120 \mathrm{~W}$ and $25 \mathrm{~W}$ incandescent kitchen ceiling and oven hood fixtures were replaced with $15 \mathrm{~W}$ and $7 \mathrm{~W}$ compact fluorescents. Similarly, $60 \mathrm{~W}$ and $25 \mathrm{~W}$ living room fixtures were also retrofitted with $15 \mathrm{~W}$ and $7 \mathrm{~W}$ compact fluorescents.

Exterior and common area lighting power levels were also reduced with the replacement of oversized inefficient fixtures. Ten exterior carport, and thirteen first floor corridor $120 \mathrm{~W}$ mercury vapor fixtures were retrofitted with $45 \mathrm{~W}$ high-pressure sodium fixtures. Also, seven $150 \mathrm{~W}$ incandescent exterior fixtures were replaced with $45 \mathrm{~W}$ high-pressure sodium fixtures.

\subsection{ENERGY MANAGEMENT SYSTEM (EMS)}

\subsubsection{Original Thermostat Control}

The Margolis building was heated with locally-controlled electric resistance baseboards and cooled mostly by natural ventilation. Original heating control was through thermostats adjusted by the tenants. Infiltration problems, intensified with high speed cold winds from the northwest, contributed to a polarity in thermostat set points within the building. Residents on the northwest side complained of extreme draftiness and set thermostats above $78^{\circ} \mathrm{F}$. At the same time, southeast residents experiencing overheating, turned thermostats back and sometimes opened windows. These manually operated thermostats were not equipped with night setback controls. 


\subsubsection{New EMS}

The manual thermostats within the apartments were replaced with a central energy management system (EMS) that can control individual apartment temperatures. The new EMS was installed with the intentions of controlling the range of daytime set points and implementing nighttime setbacks. However, the new system could be overridden by the tenants. At the time of this study, the night setback function had been disengaged in order to minimize tenant complaints.

\section{MODELING APPROACH AND AVAILABLE DATA}

Often the means of evaluating the benefits of a retrofit or series of retrofits is achieved with an analysis of the building's energy consumption before and after each retrofit installation. Unfortunately, this approach can be time-consuming and expensive while producing unreliable results. Climate, building occupancy, and usage can alter the base mode of energy consumption of the building and thus skew the results of such a comparison method. Yet another problem with this approach is the inability to clearly evaluate retrofit interactions, and thus, the ultimate success of the individual retrofit measures.

One means of reducing these problems is to use a fitted simulation model of the building's energy consumption. This approach is taken in this study. Architectural drawings, photographs and site reports were used in the development of the simulation model. Information on occupant-driven energy consumption was limited and had to be estimated using data from previous studies (ACEEE 1986, PG\&E 1987). The availability of whole-building hourly consumption data helped to fine-tune some of the parameters within the model. The final postretrofit model was then used to determine the effectiveness of the retrofit measures both on an individual and combined basis. 


\subsection{AVAILABLE DATA}

\subsubsection{Hourly Data}

Hourly electricity consumption data were obtained from BECo time-of-day electric meters. These data were available from May 1991 through April 1993. Hourly data helped to determine such things as occupant related loads, building response to infiltration, and the performance of the newly installed retrofits. The lack of a significant amount of cooling equipment allowed for year-round occupant related loads to be determined with summer hourly consumption profiles. The availability of these data simplified the task of matching the energy consumption of the computer model to the actual building.

\subsubsection{Monthly Data}

Recall that Figure 2.2 showed the peak and off-peak consumption and peak demand profiles obtained from monthly utility data, (BECo 1993a). This data spanned the period of December 1990 through September 1993. Monthly utility data also included power factor levels and utility charges which were used in the evaluation of the quality of the energy simulation model, and in the corresponding cost analysis. Monthly data were also compiled from the hourly data collected by the utility meter. These two sources of monthly information were found to be compatible over the intersecting periods.

\subsubsection{Weather Data}

The hourly weather data were obtained from a National Weather Service station located at Boston's Logan International Airport, (NOAA 1993). The airport is located approximately two miles south of the Margolis building. The weather data included hourly conditions from 1991 
through 1993. These hourly weather data were used in the calibration of the computer model for the pre- and post-retrofitted Margolis building. In order to remove climatic variations from the consumption models, normalized weather data were used in the determination of overall benefits. These data were also obtained from the National Climatic Data Center for the Logan International Airport and statistically represent a "typical" meteorological year, or TMY, for the Boston area.

\subsection{SIMULATION MODEL}

The energy simulation program used for the analysis of the Margolis apartment building was the DOE-2.1D Building Energy Analysis Program (LBL 1981, 1989). DOE-2.1D is an hourly energy simulation model which has been widely accepted for performing building simulations. The program uses transfer functions, as opposed to iterative methods, to calculate the dynamic thermal behavior of a building. Results of the simulation allow the user to examine building loads and whole-building and end-use energy consumption, on an hourly or monthly basis.

The DOE-2.1D program consists of four major calculation routines : 1) LOADS, 2) SYSTEMS, 3) PLANT, 4) ECONOMICS. The building energy loads are calculated in LOADS assuming fixed interior space temperatures. These loads are then sent to the SYSTEMS routine, where along with HVAC system and control information, actual space temperatures and HVAC system responses are determined. The performance of the HVAC equipment is then passed to the PLANT routine, where fuel and electricity requirements for the HVAC equipment, and the whole-building, are calculated. Using the results of the PLANT routine, energy costs may then be determined in ECONOMICS.

Along with the hourly weather data, the DOE-2.1D program requires a user input file written using the BDL format (Building Description Language). The input file is divided into four parts corresponding to the four routines within the program. The Margolis building actually has two input files, one for pre- and one for post-retrofit simulations. The post-retrofit model includes 
the improvements made in lighting, windows, and infiltration (resulting from window replacement). These files are listed in Appendix A.

Due to the complexity of the BECo rate structure, the ECONOMICS routine in DOE-2.1D is not capable of properly determining the economic costs of energy consumption for the Margolis building. An external routine incorporating the exact utility billing charges and rate schedules was developed and used to properly calculate Margolis energy costs from the hourly consumption results obtained with DOE-2.1D.

\subsection{ENERGY AND COST SAVINGS CALCULATIONS}

The development of the input files for the simulation program began with a model based on architectural drawings, site-audit reports, and photographs. This initial model was then compared to hourly whole-building data. Parameters were then calibrated iteratively using available information from audits, existing data on components of residential consumption, and engineering insight. This calibration method was used in the pre-retrofit model. The only parameter requiring calibration in the post-retrofit model was infiltration, since it had not been quantified. Details of the model calibration are discussed in the next section.

The final pre- and post-retrofit models were used to determine energy and demand reductions in the first year of retrofit. These two models were also run with normalized weather data to determine the average effectiveness of the retrofits. A final study was performed, using normalized weather data, to determine possible interactive effects of the retrofits and to quantify consumption savings that could be realized if the control system were to be operated properly.

\section{ADJUSTMENT OF MODEL PARAMETERS}

A preliminary model of the Margolis building was developed using architectural and mechanical drawings, photographs and information obtained from the LBL audit, and a technical 
assessment by BECo's retrofit contractor, Citizens Conservation Corporation, (HUD 1973, LBL 1992, Citizens 1992). This information included building orientation, number of occupants, envelope construction, installed lighting, appliances, and heating and ventilation equipment. In addition, internal load schedules were estimated using residential load profiles taken from ACEEE (1986) and PG\&E (1987) studies.

Pre-retrofit input parameters, such as lighting, appliance, and occupancy levels and schedules, were adjusted until hourly whole-building simulated consumption profiles matched those from the hourly monitored data. Specifically, hourly summer data were used to calibrate these loads since the minimal amount of air-conditioning equipment meant that most summer consumption could be attributed specifically to internal loads. Boston weather data for 1991 and 1992 were used in the simulation of the pre-retrofit Margolis building.

This technique of model calibration is referred to as conformed output. Alternatively, conformed input refers to the strict implementation of specific building information in the model, without fine-tuning through comparison with actual data. A study performed on commercial buildings compared the success of these two methods for models simulated with DOE-2.1D, (Corson 1992). The Corson study used monthly whole-building and end-use data to develop the conformed output models. It was determined that models built using the conformed output method exhibited $15 \%$ and $6 \%$ average monthly divergences in consumption, for small retail and large office buildings respectively. Conversely, the conformed input models displayed average monthly consumption divergences of $40 \%$ and $33 \%$, for small retail and large office buildings. The calibration of the Margolis building used, as a basis, the conformed output approach. However, with the additional use of hourly whole-building consumption data, the modeling process was more rigorous than that followed in the Corson study.

The post-retrofit model was not fine-tuned in the same manner as the pre-retrofit model. Hourly post-retrofit data were available only through March of 1993 , and monthly data through August. Lighting, window replacement, and thermostat retrofits were quantified and 
implemented in the post-retrofit model and required little adjustment to fit the data. Boston weather data for late 1992 and 1993 were used in the post-retrofit simulation.

\subsection{ADJUSTED PARAMETERS}

The calibration process followed in the development of the pre-retrofit Margolis building was quite involved. A legitimate model requires a considerable amount of engineering judgment when end-use hourly data is unavailable. Internal loads were adjusted until the summer hourly model matched the data. An infiltration model was selected after considerable investigation into several methods. The final product reflects a detailed calibration of internal loads and infiltration. Several of the significant parameters used in the pre-retrofit model are given in Table 4.1. Further details may be found in the input file, located in Appendix A.

Table 4.1 Significant parameters utilized in the Margolis building pre-retrofit model

\begin{tabular}{|c|c|}
\hline $\begin{array}{l}\text { Lighting } \\
\text { Apartments } \\
\text { Corridors } \\
\text { Garage } \\
\text { Exterior }\end{array}$ & $\begin{array}{l}0.8 \mathrm{~W} / \mathrm{ft}^{2} \\
1.0 \mathrm{~W} / \mathrm{ft}^{2} \\
0.40 \mathrm{~W} / \mathrm{ft}^{2} \\
3.9 \mathrm{~kW}\end{array}$ \\
\hline$\frac{\text { Appliances }}{\text { Apartments: }}$ & $1.0 \mathrm{~W} / \mathrm{ft}^{2}$ \\
\hline $\begin{array}{l}\text { Infiltration } \\
\text { Apartments } \\
\text { Corridors } \\
\text { Stairwells } \\
\text { Elevator Shafts }\end{array}$ & $\begin{array}{l}0.8 \mathrm{ACH},\left(0.11 \mathrm{cfm} / \mathrm{ft}^{2}\right) \\
0.2 \mathrm{ACH},\left(0.026 \mathrm{cfm} / \mathrm{ft}^{2}\right) \\
0.7-1.82 \mathrm{ACH},\left(0.11-1.99 \mathrm{cfm} / \mathrm{ft}^{2}\right) \\
0.7-1.89 \mathrm{ACH},\left(0.11-0.29 \mathrm{~cm} / \mathrm{ft}^{2}\right)\end{array}$ \\
\hline $\begin{array}{l}\text { Windows/Glass Doors } \\
\text { Regular Windows } \\
\text { Sliding Glass Doors }\end{array}$ & $\begin{array}{l}\text { Double-pane, glass conductance }=0.88 \mathrm{Btu} / \mathrm{hr}-\mathrm{ft}^{2}-{ }^{\circ} \mathrm{F} \\
\text { Double-pane, glass conductance }=0.92 \mathrm{Btu} / \mathrm{hr}^{-}-\mathrm{ft}^{2}-{ }^{\circ} \mathrm{F}\end{array}$ \\
\hline $\begin{array}{l}\text { Significant Heating Equipme } \\
\text { Apartments: } 889,954 \mathrm{~B} \\
\text { Stairwells: } 153,636 \mathrm{Btu} \\
\text { Elevator Areas: } 50,974 \\
\text { Heating Equipment Control } \\
\text { Temperature set points: }\end{array}$ & $\begin{array}{l}\text { ent } \\
\text { tu/hr Electric Resistance Baseboards } \\
\text { /hr Electric Resistance Baseboards } \\
\text { Btu/hr Electric Resistance }\end{array}$ \\
\hline
\end{tabular}


The development process for the post-retrofit model was less involved than that for the pre-retrofit. Changes made to lighting levels and glazing were easily quantified from the Citizens assessment report (1992). These changes were applied to the pre-retrofit model to produce the post-retrofit model. Because hourly whole-building data were available only through April 1993, monthly utility data through August 1993 were used to calibrate additional cooling months. Table 4.2 shows a summary of post-retrofit parameters.

The pre-retrofit lighting and appliance levels were initially estimated using architectural drawings and a lighting technical assessment included in an energy conservation study on the Margolis building, (Citizens 1992). The consumption profile of the lighting was scheduled to follow a typical dual peak residential trend. These initial estimates were incorporated into the

Table 4.2 Significant parameters used in the Margolis building post-retrofit model

Lighting

$\begin{array}{ll}\text { Apartments } & 0.46 \mathrm{~W} / \mathrm{ft}^{2} \\ \text { Corridors } & 1.0 \mathrm{~W} / \mathrm{ft}^{2} \\ \text { Garage } & 0.15 \mathrm{~W} / \mathrm{ft}^{2} \\ \text { Exterior } & 3.2 \mathrm{~kW}\end{array}$

Appliances

Apartments: $\quad 1.0 \mathrm{~W} / \mathrm{ft}^{2}$

$\underline{\text { Infiltration }}$

Apartments

Corridors

$0.68 \mathrm{ACH},\left(0.09 \mathrm{cfm} / \mathrm{ft}^{2}\right)$

Stairwells

$0.17 \mathrm{ACH},\left(0.022 \mathrm{cfm} / \mathrm{ft}^{2}\right)$

Elevator Shafts

$0.59-1.55 \mathrm{ACH},\left(0.09-1.22 \mathrm{cfm} / \mathrm{ft}^{2}\right)$

$0.59-1.6 \mathrm{ACH},\left(0.09-0.25 \mathrm{cfm} / \mathrm{ft}^{2}\right)$

Windows/Glass Doors

Regular Windows

Double-pane argon-filled, glass conductance $=0.6 \mathrm{Btu} / \mathrm{hr}-\mathrm{ft}^{2}-{ }^{\circ} \mathrm{F}$

Sliding Glass Doors

Double-pane argon-filled, glass conductance $=0.49 \mathrm{Btu} / \mathrm{hr}-\mathrm{ft}^{2}-{ }^{\circ} \mathrm{F}$

Significant Heating Equipment

Apartments: $889,954 \mathrm{Btu} / \mathrm{hr}$ Electric Resistance Baseboards

Stainwells: 153,636 Btu/hr Electric Resistance Baseboards

Elevator Areas: $50,974 \mathrm{Btu} / \mathrm{hr}$ Electric Resistance .

Heating Equipment Control

Temperature set points: Oct. 16 - May $31: 78^{\circ} \mathrm{F}$, no setbacks

June 1 - Oct. 15 : $72^{\circ} \mathrm{F}$, no setbacks 
DOE-2.1D model. Since the building lacked a significant amount of cooling equipment, hourly summer consumption components consisted mainly of lights and appliances. Careful calibration of these loads with summer whole-building hourly data resulted in an installed lighting capacity of $0.8 \mathrm{~W} / \mathrm{ft}^{2}$. Figure 4.1 shows an hourly comparison of the model for the cooling month of July 1992.
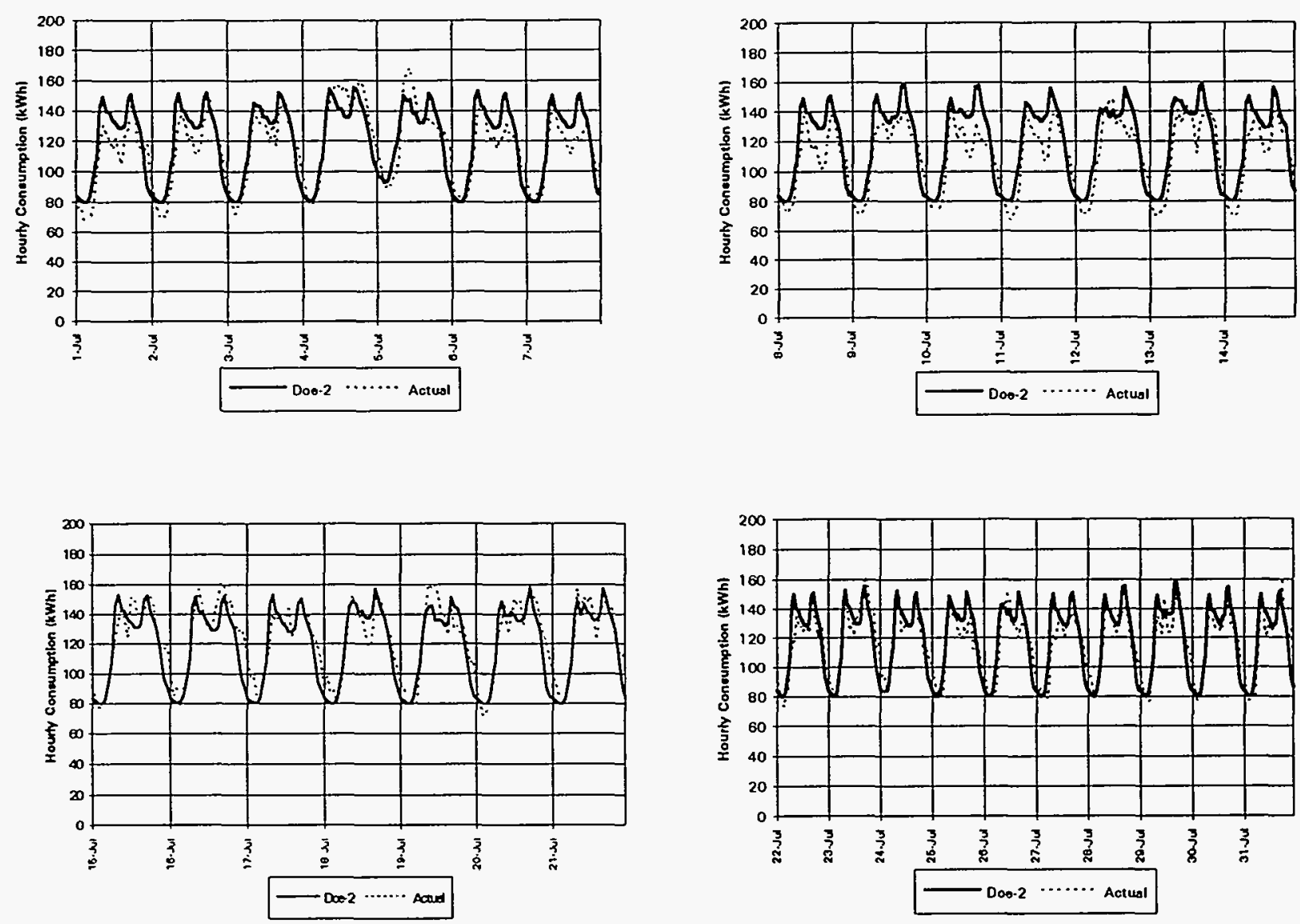

Figure 4.1 Pre-retrofit comparison of DOE-2.1D and whole-building hourly data, July 1992

Post-retrofit lighting included the replacement of apartment incandescent bulbs with lower wattage, compact fluorescents. This reduced the estimated apartment lighting capacity to $0.46 \mathrm{~W} / \mathrm{ft}^{2}$. Hourly whole-building data were unavailable for the cooling months after these 
lighting retrofits were installed. Thus, a comparison of summer data had to be done using monthly utility data alone. Figure 4.2 shows the post-retrofit comparison of monthly DOE-2.1D demand and consumption with actual utility data. The simulated peak and off-peak consumption levels during summer months are within $0 \%-12 \%$ of the utility monthly data. Demand models were found to be less accurate, at $8.2 \%-19.8 \%$ below actual demand during the summer months of 1993. This deviation in demand is assumed to be a result of the slight decrease in power factor accompanying the new fluorescent ballasts.
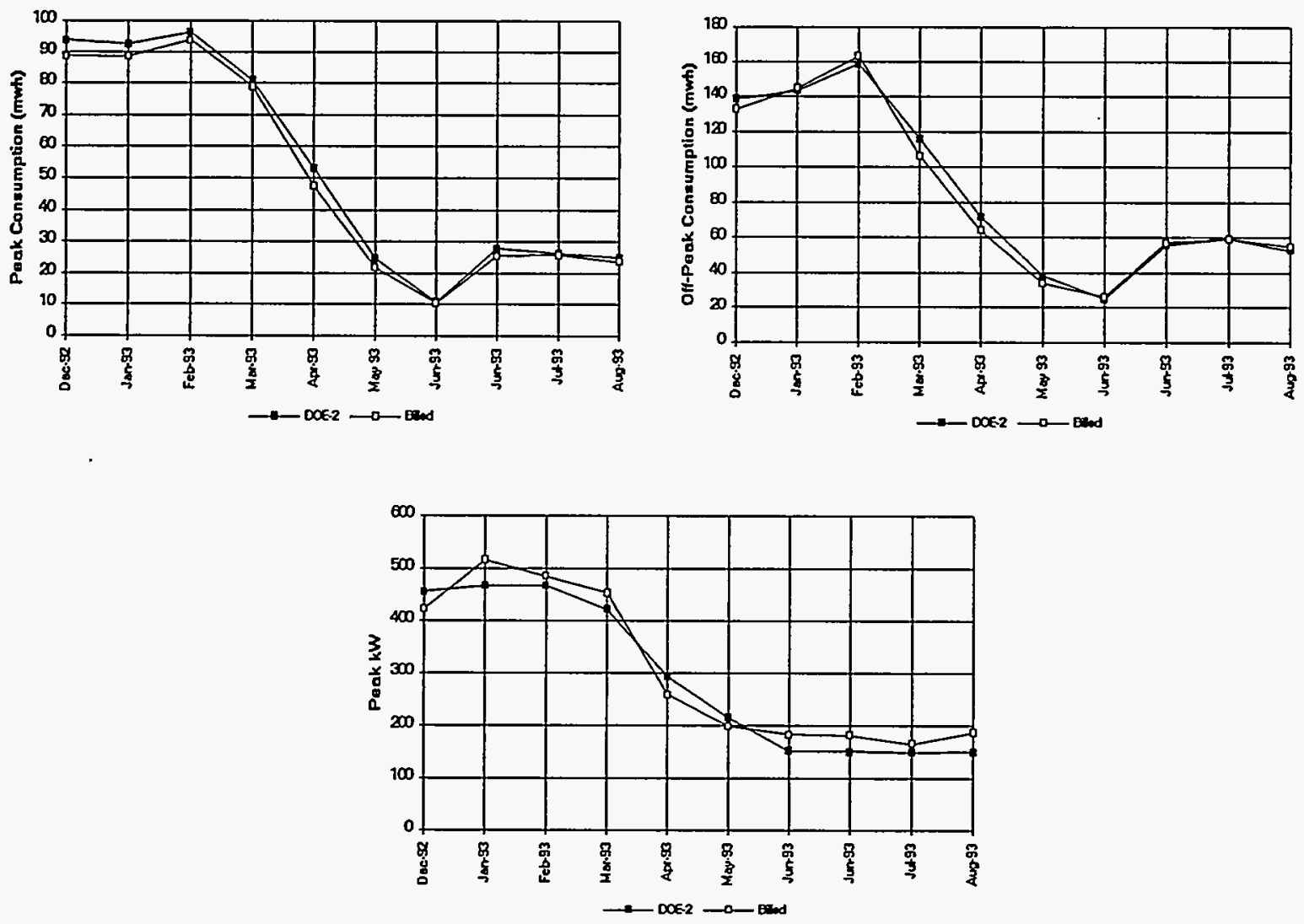

Figure 4.2 Post-Retrofit comparison of DOE-2.1D model and monthly utility data, 1993

According to site visit reports, infiltration was a major problem in the Margolis building. Northwest facing units experienced high amounts of infiltration from cold northwest winds during the winter months. Tenants in these units often set thermostats well above $78^{\circ} \mathrm{F}$. At the same 
time, the lack of proper ventilation prevented southeastern tenants from receiving adequate amounts of outside air, resulting in over-heated apartments. Some southeastern tenants responded by opening windows. A user-defined function routine in DOE-2.1D accounted for the open southeastern windows on the warmer days in winter months.

The DOE-2.1D simulation routine offers two options for modeling infiltration in a large building. The Crack Method incorporates pressure effects of the air density gradient (the stack effect) and wind velocity to determine the total pressure difference across the exterior wall. Similar to an orifice flow calculation, the Crack Method calculates infiltration for the building with pressure coefficients and exponents characteristic to the building. The Air-Change Method, the other option, has two sub-options. The user may specify either infiltration flowrates, which are independent of wind speed, or specify air-changes (rated at $10 \mathrm{mph}$ ), which are adjusted linearly with wind speed.

The infiltration study on the Margolis building included blower door measurements on selected apartments. The original intention of the study was to gather quantitative site information for the development of a whole-building air-flow model for computer simulation. The simulation routine used was COMIS, a joint internationally developed program sponsored by LBL, (COMIS 1990, 1992). The Margolis COMIS model was quite detailed and its development required a great deal of time and effort. The results from the model included a few cases covering specific boundary conditions. These results were helpful enough to be used as a basis for the model of infiltration loads in the DOE-2.1D whole-building simulation. COMIS infiltration rates, at various wind speeds and temperature differentials, are listed in Appendix B of this report.

Initial tests for modeling infiltration using the DOE-2.1D program began with the Crack Method. Test results seemed to indicate that while the infiltration flow coefficients and exponents for walls and windows were reasonable, problems existed with the DOE-2.1D calculation of total pressure differentials across exterior walls. The DOE-2.1 engineers manual suggests that stack pressures may be 18 - 38\% greater than actual stack pressures, (LBL 1982). The manual also notes that wind velocity pressures may be overestimated by as much as $46 \%$. 
Further investigation into the actual DOE-2.1D code found that when the angle of the wind was negative with respect to the outward normal of the wall examined, wind pressure would be completely neglected, resulting in low estimates of infiltration. While errors in wind-direction were easily corrected with a function routine, other problems with the Crack Method required more in-depth attention.

To accommodate the shortcomings of the Crack Method, user-defined function routines were developed for walls and windows. These routines used air-flows from the COMIS results to predict coefficients and exponents for wind and stack pressures. The COMIS data contained windward and leeward air-flows at wind speeds of 0,9,18 and $27 \mathrm{mph}$ with corresponding indoor/outdoor temperature differentials of $0^{\circ} \mathrm{F}, 36^{\circ} \mathrm{F}$, and $72^{\circ} \mathrm{F}$. Because only one angle of wind approach was available, extrapolation of the wind pressure coefficients was felt to be unreliable.

The Crack Method model using the COMIS information improved hourly consumption only slightly over the original DOE-2.1D Crack routine. Figure 4.3 shows, along with hourly temperatures and wind speed, a comparison of the two approaches with actual hourly data for the week of January 15,1992 . The hourly data suggest that both Crack models are too sensitive to wind speed. Early January 15th, while wind speeds exceed $30 \mathrm{mph}$, both models overestimate consumption by as much as $150 \mathrm{kWh}$. On the $21 \mathrm{st}$, wind speeds fall below $10 \mathrm{mph}$ and resulting models underestimate building consumption by a maximum of $150 \mathrm{kWh}$ per hour.
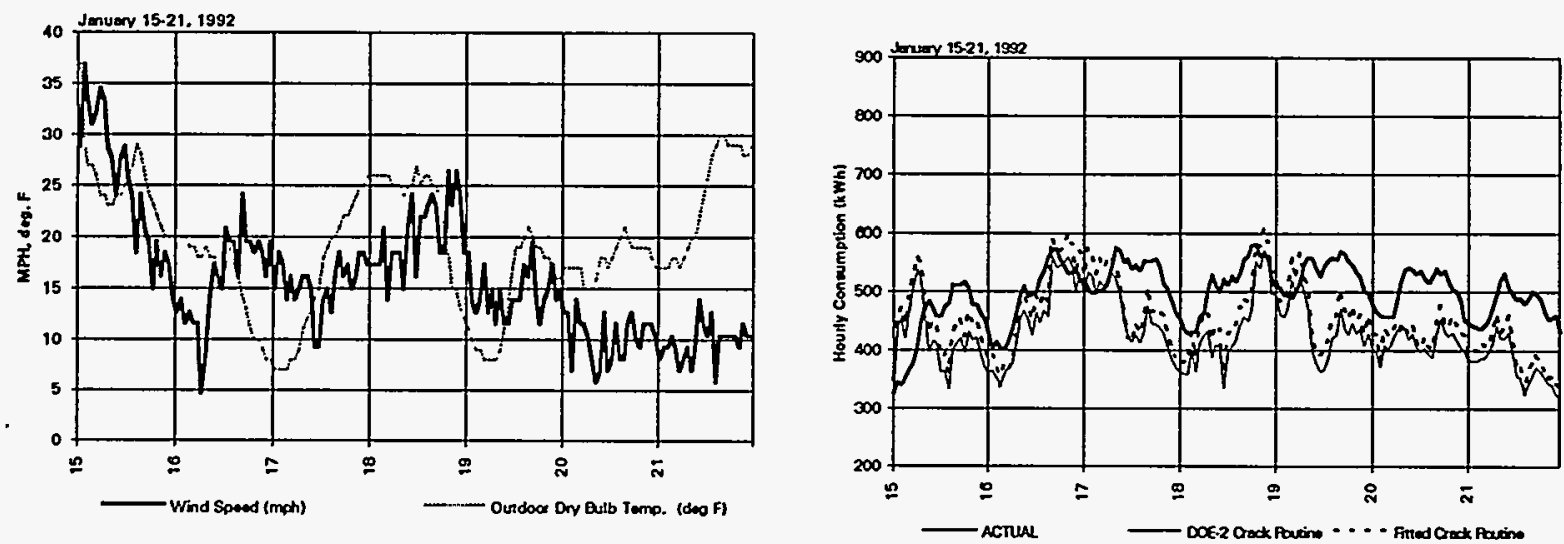

Figure 4.3.a Hourly weather data for January 15-21, 1992, (NCDC, 1992) 4.3.b Comparison of Crack Method hourly consumption models with actual data 
According to National Climatic Data Center standards, hourly wind speed and direction represent average values recorded during a five minute sample taken once an hour. This method can not accurately represent the average hourly wind velocity at the weather station and probably does not reflect the wind conditions experienced by the building. The inability of the Crack Method to adjust airport wind speed to site wind speed may have contributed to the difficulties experienced with the Margolis infiltration modeling.

Because of the apparent problems with wind data, the next step was to focus on the development of a model using the Air-Change Method. Both Air-Change models incorporated infiltration information from the LBL study. The first model includes air-changes per hour with corrections for wind speed. The second also uses air-changes per hour, however these are input as constant flowrates per unit of floor area. Once again, in order to evaluate the candidate methods, hourly comparisons with actual data were performed.

The hourly comparisons of these models, for the same week in January, are given in Figure 4.4. More so than with the Crack Method, the wind adjusted Air-Change model is simply too sensitive to wind conditions. The simulation model incorporating constant air-changes lacked wind speed sensitivity and, ultimately, was selected as the best infiltration model for the Margolis building. Monthly comparisons of all models considered are given in Figure 4.5, for pre-retrofit conditions. The post-retrofit model utilized the constant Air-Change Method, with reductions in pre-retrofit infiltration of $15 \%$.

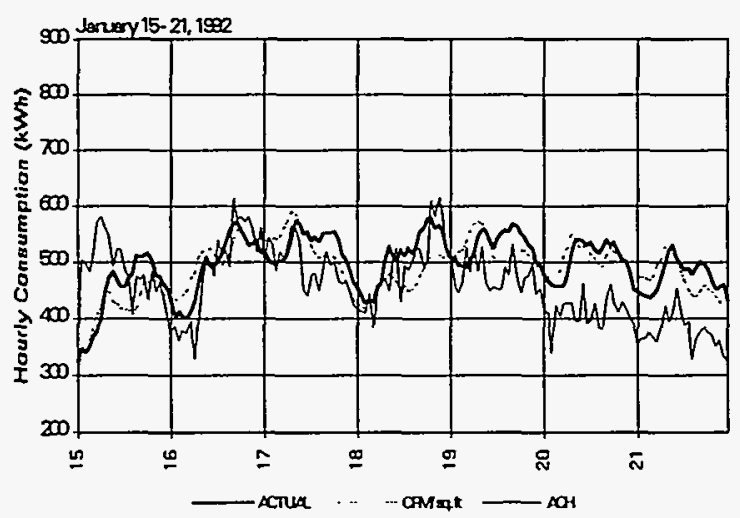

Figure 4.4 Comparison of Air-Change Method hourly consumption models with actual data 

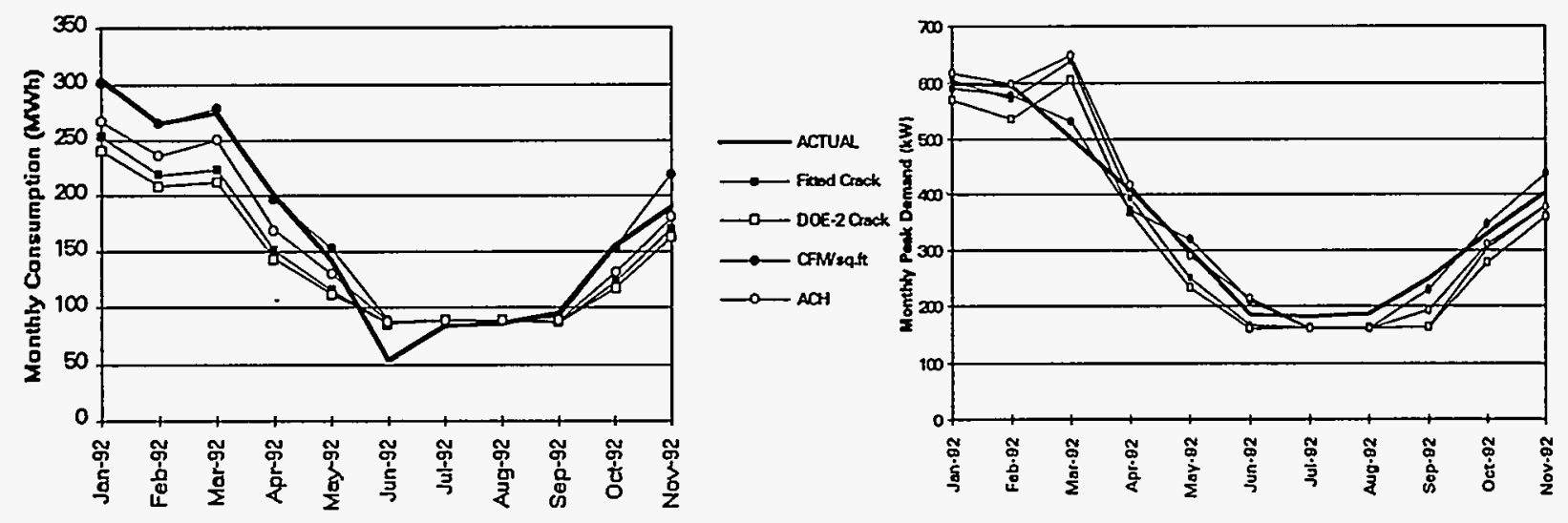

Figure 4.5 Comparisons of monthly consumption and peak demand for 1992 pre-retrofit conditions

\subsection{MONTHLY BILLING PERIOD COMPARISONS}

The monthly billing data were available for the pre-retrofit months of January 1991 through November 1992 and post-retrofit months of December 1992 through August 1993. Billing data contain peak and off-peak consumption, peak demand, and corresponding costs, (see Appendix C). Because the billing period for the Margolis building begins mid-month, the hourly simulation model was adjusted accordingly. Comparison plots of pre- and post-retrofit peak and off-peak consumption and demand are presented in Figure 4.6.a - 4.6.f. The preretrofit demand model falls within a $10 \%$ difference for the majority of the period, excluding October, 1992 , at $13.7 \%$. Similarly, the majority of pre-retrofit peak and off-peak consumption months are in agreement within $14 \%$. Post-retrofit model consumption is within $9 \%$ of actual peak and off-peak data. Finally, the post-retrofit demand model, however, is not as accurate, with an average monthly difference of $11 \%$ and a maximum of $20 \%$.

In addition to consumption and demand data, monthly utility costs from January 1991 through August 1993 were also available. The rate structures applicable to this period were used to calculate utility costs based on the simulated hourly data. Figures 4.7.a and 4.7.b show the 


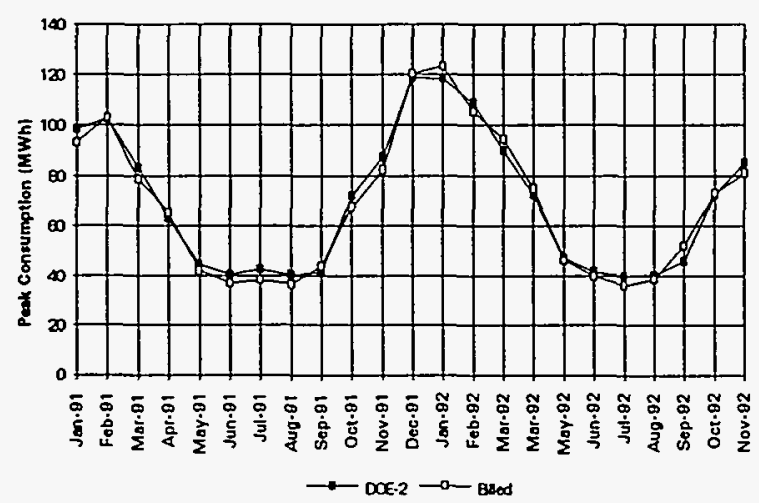

Figure 4.6.a Pre-retrofit on-peak consumption

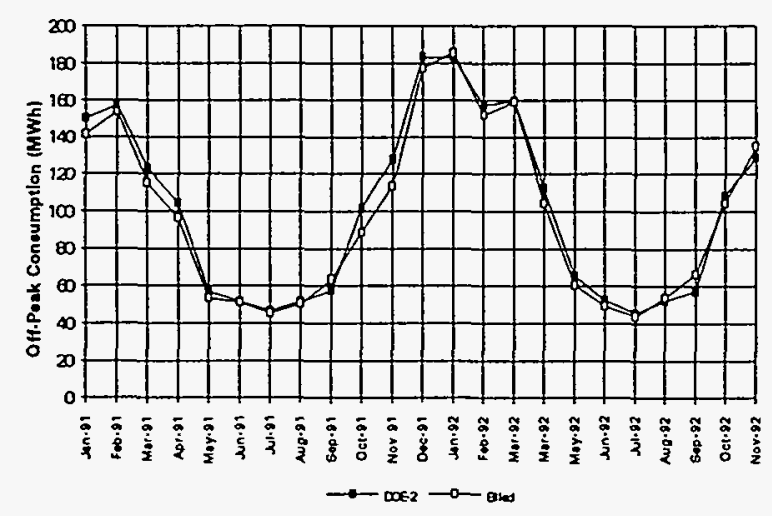

Figure 4.6.c Pre-retrofit off-peak consumption

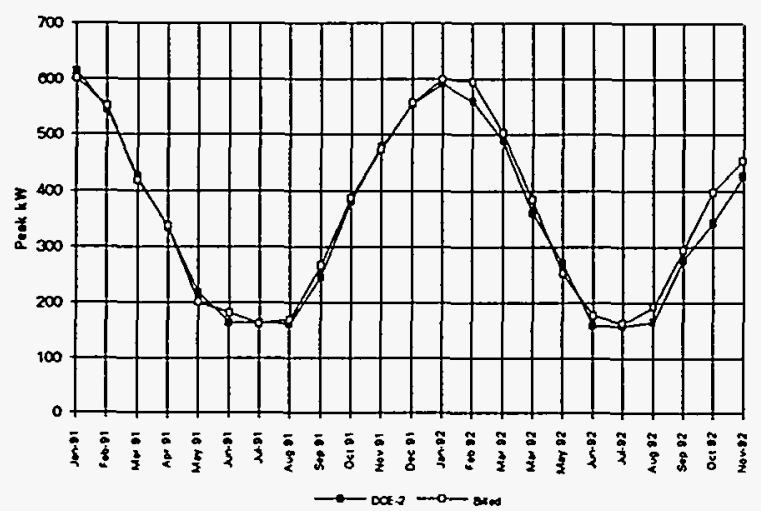

Figure 4.6.e Pre-retrofit peak demand

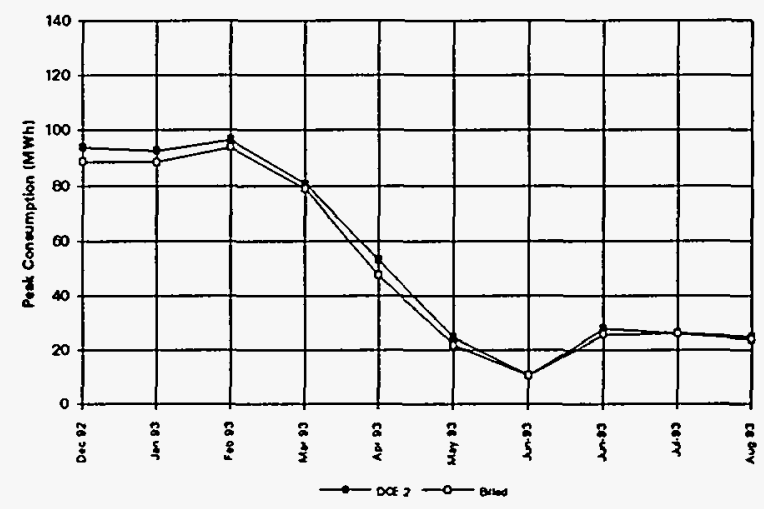

Figure 4.6.b Post-retrofit on-peak consumption

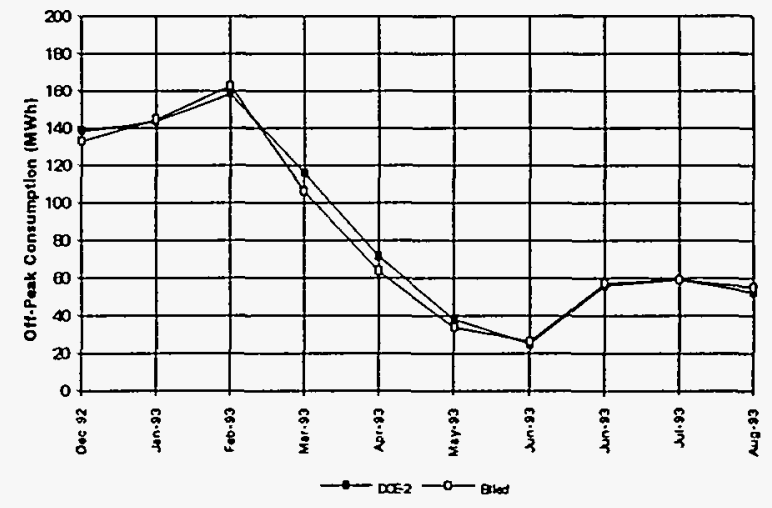

Figure 4.6.d Post-retrofit off-peak consumption

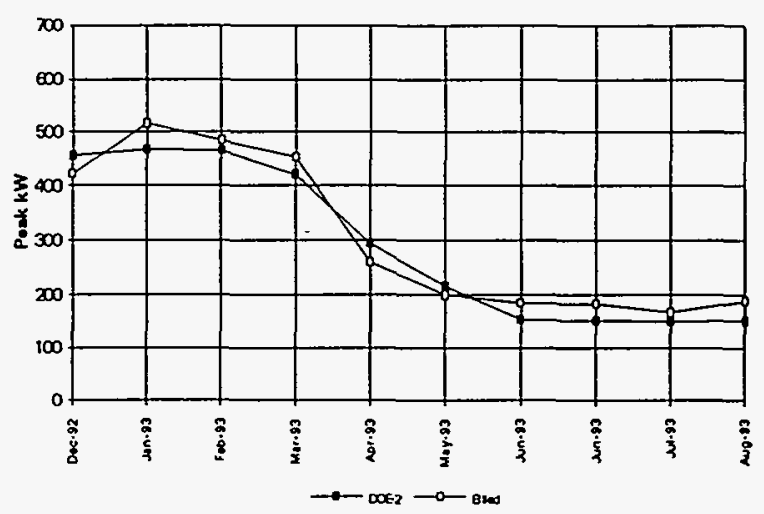

Figure 4.6.f Post-retrofit peak demand 


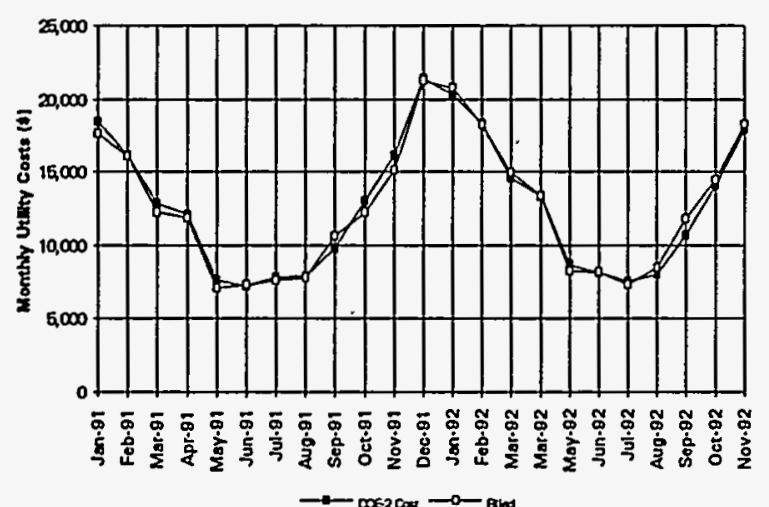

Figure 4.7.a Pre-retrofit utility costs

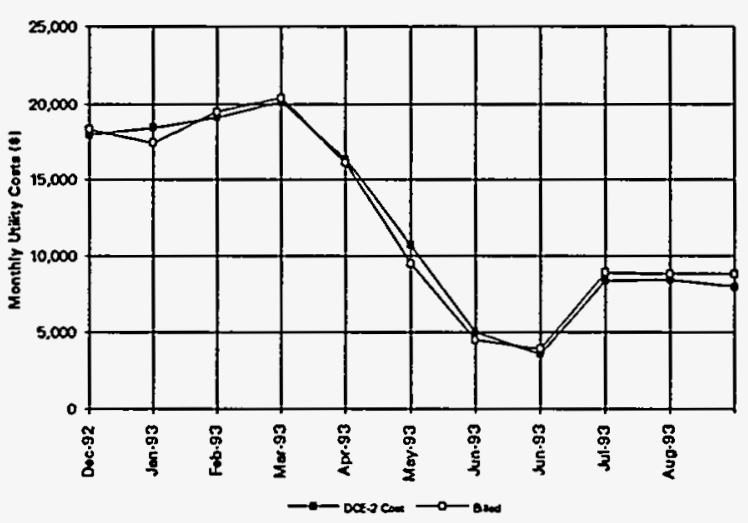

Figure 4.7.b Post-retrofit utility costs results, pre-and post retrofit, along with actual billed utility costs. The cost model determined utility costs, on average, within $5 \%$ of actual costs.

\subsection{HOURLY DATA COMPARISONS}

Hourly whole-building data, including peak demand and consumption, were available for the Margolis building during the period of January 1991 through April 1993. As previously discussed, pre-retrofit data taken during summer months were used to calibrate the baseload of

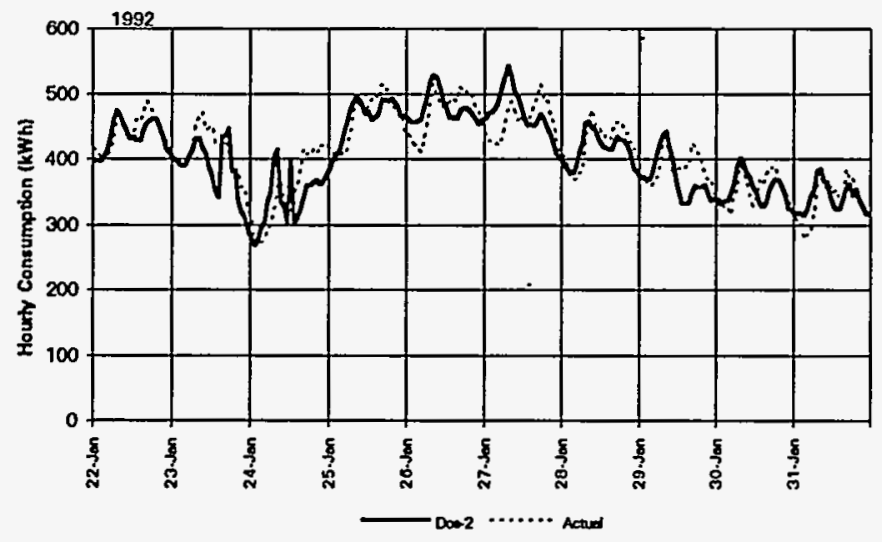

Figure 4.8 Pre-retrofit hourly comparison of simulation model and actual data, January 22-31, 1992 the building, (see Figure 4.1).

This was possible because the

Margolis building has very little cooling equipment. Once the baseload consumption was determined, hourly heating season data were used in the calibration of the infiltration model. Figure 4.8 presents hourly data comparisons during 
a pre-retrofit period in January, 1992. The simulated data agreed with the actual data within $6 \%$, on average, for these ten days. During this period, maximum error can be as high as $24 \%$, as the model has difficulty matching afternoon demand peaks.

The post-retrofit model, for the same week in 1993, is compared, on an hourly basis, to actual data in Figure 4.9. The post-retrofit simulation still exhibits difficulty in matching some afternoon peaks, with maximum error of $39 \%$, however the average difference was under $9 \%$. Several attempts were made to improve the afternoon response of the model. It was determined

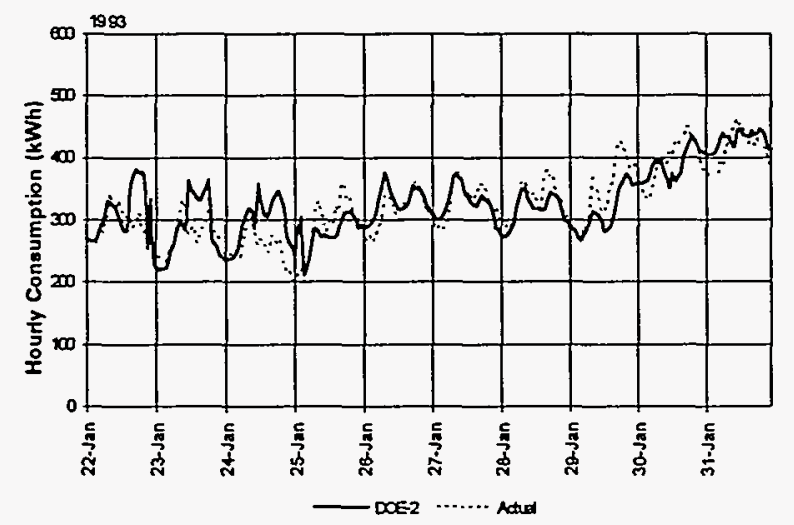

Figure 4.9 Post-retrofit hourly comparison of simulation model and actual data, January 22-31, 1993 that the deviation during afternoon peaks was due to tenant behavior and was too difficult to interpret exactly.

$$
\text { A post-retrofit model }
$$

incorporating thermostat setbacks was executed and compared to the actual hourly data. The hourly profile for the model showed significant decreases in consumption during the scheduled hours of setback. The profile of the actual data, however, does not reflect the operation of a nighttime setback. It is believed that although thermostat setback capabilities exist in the apartments, they are either not used or overridden.

\section{CONSERVATION MEASURES: ENERGY AND COST SAVINGS}

The success of installed energy conservation measures is dependent on the actual energy and demand reduction, and corresponding economics. These variables can be influenced by weather, measure, and building interactions. To effectively determine the success of energy conservation measures, these effects must be treated appropriately. 
Energy and demand responses of retrofits may vary from year to year with changes in weather patterns. A common problem occurs when unusual weather conditions in the first retrofit year result in poor energy and demand savings. In order to eliminate the weather effects, a normalized weather model for the region may be used in the DOE-2.1D simulation. The normalized model of the Margolis building used a typical meteorological year (TMY) as the weather data for Boston, MA. In this section, normalized models for the Margolis building are presented and discussed.

The success of individual retrofits may be determined only after the contribution of each is quantified. This is done by comparing a pre-retrofit consumption model to models for individual retrofits and total installed retrofits (Crown 1993). These retrofit tests often find interactions that occur either with building systems or with other measures. Additionally, it is important to verify that savings calculated by the model are realistic, relative to the wholebuilding consumption (Waltz 1992). In the interaction study, retrofit tests are performed using normalized TMY weather data. The results of these tests are also presented in this section.

\subsection{OVERALL BENEFITS}

\subsubsection{Energy and Peak Demand Savings}

Monthly comparisons of normalized peak and off-peak energy consumption, as determined by the rate structure, for full pre- and post-retrofit models are shown in Figures 5.1.a and $\mathrm{b}$. Total annual consumption is reduced by $325 \mathrm{MWh}$, in the normalized model. Over $60 \%$ of these savings occur during off-peak hours, with the improved insulative effects of retrofit windows. Total energy savings are more prevalent during the heating season and reflect an average reduction in pre-retrofit annual consumption of $15 \%$. 


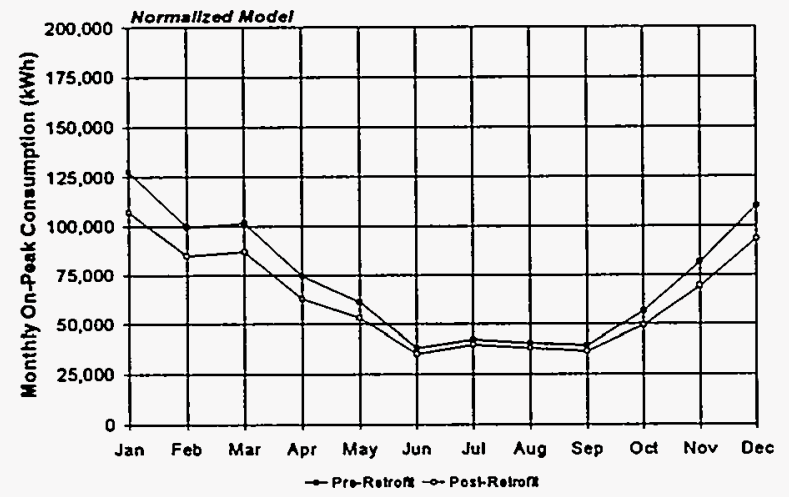

Figure 5.1a Normalized monthly on-peak energy consumption

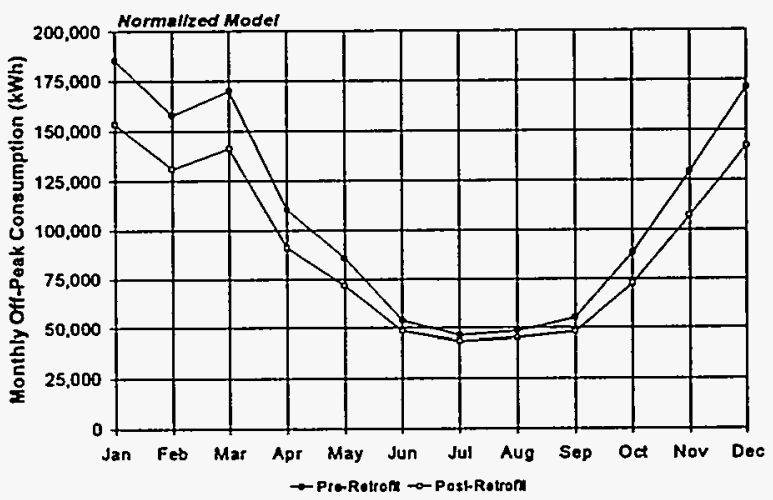

Figure 5.1.b Normalized monthly off-peak energy consumption

Similarly, the demand comparison for the normalized model is shown in Figure 5.2. The demand peaks displayed in Figure 5.2 reflect peaks as defined in the utility rate schedule and do

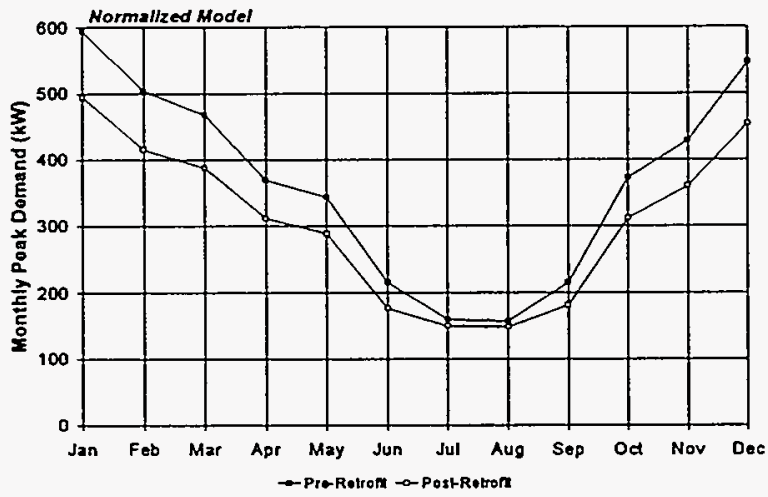

Figure 5.2 Normalized monthly peak demand not necessarily reflect overall peak values. This monthly peak demand is reduced, on average, by $61 \mathrm{~kW}$ and the maximum peak is reduced by $17 \%$, or $100 \mathrm{~kW}$, in January. Demand savings are most significant during colder months as retrofit windows reduce the demand for electric resistance heat.

\subsubsection{Component Energy Used}

The components of energy consumption for the normalized model were calculated by the simulation routine. This pre- and post-retrofit information is given, on a per area basis, in Table 5.1. The electric resistance heating system in the Margolis building constitutes nearly half of the whole-building energy consumption. Post-retrofit measures reduced space heating requirements by $2.6 \mathrm{kWh} / \mathrm{ft}^{2}$ and lighting consumption by $0.68 \mathrm{kWh} / \mathrm{ft}^{2}$. The large contribution of 
space heating to whole-building consumption indicates the vast potential for conservation in this area. National data on residential energy use show that multifamily buildings, in a similar climate, consume approximately 5-6 kWh/ft ${ }^{2}$ for space heating, (EIA 1993). While space heating consumption was reduced with the retrofit, at $8.5 \mathrm{kWh} / \mathrm{ft}^{2}$, apparently there is still room for improvement.

Table 5.1 Components of energy consumption for the Margolis building, as determined by normalized simulation model

\begin{tabular}{||c|c|c||}
\hline Component & $\begin{array}{c}\text { Pre-Retrofit Consumption } \\
\left(\mathrm{kWh} / \mathrm{ft}^{2} / \mathrm{yr}\right)\end{array}$ & $\begin{array}{c}\text { Post-Retrofit Consumption } \\
\left(\mathrm{kWh} / \mathrm{ft}^{2} / \mathrm{yr}\right)\end{array}$ \\
\hline Space Heating & 11.10 & 8.54 \\
Space Cooling & 0.04 & 0.04 \\
Domestic Hot Water & 2.07 & 2.06 \\
Lights & 3.65 & 2.97 \\
Elevator & 0.695 & 0.695 \\
Misc. Equipment & 4.08 & 4.08 \\
\hline Total & 21.63 & 18.38 \\
\hline
\end{tabular}

In searching for cost effective conservation measures, one should examine the potential impacts of the candidate retrofits on related building loads (in this case heating), which is ultimately the source of the building's demand for electricity. Table 5.2 lists the effects on heating load of each of the retrofits considered for the Margolis building. Notice that the window retrofit has the largest impact on the reduction of the heating load, while the lighting retrofit actually has a negative impact. Reprogramming setbacks will reduce the overall demand

\begin{tabular}{|c|c|}
\hline Scenario & $\begin{array}{c}\text { Reduction in } \\
\text { Total Heating } \\
\text { Load (MBtu) }\end{array}$ \\
\hline Post-Retrofit (as is) & 883 \\
\hline Windows & 1000 \\
\hline Lighting & -124 \\
\hline Post- w/ Setback & 994 \\
\hline
\end{tabular}

Table 5.2. Reduction in annual heating load, by retrofit scenario 
for heat from the building's baseboard heaters. By examining the potential impacts on related load behavior, the success of individual retrofits may be predicted.

\subsubsection{Energy Cost Savings}

Utility costs for the normalized model were calculated, using hourly simulation results, to determine monetary savings associated with the final retrofits. The rates were taken from the 1993 Margolis building utility bills. Annual normalized pre-retrofit utility costs were $\$ 190,000$, while post-retrofit costs were $\$ 162,000$. Figure 5.3 shows the monthly consumption charges for

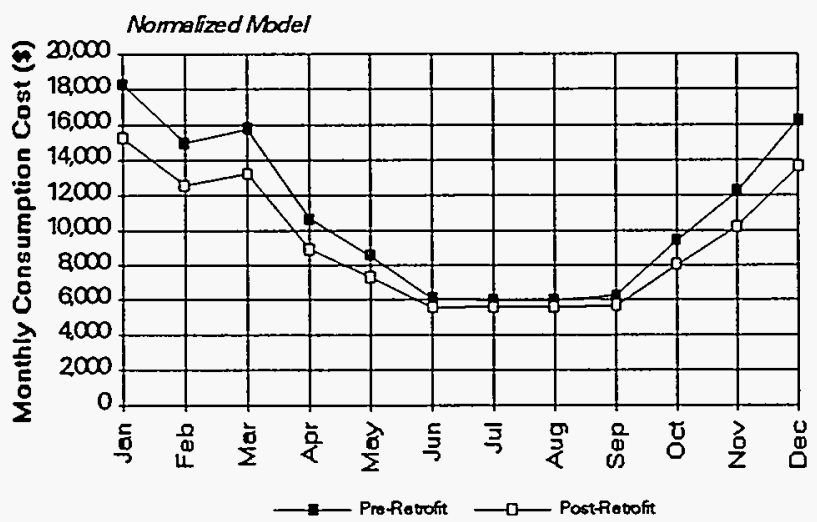

Figure 5.3 Monthly consumption costs, pre- and post-retrofit, for normalized model the normalized year, pre- and postretrofit. The savings in total energy costs for the year are $\$ 28,000$, which represent $14.6 \%$ of pre-retrofit utility costs.

As shown previously, over $60 \%$ of all energy savings occurred during utility off-peak hours.

Unfortunately, lower off-peak utility rates reduce the potential for cost savings associated with a large reduction in consumption. As a result, ratios of cost savings to $\mathrm{kWh}$ savings are higher for peak consumption, at $0.0668 \$ / \mathrm{kWh}$, compared to $0.0525 \$ / \mathrm{kWh}$ for off-peak consumption.

Demand cost savings for the normalized model are presented in Figure 5.4. The annual savings in demand costs represent a $16 \%$ reduction in pre-retrofit levels and account for $33 \%$ of total utility cost savings. Demand cost savings, which are enhanced during winter months and minimized during the summer, reflect the success of the window retrofit in reducing demand for electrical heat. 


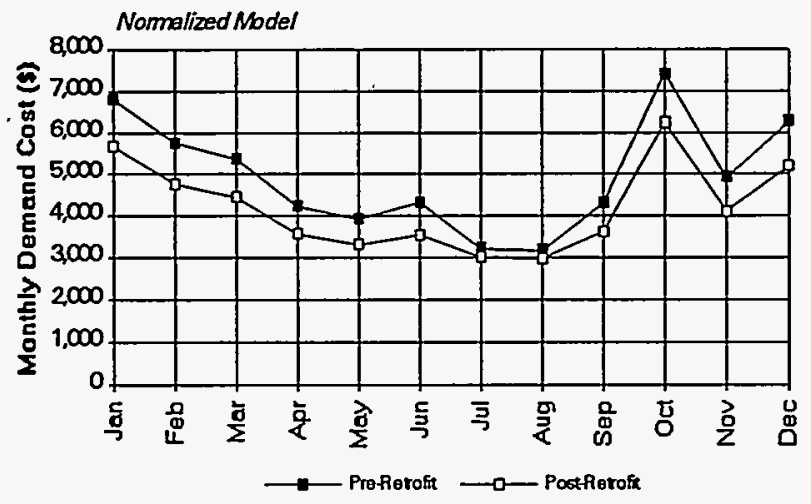

Figure 5.4 Monthly demand costs, pre- and post-retrofit, for normalized model

\subsection{COST/BENEFITS OF THE INDIVIDUAL MEASURES}

Breakdowns of the contribution of each retrofit component to annual energy and demand savings are presented in Figures 5.5.a. and 5.6.b. The energy savings attributed to lighting retrofits are smaller than calculated when estimations are based on the reduction in lighting capacity, alone. Similarly, demand savings from lighting retrofits are also incredibly small. The large contribution of the glazing retrofit to energy and demand savings reaffirms the fact that reduction in demand for electric resistance heat should be a priority.

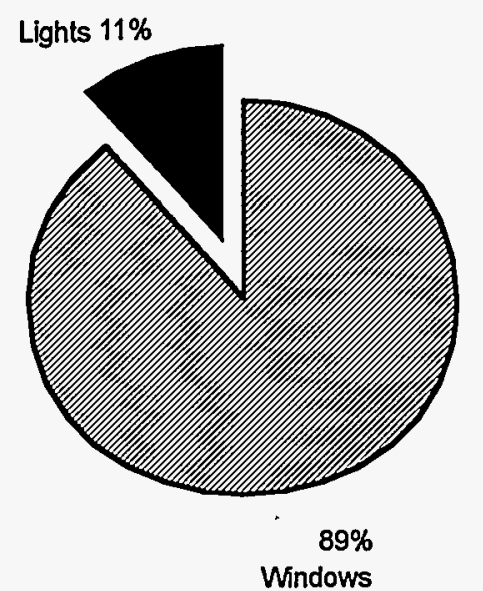

Figure 5.5.a Contribution of retrofit components to energy savings

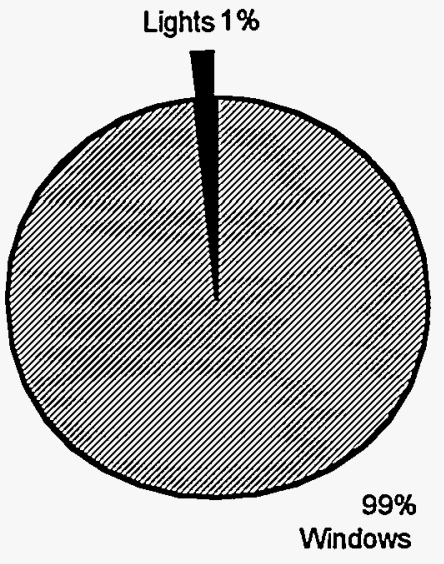

Figure 5.5.b Contribution of retrofit components to demand savings 
Overall energy savings are reduced with the lighting retrofit when the demand for electric baseboard heating is increased. As discussed previously, this building consumes a large amount of energy in space heat. Along with the reduction in lighting illumination and power, a reduction occurs in the space heat provided by the lighting. This reduction was significant enough to require an increase in the demand for electric resistance heat, especially during the colder winter months. A study on lighting retrofits found similar results: shell-dominated buildings in colder climates experience an increase in heating requirements with certain lighting conservation measures, (Higgins 1992). The Margolis building, as a result of ventilation and infiltration problems, definitely exhibits shell-dominant tendencies during the cooler months of the year.

\subsubsection{Monthly Benefit Contributions}

The effects of individual and combined retrofits were examined on a monthly basis, to understand interaction effects with the building and with each other. The results of these runs are presented in Figures 5.6 and 5.7, for consumption and demand respectively. Note that the information given in the figures represents savings relative to normalized pre-retrofit conditions and not actual consumption and demand values.

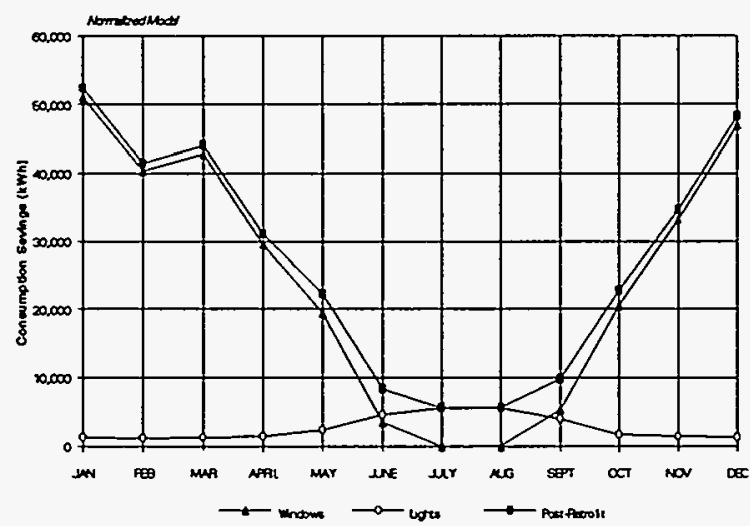

Figure 5.6 Consumption savings of retrofit models relative to pre-retrofit conditions

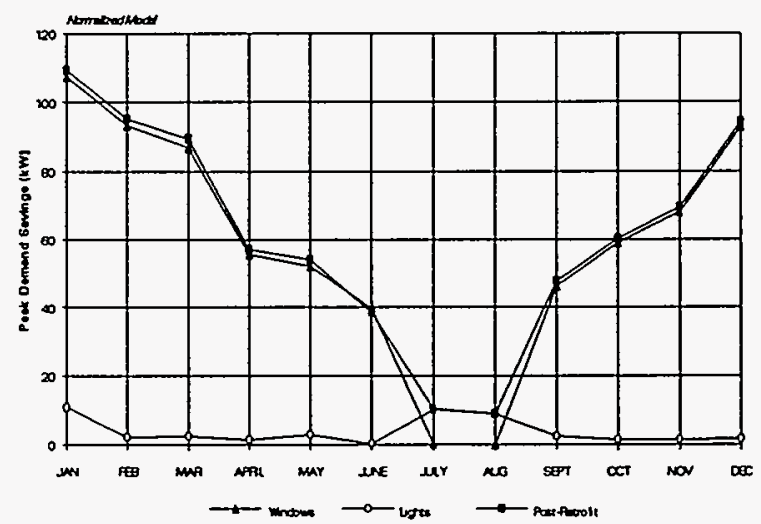

Figure 5.7 Peak demand savings of retrofit models relative to pre-retrofit conditions 
Lighting Savings. Savings from lighting retrofits, both in consumption and demand, are significant during summer months, when heating demand is nonexistent. Peak lighting consumption savings occurs in July, at $5,600 \mathrm{kWh}$, or $6.3 \%$ of July pre-retrofit consumption. Similarly, peak demand in July is reduced by $10.5 \mathrm{~kW}$, a $6.5 \%$ reduction. The results show that during colder months, space heat previously supplied by the lights is made up by an increase in the electric resistance supply.

Window Savings. The consumption and demand savings from the window retrofit were large, as conduction and infiltration losses were reduced, resulting in the reduction in demand for electric resistance heat. Savings are strongest in January, at 51,000 kWh and $98 \mathrm{~kW}$. These savings reflect $16.3 \%$ and $16.5 \%$ reductions in January consumption and demand, respectively.

Post-Retrofit Savings. Actual retrofit savings, which include both lighting and window measures, are nearly the sum of the individual retrofits. Maximum monthly consumption and demand savings for the post-retrofit model occur in January. Including lighting and window retrofits, these savings are $52,300 \mathrm{kWh}$ and $99.7 \mathrm{~kW}$, or $16.7 \%$ and $16.8 \%$ of pre-retrofit consumption and demand.

Billing Cost Savings. A comparison of billing cost savings is given in Figure 5.8 . These savings are reflective of the consumption and demand savings discussed above. Window

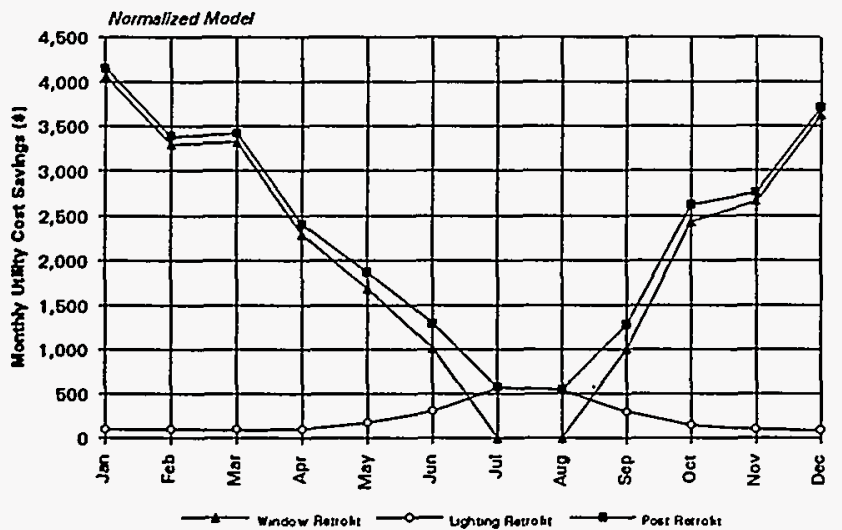

Figure 5.8 Monthly utility cost savings of retrofit models over pre-retrofit conditions retrofits provide the majority of the savings, peaking in January at $\$ 4,060$, or $16.3 \%$ of pre-retrofit costs. The highest monthly savings for lighting retrofits was $\$ 563$, a $6.1 \%$ savings over the original utility costs. The complete postretrofit model experienced maximum cost savings in January, 
at $\$ 4,150$, or $17 \%$ of pre-retrofit costs. In a life-cycle cost analysis, the significant cost savings accompanying the window retrofits make them more financially attractive.

\subsubsection{Additional Savings by Implementing Controls}

Savings have been presented for only two of the three retrofits which were installed in the Margolis building. In addition to lighting and window retrofits, an energy management system (EMS) was to reduce space heat energy consumption. The EMS was originally programmed to drop the nighttime setpoint temperatures by $4^{\circ} \mathrm{F}$, during the hours of 11 p.m. to 6 a.m. When the results of the simulation model were compared to actual hourly data, it was determined that this retrofit had not been implemented properly. The actual hourly consumption

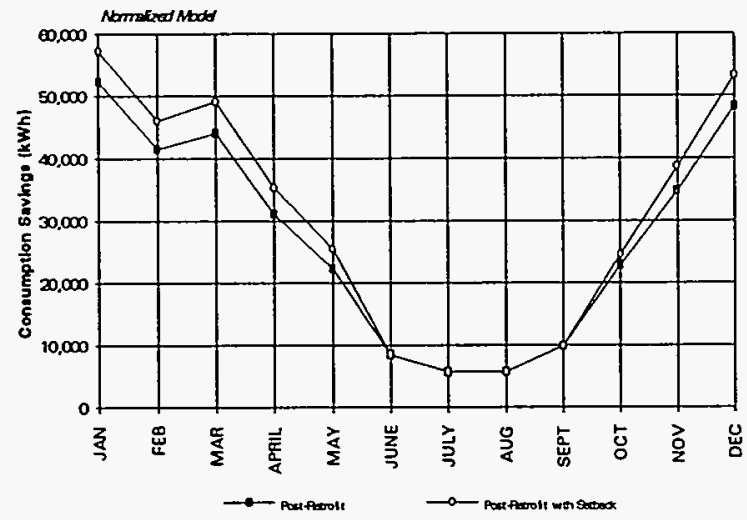

Figure 5.9 Consumption savings of retrofit model over pre-retrofit conditions

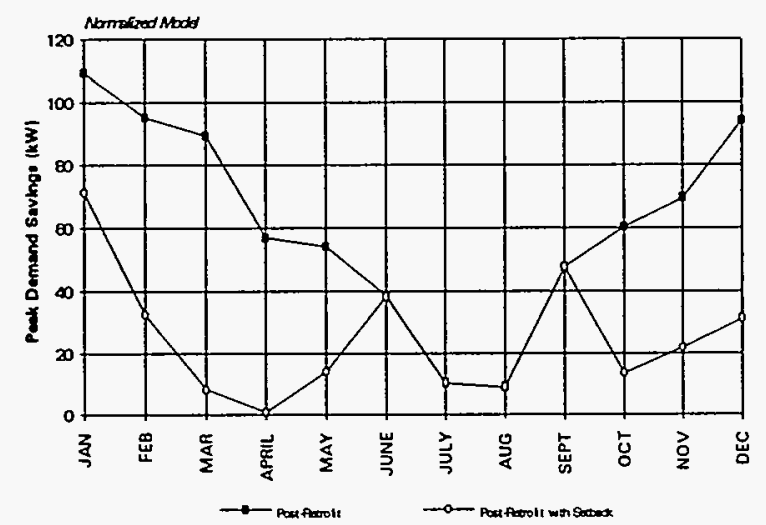

Figure 5.10 Demand savings of retrofit model over pre-retrofit conditions. profile does not show signs of reduced consumption during the intended hours of setback.

A weather-normalized simulation of the setback model was run to determine the benefits and/or penalties of the originally programmed setbacks for the Margolis building. Figures 5.9 and 5.10 show comparisons of consumption and demand savings for both the setback model and the actual post-retrofit model. The largest savings in consumption occurs during the winter months, as demand for nighttime heating is reduced with the setbacks. Additional savings in energy over existing post-retrofit conditions are 
nearly $32,000 \mathrm{kWh}$. Peak demand savings would be reduced if setbacks are implemented. This is the result of an increase in the morning demand for space heat, occurring at the end of the setback period. The cost benefits associated with this setback scheme are negative, due to the electric rate structure, and the nature of the resulting consumption and demand profiles.

Since this analysis of 1993 post-retrofit data, BECo has calibrated the EMS located in the Margolis building. BECo has indicated that the calibrated EMS has saved a significant amount of energy, however available data do not readily support this claim.

\section{DISCUSSION OF RESULTS}

\subsection{OVERALL SAVINGS}

Savings in energy consumption and peak demand are presented in Table 6.1 for each measure and for the pre- and post-retrofit models. These savings are based on the weathernormalized model, as was discussed in the previous section. Energy and demand savings are highest for the as-is post-retrofit model, which includes both lighting and window retrofits. By implementing the EMS night setback function, an additional savings of $357 \mathrm{MWh}$ could be realized, however, with a demand penalty of nearly $40 \mathrm{~kW}$. Unfortunately, the nature of the BECo rate structure financially penalizes such sharp peaks in daytime demand.

Corresponding cost savings and simple paybacks for these scenarios are shown in Table 6.2. Utility cost savings are highest for the as-is post-retrofit model, however the simple payback period, at 13.2 years, is definitely not the shortest. By implementing the existing EMS night setback, utility costs and the simple payback period will experience an increase, over the as-is post-retrofit condition. Thus, according to this model, the most cost-effective scenario is the window retrofit, which reduces total heating consumption, and lowers the excessive demand peaks that are costly under the BECo rate structure. 
Table 6.1 Summary of annual consumption and demand scenarios for the Margolis building

\begin{tabular}{|c|c|c|c|c|}
\hline Scenario & $\begin{array}{l}\text { Energy } \\
\text { Used } \\
\text { (MWh) }\end{array}$ & $\begin{array}{l}\text { Energy } \\
\text { Savings } \\
\text { (MWh) }\end{array}$ & $\begin{array}{l}\text { Peak } \\
\text { Demand } \\
(\mathrm{kW})\end{array}$ & $\begin{array}{c}\text { Demand } \\
\text { Savings } \\
\text { (kW) }\end{array}$ \\
\hline Pre-Retrofit & 2,174 & & 594 & \\
\hline Post-Retrofit & 1,849 & $\begin{array}{c}325 \\
(15 \%) \\
\end{array}$ & 494 & $\begin{array}{c}100 \\
(16.8 \%) \\
\end{array}$ \\
\hline Lighting & 2,143 & $\begin{array}{c}31 \\
(1.5 \%) \\
\end{array}$ & 593 & $\begin{array}{c}1 \\
(0.2 \%) \\
\end{array}$ \\
\hline Window & 1,883 & $\begin{array}{c}291 \\
(13.4 \%) \\
\end{array}$ & 496 & $\begin{array}{c}98 \\
(16.5 \%) \\
\end{array}$ \\
\hline $\begin{array}{l}\text { Post- w/ } \\
\text { Setback }\end{array}$ & 1,817 & $\begin{array}{c}357 \\
(16.4 \%)\end{array}$ & 534 & $\begin{array}{c}60 \\
(10.1 \%)\end{array}$ \\
\hline
\end{tabular}

Table 6.2 Summary of measure costs, utility costs and simple payback for the Margolis building

\begin{tabular}{||c|c|c|c|c||}
\hline Scenario & $\begin{array}{c}\text { Measure } \\
\text { Cost } \\
(\$)\end{array}$ & $\begin{array}{c}\text { Annual Utility } \\
\text { Cost } \\
(\$)\end{array}$ & $\begin{array}{c}\text { Annual Utility } \\
\text { Cost Savings } \\
(\$)\end{array}$ & $\begin{array}{c}\text { Simple } \\
\text { Payback } \\
\text { (yrs) }\end{array}$ \\
\hline Pre-Retrofit & 189,880 & 131,880 & $\begin{array}{c}28,000 \\
(14.6 \%)\end{array}$ & 13.2 \\
\hline Post-Retrofit* & 372,000 & 187,330 & $\begin{array}{c}2,550 \\
(1.2 \%)\end{array}$ & 9.2 \\
\hline Lighting & 23,500 & 164,480 & $\begin{array}{c}25,400 \\
(13.4 \%)\end{array}$ & 7.5 \\
\hline Window & 192,000 & 164,390 & $\begin{array}{c}25,490 \\
(13.3 \%)\end{array}$ & 14.7 \\
\hline Post- w/ Setback & 372,000 & \multicolumn{2}{|c|}{} \\
\hline
\end{tabular}

*Includes cost of installed EMCS, at $\$ 156,500$ 


\subsection{WINDOW REPLACEMENT}

Reports from site visits indicate that original windows had condensation between the panes and were very leaky. Original double-pane windows in the Margolis building were replaced with double-pane argon-filled windows. Similarly, large, double-pane sliding glass doors were retrofitted with double-pane argon-filled glass doors. Some consideration was given to replacing the sliding glass doors with French doors. Tenants objected and the double-pane glass doors were used instead.

The reduction in building heating loads from the window retrofit were impressive. Annual building loads from glass heat conduction were reduced by $590 \mathrm{MBtu}$, with a peak reduction of $190 \mathrm{kBtu} / \mathrm{hr}$. The load reduction associated with increased window resistivity reflected $16 \%$ of the total pre-retrofit building load. Also, a reduction in infiltration corresponding to the tighter windows was estimated at $15 \%$. Corresponding annual infiltration loads were decreased by 540 MBtu, and peak infiltration loads by $190 \mathrm{kBtu} / \mathrm{hr}$. A direct result of the decrease in these heating loads is the decrease in energy consumption and peak demand during the heating season.

Reductions in energy consumption and demand resulting from lower conductivity and infiltration loads were considerable for the window replacement. Recall that energy and demand savings were $13.4 \%$ and $16.5 \%$ of pre-retrofit conditions. The window retrofit contributed $89 \%$ of total energy and $99 \%$ of total demand post-retrofit savings.

\subsection{LIGHTING}

The Chelsea building was designed in the early 1970 s and consequently the installed lighting was abundant and inefficient. Pre-retrofit apartment lighting levels were at $0.8 \mathrm{~W} / \mathrm{ft}^{2}$, with predominantly incandescent fixtures. The lighting retrofit replaced these fixtures with reduced wattage fluorescents and compact fluorescents, resulting in an installed capacity of $0.46 \mathrm{~W} / \mathrm{ft}^{2}$. 
Whole-building lighting capacity was reduced from $102 \mathrm{~kW}$ to $70 \mathrm{~kW}$ with the lighting retrofit. Lighting consumption decreased by $68,000 \mathrm{kWh}$, or $3 \%$ of total annual consumption. However, the corresponding reduction in the heat supplied by the lights had to, instead, be supplied by the electric resistance heating system. Peak demand on the heating system was increased by $19.4 \mathrm{kBtu} / \mathrm{hr}$, or $5.8 \mathrm{~kW}$, while the annual heating load was increased by $125 \mathrm{MBtu}$, or $36,800 \mathrm{kWh}$. As a direct result of the increased load on the heating system by the lighting retrofits, overall consumption and demand savings were reduced. The resulting energy savings were $31,000 \mathrm{kWh}$, with peak demand reduction around $1 \mathrm{~kW}$, for the lighting retrofit.

\subsection{ENERGY MANAGEMENT SYSTEM}

Along with window and lighting retrofits, an energy management system was installed in the Margolis building. The EMS was intended to implement nighttime setbacks. After examining hourly heating season data, it was evident that setbacks were not used for a time and had been disengaged altogether. Apparently the setback function was manually overridden by tenants and then deprogrammed from the central control system. As a result, total energy savings associated with the energy management system have not been realized.

With the implementation of the initial setback scheme, additional savings in energy could be nearly $33 \mathrm{MWh}$, which represent a $10 \%$ increase in existing energy savings. Unfortunately, peak demand should increase by $40 \mathrm{~kW}$ with an increase in the demand for heating, at the end of the setback period. Because of the nature of the utility rate structure, it should be noted that the higher demand levels will increase annual utility costs by around $\$ 2,000$ $-\$ 3,000$ over post-retrofit costs, if the setbacks are implemented.

Immediately following the operating period examined in this report, the EMS was calibrated properly and brought back on-line. BECo representatives believed that the EMS was responsible for a significant amount of energy saved during the Margolis retrofit. Unfortunately, 
this claim could not be verified with the small amount of related data available at the release of this report.

\subsection{PREDICTED ENERGY AND COST SAVINGS BY MEASURE}

Prior to the installation of the retrofits, retrofit cost, and energy and cost savings were estimated on a measure-by-measure basis. Financial support for the retrofits was supplied jointly by the utility, an energy service company and the local housing authority. Table 6.3 presents a breakdown of these estimates, as calculated by BECo (1993b), along with corresponding payback periods.

Table 6.3 Costs, and energy and cost savings, by measure

\begin{tabular}{|c|c|c|c|c||}
\hline Retrofit Measure & $\begin{array}{c}\text { Energy } \\
\text { Savings } \\
(\mathrm{MWh})\end{array}$ & $\begin{array}{c}\text { Measure } \\
\text { Cost } \\
(\$)\end{array}$ & $\begin{array}{c}\text { Energy Cost } \\
\text { Savings } \\
(\$)\end{array}$ & $\begin{array}{c}\text { Simple } \\
\text { Payback } \\
(\mathrm{yrs})\end{array}$ \\
\hline Lighting & 29.5 & 23,500 & 2,800 & 8.4 \\
\hline Windows & 68.2 & 192,000 & 6,500 & 29.5 \\
\hline Energy Management & 270 & 156,500 & 25,650 & 6.1 \\
\hline
\end{tabular}

The estimates shown in Table 6.3 can be compared with the results from the simulation model to determine the differences from the feasibility study. When compared with the information from Table 6.1 , it is evident that the window retrofit provided more energy and cost savings than had originally been estimated. Lighting savings were on par with the early predictions so apparently designers did give attention to possible heating system interaction. Finally, the energy management system, as installed, was supposed to save eight times more energy than the simulation model had estimated. However, energy management controls are 
not used as specified, and thus the energy savings designated to the EMS are actually negligible. Additional simulations were performed to try to determine the best operating scheme for the EMS. These runs indicate that although the potential for energy savings exists with nighttime setbacks, the utility rate structure does not encourage this through any kind of financial reward.

\section{CONCLUSIONS}

This report examined the results of the installation of energy saving retrofits in a tall, multifamily residential building. Hourly and monthly whole-building consumption data were available for the Margolis building study. In addition, an hourly DOE-2.1D energy simulation model was developed to gain greater insight into the behavior of the building. The DOE-2.1D model was calibrated through comparison with actual hourly and monthly utility data. Calibrated parameters included lighting capacity, appliance and hot water demand, and infiltration. While the results of the final model were reasonable, a better understanding of building infiltration would be desirable.

Lighting reductions, window replacement and controllable thermostats were the energy conservation measures installed in the Margolis building. The post-retrofit annual energy reduction was calculated to be nearly $325 \mathrm{MWh}$, with a peak demand savings of $100 \mathrm{~kW}$. These savings result in annual utility bill cost savings of approximately $\$ 28,000$. Most of the energy and cost savings occur during winter months, as the demand on the electric resistance heating system is reduced.

The majority of the energy and cost savings was attributed to the installation of insulative windows throughout the building. Leaky double-pane windows and sliding glass doors were replaced with double-pane, argon filled windows and doors. The energy and demand savings, accompanying the window replacement, were calculated to be nearly $290 \mathrm{MWh}$ and $98 \mathrm{~kW}$. Corresponding energy cost savings were over $\$ 25,000$. Weatherization of the building, through 
window replacement, decreased the demand on the electric-resistance heating system, which is the largest energy consumer in the building.

Lighting retrofits produced some savings in energy but little savings in peak demand. The replacement of the original incandescent lighting in the apartments with reduced wattage fluorescent fixtures produced an estimated annual energy savings of $31,000 \mathrm{kWh}$ and demand savings of only $1 \mathrm{~kW}$. The savings were reduced because the space heating supplied by the old lights was reduced in retrofit and had to be supplemented by the electric-resistance heating system. The interaction of lighting retrofits with building heating and/or cooling systems must be considered. In this study, heating energy penalties were significant for the electrically heated building, located in the Boston Climate. Such penalties will be less significant for more efficient heating systems.

The Margolis building rehabilitation also included the installation of an energy management system. The EMS was programmed to implement a nighttime setback of $4^{\circ} \mathrm{F}$, during colder months. The study found that the setbacks were not used and thus anticipated energy savings were not realized. If the setbacks are used, additional annual energy savings will be nearly $32,000 \mathrm{kWh}$. Notably though, peak demand is expected to increase, by nearly $40 \mathrm{~kW}$, due to the increase in space heating demand in the morning hours after set points are returned to their original values. The resulting overall cost savings from this EMS strategy are expected to be negative. BECo has since calibrated the EMS and believes that significant energy savings have occurred as a result. Unfortunately, at the release of this report, detailed data were not available to support this claim.

The mechanical ventilation system for the Margolis building was inoperable for the duration of this study. In November 1994, repairs were to be finished and the system was expected to be back on-line with one additional improvement: gas-heated supply air. Information is presently being gathered on the whole-building energy consumption and airmovement implications of the operating supply system. Follow-up analysis of this system may be published as a supplement to this report. 


\section{REFERENCES}

ACEEE 1986. "Appliances and Equipment," Proceedings from the ACEEE 1986 Summer Study on Energy Efficiency in Buildings, Vol. 1.

BECo 1993a. Margolis building utility records and hourly consumption data, Boston Edison Co., Boston, MA.

BECo 1993b. Cost and conservation estimates from "Boston Edison Company: Public Housing Electric Efficiency Program," Boston Edison Co., Boston, MA.

Citizens 1992. Electric Conservation Improvements at Margolis Apartments, Citizens Conservation Corporation, Boston, MA.

COMIS 1990. COMIS Fundamentals, Lawrence Berkeley Laboratory, Berkeley, CA.

COMIS 1992. COMIS 1.2 User Guide, Lawrence Berkeley Laboratory, Berkeley, CA.

Corson, G. 1992. "Input-Output Sensitivity of Building Energy Simulations," ASHRAE Transactions, 98(1), 618-625.

Crown, S., M. Pate and H. Shapiro 1993. "A Method to Account for Energy Conservation Measure Interactions," ASHRAE Transactions, 99(1), 201 - 206.

EIA 1993. Household Energy Consumption and Expenditures 1990, U.S. Energy Information Administration, DOE/EIA-0321(90).

Higgins, J. and J. Tichy 1992. "Simulated Savings Due to Switching Off Fluorescent Lamps, Including Energy and Replacement Costs," ASHRAE Transactions, 98(1), 251 - 256.

HUD 1973. Housing for the Elderly, Project $16-4$, Chelsea, MA, Department of Housing and Urban Development.

LBL 1981. DOE-2 Reference Manual, Version 2.1 A, Lawrence Berkeley Laboratory, LBL-8706, Rev. 2.

LBL 1982. DOE-2 Engineers Manual, Version 2.1 A, Lawrence Berkeley Laboratory, LBL-11353.

LBL 1989. DOE-2 Supplement, Version 2.1D, Lawrence Berkeley Laboratory, LBL-8706, Rev. 5.

LBL 1992. Chelsea Public Housing Study: Ventilation and Infiltration Survey, Interim Report, Lawrence Berkeley Laboratory, Berkeley, CA. .

Feustel, H. 1993. Partial COMIS results for Margolis building infiltration study, Lawrence Berkeley Laboratory, Berkeley, CA.

NOAA 1993. Weather data, TD-1440 format, 1991-1993, National Oceanic and Atmospheric Administration, Asheville, NC.

PG\&E 1987. Residential Appliance Load Study, 1985 - 1986, Pacific Gas and Electric Company, San Ramon, CA.

Waltz, J. 1992. "Practical Experience in Achieving High Levels of Accuracy in Energy Simulations of Existing Buildings," ASHRAE Transactions, 98(1), 606 - 617. 
A-1

APPENDIX A: DOE-2.1D Pre-Retrofit Input File 
NPUTLOADS

S Pro-Retrofit Models

TITEE LINE-1 "MARGOLIS APARTMENT BURDNG'

LINE-2 'CHELSEA, MASSACHUSETTS"..

DUGNOSTKC=CAUTIONS ..

ABORT=ERRORS ..

LONOS-REPORT S=(LS-C,LS-D,LS-P) .

RUNPERIOD JAN 011991 THRU DEC 311991

BULDING-LOCATKON LATITUDE $=\mathbf{4 2 . 3 7}$ LONGTIUDE $=71.03$

TIME-ZONE $=5 \quad$ ALTIUDE $=15 \quad A Z=315$

\$ SCHEDULES \$

OCI=DSCH $\quad(1,7)(.85)(8,9)(.8)(10,16)(.00)$

$(17,21)(8,8,85,85,85)(22,24)(.85)$

$\infty \mathrm{C}=0 . \mathrm{SCH} \quad(1,8)(.25)(0,10)(.8)(11,18)(.7)(19,24)(\infty 5)$

OC3=D-SCH $\quad(1.7)(.85)(8,10)(.9 .9 ., 8)(11,16)(.7)(17,19)(.8)$ $(20,24)(.95)$

OC4=DSCH $\quad(1,7)(0)(8,12)(.85)(13)(.65)(14,17)(.25)(18,24)(.01)$..

$O C S=D S C H \quad(1,24)(.01)$

$O C B=D S C H \quad(1,7)(.01)(8,20)(1)(21,24)(01)$.

$\propto C 7=\mathrm{DSCH} \quad(17)(01)(8,18)(75)(19,24)(01)$

OCB=D-SCH $\quad(1,7)(0)(8,17)(85)(18,2)(.45)(23,24)(1)$

OCOUP1=SCH THRU DEC 31 WD) OC1 (SATOC2 (SUN,HOL) OC3

OOCUP2=SCH THRU DEC 31 (WD) OCA (SAT) OCS (SUN,HOL) OCS

OCCUP3 $=S C H \quad$ THRU DEC 31 (WD) OC6 (SAT) OCS (SUN,HOL) OC6.

OCOUP4=SCH THRUDEC 31 (WD) OC7 (SAT) $O C 7$ (SUN,HOL) $O C 7$.

OCOUPS=SCH THRU OEC 31 (WD) OC7 (SAT) OC7 (SUN,HOL) OC7

OCCUPQ=SCH TMRU DEC 31 (WD) OCS (SAT) OCB (SUN,HOL) OC8 ..

LG1S=DSCH (1,5)(13) (8.11)(15,2,25,3,25.20

$(12,14)(.21)(15,21)(.22,25,28,28,25,2,2)$

$(20,24)(15,13,13)$

LGIW $=$ DSCH

$(1,5)(.13)(8,11)(15,22,26,32,27,24)$

$(12,14)(.23)(15,21)(24,27,3,3,27,22,22)$

$(22.24)(17,15,15)$

$\mathrm{LG}=\mathrm{DSCH}$

$(1.6)(05)(7.8)(.15,25.25)(10.17)(35)(18.22)(.8)$

$(23,24)(5,25)$

LG $=0-S C H$

$L G A=D-S C H$

LGS $=\mathrm{D}-\mathrm{SCH}$

LGe $=\mathrm{DSCH}$

LG7 $=$ D S SCH

LGHTSI $=$ SCH

$(1,7)(1,0)(8,17)$

$(1,24)(1.0)$

$(1.7)(1.0)(8,17)(0)(16,24)(1.0)$

THRU MAR 31 (ALL) LGIW THRU SEP 30 (ALL) LGIS THRU DEC 31 (ALL) LGIW

UGHTSZ=SCH THRU DEC 31 (WD) LG3 (SAT) LGA (SUN,HOL) LGA ..

UGHTS3=SCH THRU DEC 31 MDD) LGS (SAT) LGS (SUN,HOL) LGS ..

LGHTSA=SCH THRU DEC 31 (WD) LGS (SAD) LGO (SUN,HOL) LG6 ..

UGHTSS=SCH THRU DEC 31 (WD) LGO (SAT) LGO (SUN,HOL) LGO ..

UGHTSO=SCH THRU DEC 31 (WO) LG3 (SAT) LG3 (SUN,HOL) LG3..

UGHTS $=5 \mathrm{CH}$

THRU DEC 31 (WD) LG7 (SAT) LG7 (SUN,HOL) LG7 ..

$A P 1=0-5 C H$

AP2 $=\mathrm{DSCH}$

$(1,7)(.1)(8.18)(.25)(19,24)(.1)$

$(1,7)(39)(8,9)(55,55)(10,16)(51)$

$(17,18)(62,59)(18,24)(51,51, .51, .47,45,4)$

$A P 3=0-S C H \quad(1,7)(0)(8,12)(.85)(13)(65)(14,17)(85)(18,24)(.01)$

$\triangle P 4=0-5 C H \quad(1,20)(01)$

APS $=$ DSCH $\quad(1.7)(.01)(8.18)(.4)(19.24)(02)$

$A P O=D S C H \quad(1,8)(01)(9.17)(.75)(18,24)(.02)$.

AOT=DSCH $\quad(1,7)(.2)(8,20)(.5)(21,24)(.2) \ldots$

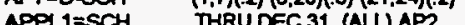

APPL $2=S C H$ THRU DEC 31 WD) AP3 (SAD AP4 (SUN,HOL) AP4 ..

APPLS $=S C H$ THRU DEC 31 (WD) APS (SAT) APO (SUN,HOL) APO ..

APPL $6=S C H$ THRU DEC 31 (ALL) AP7

$D H 1=D S C H \quad(1,24)(00,05,02,02,09,28,38,47, .47, .52,52,47, .45$

DH-2=0.SCH $\quad(1,24)(14,07,03,03,14,42,58,70,70,7 \pi, 77,70$

$\quad .67, .58, .56, .56,62,70,70,70, .56, .42,14, .14) \ldots$

THRU MAR 31 (ALL) DHR

THRU OCT 31 (ALL) DHT

THRU DEC 31 (ALI) DHR

EII $=\mathrm{DSCH}$

$(1,0)(\cos )(7,24)(2,2,4,5,35,4,35,35,3,3,3,4$ $.45,5,4,35,25,1.007$

E.2=0.SCH $\quad(1,6)(05)(7,24)(1,25,45,55,5,4,45,45,4,4$

$.5, .45,5, .45,3,3,25.15$

$\mathrm{EL}=\mathrm{O}=\mathrm{SCH} \quad(1,6)(.05)(7,24)(1,1,2,3,4, .5,4,45,4,4,4,5$,

EEV $=S C H \quad T H R U$ DEC 31 (WD) Eli (SAT) Ë2 (SUN,HOL) EL3 ..

SHAESCH $=S C H$ THRU DEC 31 (ALL) $(1,8)(1.0)(9.18)(.25)$

$(18.24)(1.0)$

S MATERIALS NOT IN DOE-2 LIBRARY S

EARTH=MAT

$\pi H=2.50$ COND $=0.50$ DENS $=120 \mathrm{~S}-H=0.20 \ldots$ 


\section{S CONSTRUCTION S}

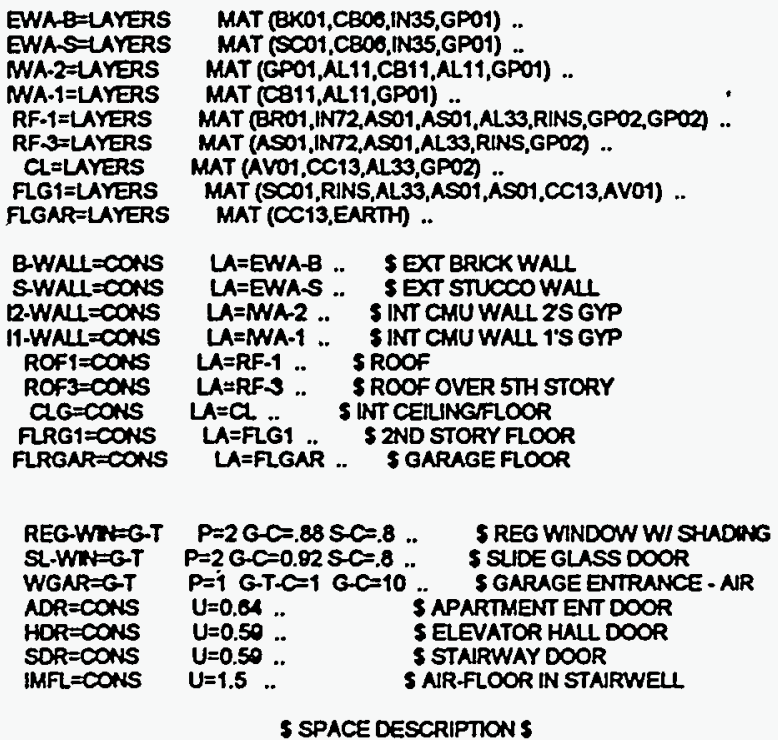

APTMT $=S P A C E-C O N D T R O N S$

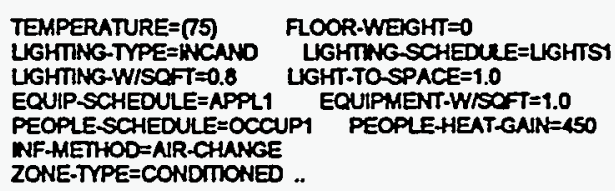

OFFICE $=S P A C E-C O N D T I O N S$

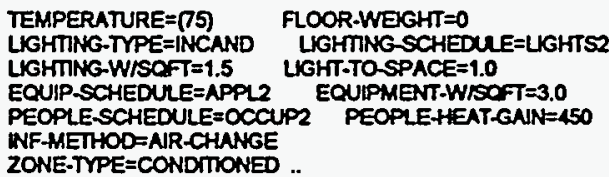

STAR=SPACE-CONDITONS

TEMPERATURE=(72) FLOOR-WEGHT $=0$

LGHTING-TYPE=SUS-FLUOR LIGHNG-SCHEDULE=LUGHTS LIGHING-WISOFT $=0.3$ LIGHT-TOSPACE $=10$ PEOPLE-SCHEDULE=0CCUP3 PEOPLE+HEAT.GAIN=450 WNF-METHOD $=$ NR-CHANGE ZONE-TYPE=CONDTIONED

EHAL1=SPACE-CONOTIONS

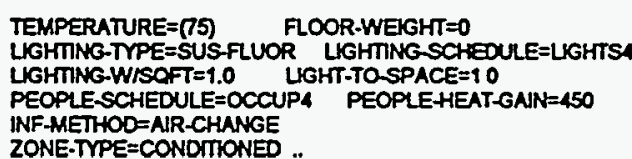

EHAL2=SPACE-CONOMONS

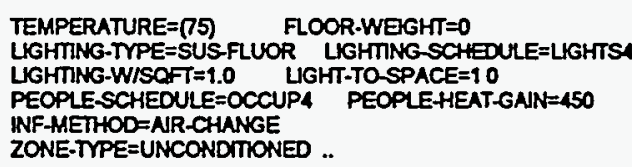

LAUNDESPACE-CONDTIONS

TEMPERATURE $=(75)$ FLOOR-WEGHT $=0$ LGHTNG.TYPE=SUS-FLUOR LIGHTINGSCAEOULE=LIGHTSS LUGHTING-WISOFT=1.0 LUGHT-TOSPACE $=1.0$

EOUIP.SCHEDULE=APPLS EQUIPMENT-W/SOFT $=150$ PEOPLESCHEDULE=OCCUPS PEOPLEHEAT-GAN=450 WFHETHOD=AR-CHANGE ZONE-TYPE=CONDTIONED . 
ACTIVITY=SPACE-CONDITONS

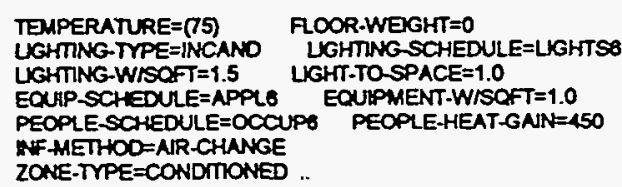

GARAGE=SPACE-CONOTONS

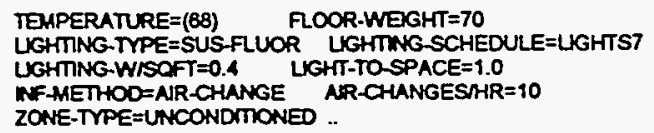

BUILDING-RESOURCE VERT-TRANS-KW=30 VERT-TRANSSCHEEEV HOT-WATER $=184000$ HW SCAEDULE=DHW $E-W W=3.9 \quad$ ESCH=LIGHTS7 ..

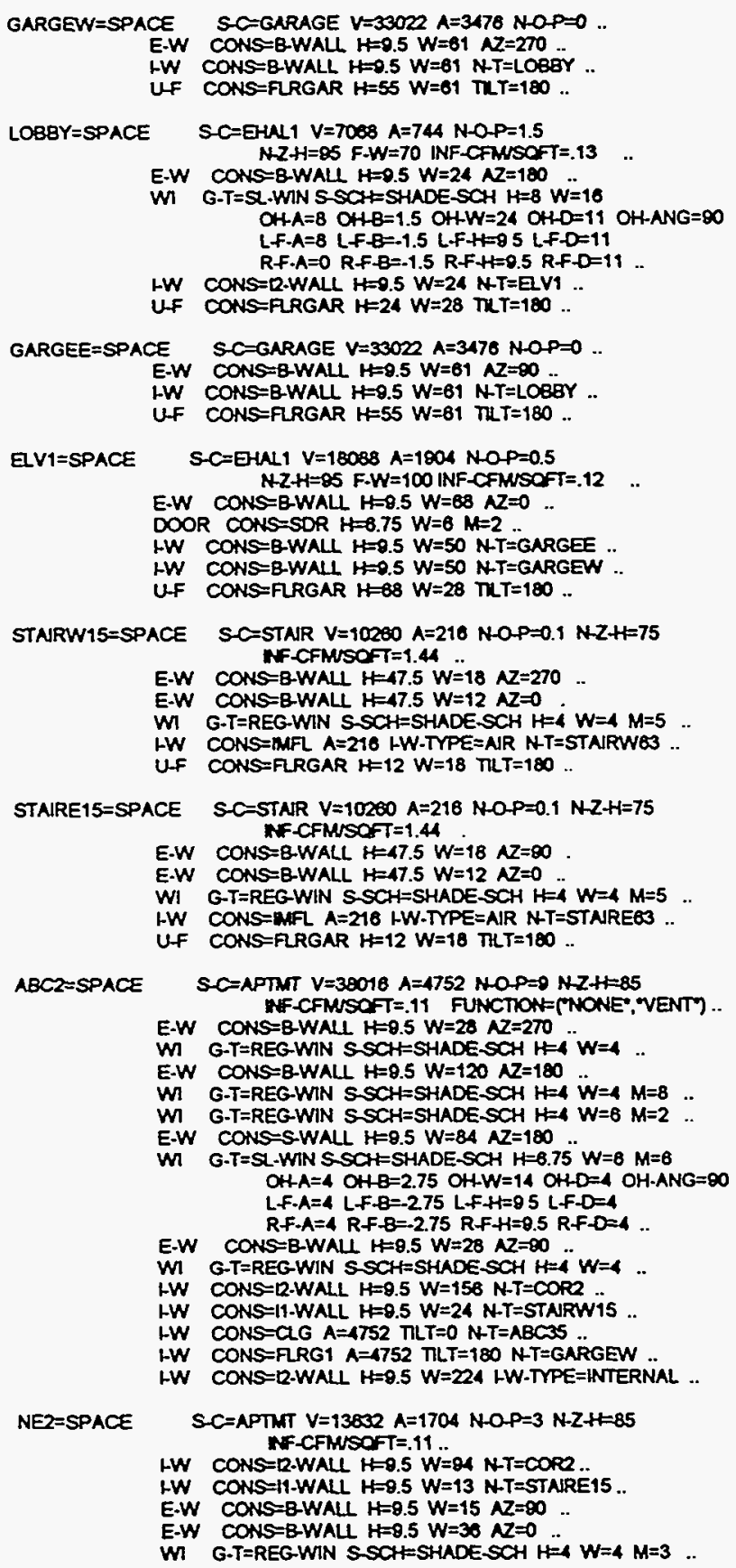


E.W CONS=S.WALL $H=0.5 \quad W=42 \quad N Z=0.77 \quad W=6 \quad M=3$

$O H-A=4$ OH $B=2.75$ OH-W $=14$ OH-D=4 OH-ANG $=00$

L.F-A=A L.F- $B=-2.75$ LF-H=0.5 LF-D $=4$

HW CONS=CLG $A=1704$ TLT=0 N-T=NE35

LW CONS=FLRG1 $A=1704 \mathrm{TLT}=180 \mathrm{~N}-\mathrm{T}=$ GARGEE

HW CONS=12-WALL $H=9.5 \mathrm{~W}=56 \mathrm{HW}$-TMPE=INTERNAL.

NWZ=SPACE

$S-C=A$ PIMT $V=13032$ A=170 $N \cdot O-P=3 \quad N-Z-H=65$ DNF-CFMUSOFT $=.11$.

E.W CONS=B-WALL $H=9.5 \quad W=15 \quad A Z=270$

IW CONS=11.WALL $H=0.5 W=13$ NT T=STAIRW 15 .

HW CONS $=12$-WALL $H=0.5 W=66 \quad N \cdot T=C O P 2$.

IW CONS=12.WALL $H=0.5 W=28 \mathrm{~N}-\mathrm{T}=E \mathrm{WV} 2$..

$E \cdot W$ CONS=B-WALL $H=9.5 W=36 \quad N Z=0$

WI G.T=REG.WIN SSCH=SHADESCH H=4 $W=4 M=3$..

$E \cdot W$ CONS=S-WALL $H=0.5 W=12 \quad A Z=0$.

WI G-T=SL-WIN SSCH=SHADESCH $H=8.75 W=6 \quad M=3$ $O H-A=4$ OHE $=2.75$ OHWW=14 OHHO=4 OH+ANG=90 $L-F \cdot A=4$ LF- $B=-2.75$ LF $H=0.5$ LF-D=4 R.F.A $A=4$ R-F-B $=2.75$ RFH=0.5 R-F-D $=4$..

HW CONS=CLG $A=1704$ TILT=0 N-T=NW35

HW CONS=FLRGI $A=1704$ TLT=180 NTT=GARGEW

HW CONS $=12-W A L L ~ H=9.5 W=50$ H.W.TYPE=INTERNAL .

EV2=SPACE

$S-C=E$ HL2 $V=6384 \quad A=672$ NOP $=0.5$

$F \cdot W=100 \quad N-Z$ H= $=85$ INF-CFWSOFT $=.29$..

IW CONS=12.WALL $H=0.5 W=24 N-T=C O R 2$.

E.W CONS $=$ B-WALL $H=9.5 W=24 \quad A Z=0$

HW CONS=CLG $A=512$ TLT=0 N-T=ELV35

IW CONIS=FLRG1 $A=512$ TILT=180 N-T=ELV1 ..

COR2 $=S P A C E S C$ SEEHAL1 $V=0240 A=780 N-0 P=0.5$

MF.CFMSOFT $=020$

IW CONS=11-WALL $H=9.5 W=5$ N-T=STARW15..

IW CONS-11-WALL $H=0.5 W=5 N-T=S T A R E 15$.

IW CONSS=CLG $A=780$ TLT $=0$ N-T=COR35

IW CONS=FLRG1 $A=780$ TLT=180 NTT=GARGEE.

$A B C 35=S P A C E$

$S-C=A P T M T V=38016 \quad A=4752 \quad \mathrm{NOP}=9 \mathrm{NZZH}=25$

$F+H=3$ INF-CFMSOFT $=.11$ FUACTION=MNONE", VENTM ..

$E-W$ CONS=B-WALI $H=9.5 W=28 \quad A Z=270$

$W$ GT=REG-WIN S-SCH=SHADE-SCH $H=4 " W=4$.

E.W CONS=B.WALL $H=9.5 W=120 \quad A Z=180$

WI G-T=REG.WIN S-SCH=SHADESCH H=4 $W=4 M=8$.

WI G-T=REG.WIN S-SCH=SHADESCH H=4 $W=6 \quad M=2$.

E.W CONS=S-WALL $H=9.5 W=84 \quad A Z=180$

W G-T=SL-WIN SSCH $=$ SHADESCH $H=0.75 \mathrm{~W}=0 \quad \mathrm{H}=0$ $O H-A=4$ OH-B $=2.75$ OHW $=14$ OH-D $=4$ OH-ANG $=\infty$ $L F \cdot A=4$ L $F-B=-2.75$ LF $H=0.5$ L-F-D $=4$ RF-A $=4$ RF-B $=275$ RFH $=0.5$ RF-D $=4$

E.W CONS=BWAU $H=9.5 W=28 \quad N Z=\infty$

WI G.T=REG-WIN SSCH=SHADESCH H=4 W=4..

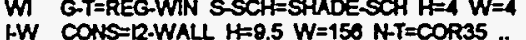

IW CONS=11.WALL $H=9.5 W=24$ NTT=STAIRW15

HW CONS=CLG A=4752 TLTT=0 HW-TYPE $=A D I A B A T C$

IW CONS=12-WALL $H=0.5 W=224$ HW-TMPE=INTERNAL ..

NE35=SPACE $\quad S-C=A P T M T V=13632 \quad A=1704 \mathrm{~N}-\mathrm{P}=3 \mathrm{~N}-\mathrm{Z} \cdot \mathrm{H}=65$ $F-M=3$ INF-CFMSOFT $=11$.

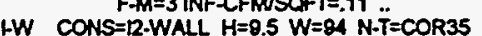

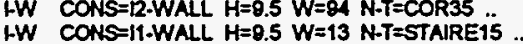

E.W CONS $=8$ WALL $H=0.5 W=15 \quad N Z=\infty$..

$E \cdot W$ CONS $=B$ WALL $H=0.5 W=36 \quad A Z=0$..

$W$ G-T=REG-WIN S-SCH=SHADE-SCH $H=4 W=4 M=3$..

$E \cdot W$ CONS=S-WALL $H=9.5 W=42 \quad A Z=0$

W G.T=SL-WIN SSCHFSHADESCH $\quad H=0.75 \mathrm{~W}=6 \mathrm{~m}=3$ $O H-A=4$ OH $B=2.75$ OHW $W=14$ OHD $=4$ OHANG $=90$ LF.A=4 LF.B $=275$ LFH=9.5 LF.D $=4$ RF-A=A R-F-B=-2.75 RF+t=9.5 R-F-D=4

HW CONS=CLG $A=1704$ TLTT=0 HW-TMPE=ADIABATIC ..

HW CONS=12.WALL $H=9.5 W=56$ HW-TMPE=INTERNAL."

AW35=SPACE SC=APTMT $V=13832 \mathrm{~A}=1704 \mathrm{NOP=3} \mathrm{N}-\mathrm{Z} \cdot \mathrm{H}=05$ F.H $=3$ INF-CFMISOFT $=11$

E.W CONS=BWAL $H=9.5 W=15$ A $=270$

LW CONS=11-WALI $H=0.5 W=13$ NTT=STARTW15

HW CONS=12.WALL $H=0.5 W=24 N T=C O R 35$...

LW CONS=12.WALL $H=0.5 \quad W=24$ NT=COR35 ..

E.W CONS=B-WALL $H=9.5 \quad W=30 \quad A Z=0$

WI G-T=REG.WIN S-SCH=SHADESCH $H=4 \mathrm{~W}=4 \mathrm{m=3}$..

E.W CONS=S-WALL $H=0.5 \quad W=42 \quad N Z=0$

WI G-T=SL.WIN S.SCH=SHADESCH $H=6.75 W=6 \quad M=3$ $O H-A=4$ OH-B $=2.75$ OH-W $=14$ OH-D $=4$ OH-ANG $=90$ L.F.A=4 L.F.B $=-275$ L.F.H=0.5 L.F.D $=4$ R-F.A $=4$ R-F-B=.275 R-F.tE.5 R-F-D =4

HW CONSECY A=1704 THT=0 LW-TYPE=AOUABATC

HW CONS=12-WAL H=9.5 W=50 HW.TYPE=INTERNAL"

ELV35=SPACE

S-C=EHAL2 $V=6384 A=672$ N-O.P=0.5 F-W $=100$

$N-Z H=65$ F $M=3$ INF.CFMSOFT $=.27$

IW CONS=L-WALL $H=0.5 W=24 \quad N-T=C O R 35$

$E \cdot W$ COASE=E-WALL $H=9.5 W=24 \quad N Z=0$. 
IW CONS=CLG A=512 THTT=O H-W-TYPE=ADABATC ..

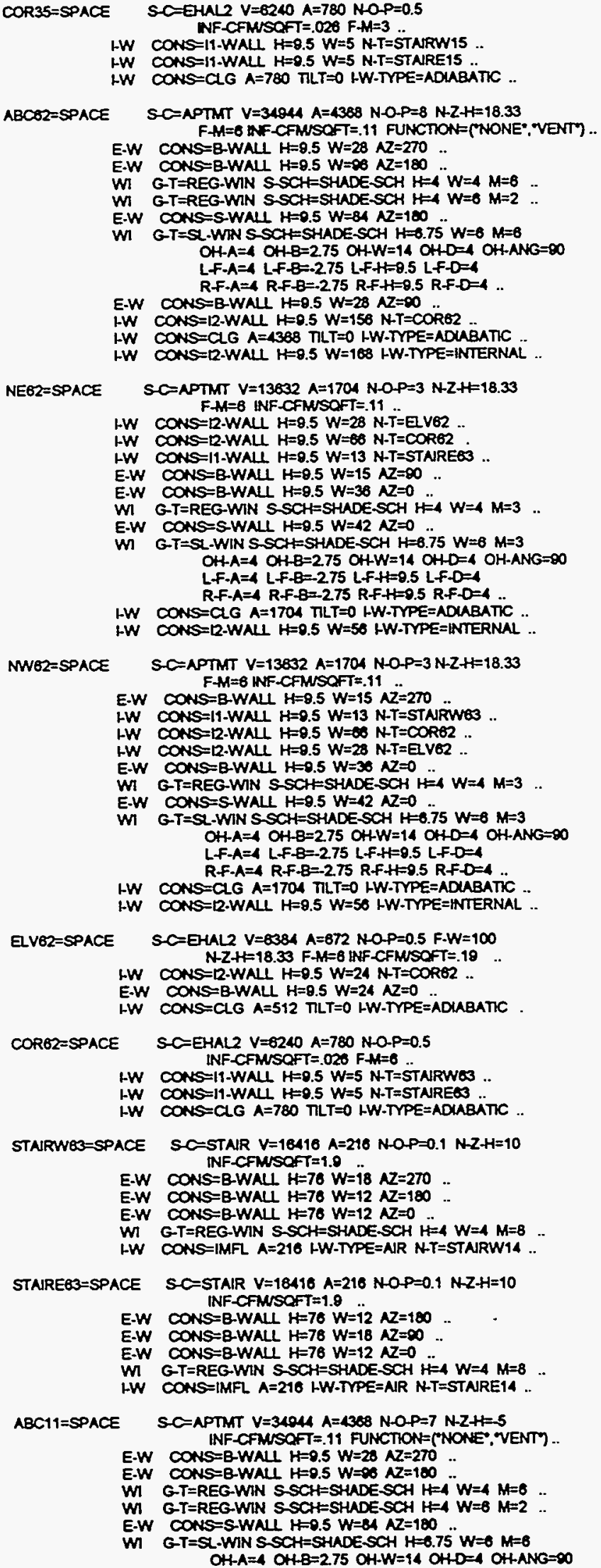




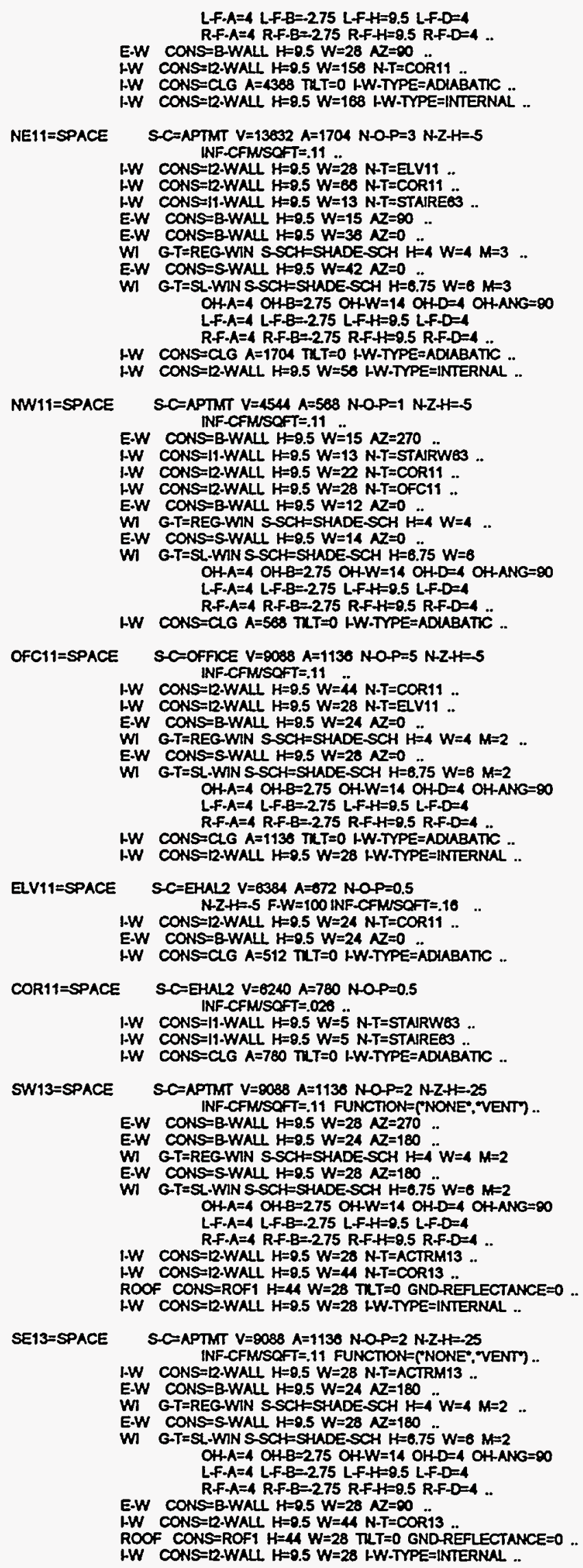




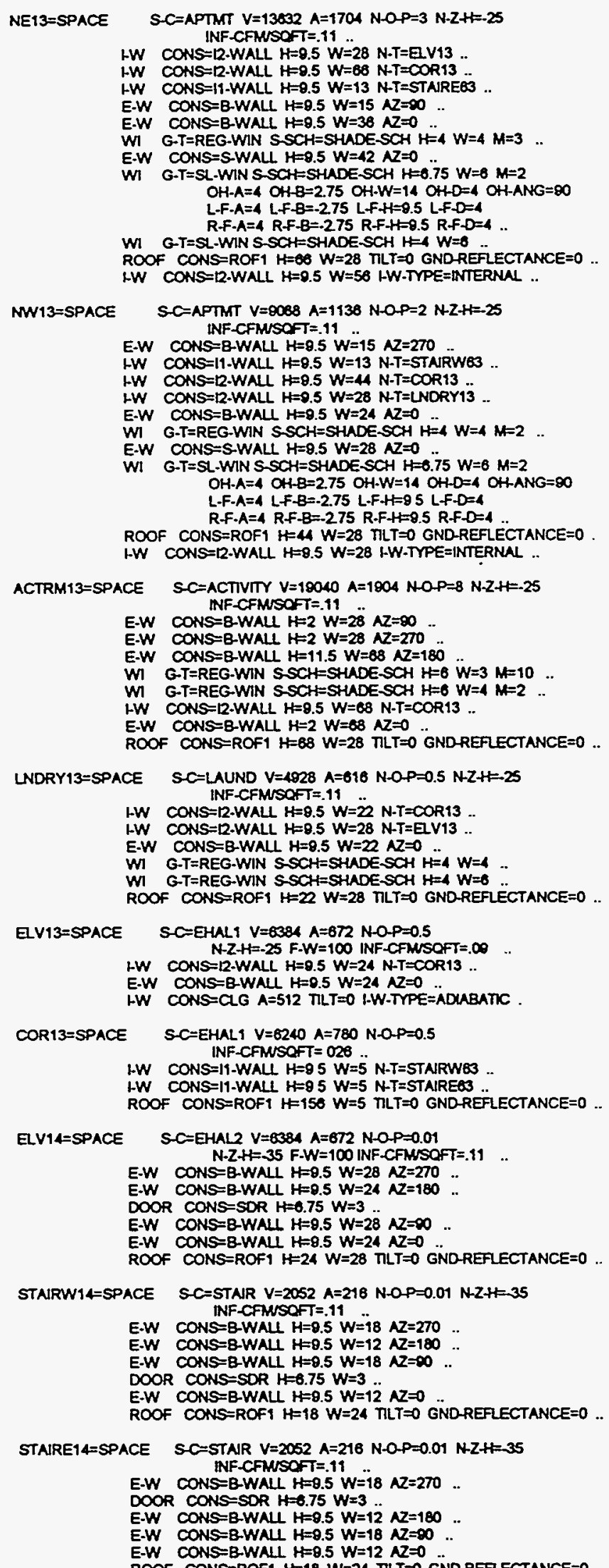

END .. 
FUNCTION MAME=VENT .

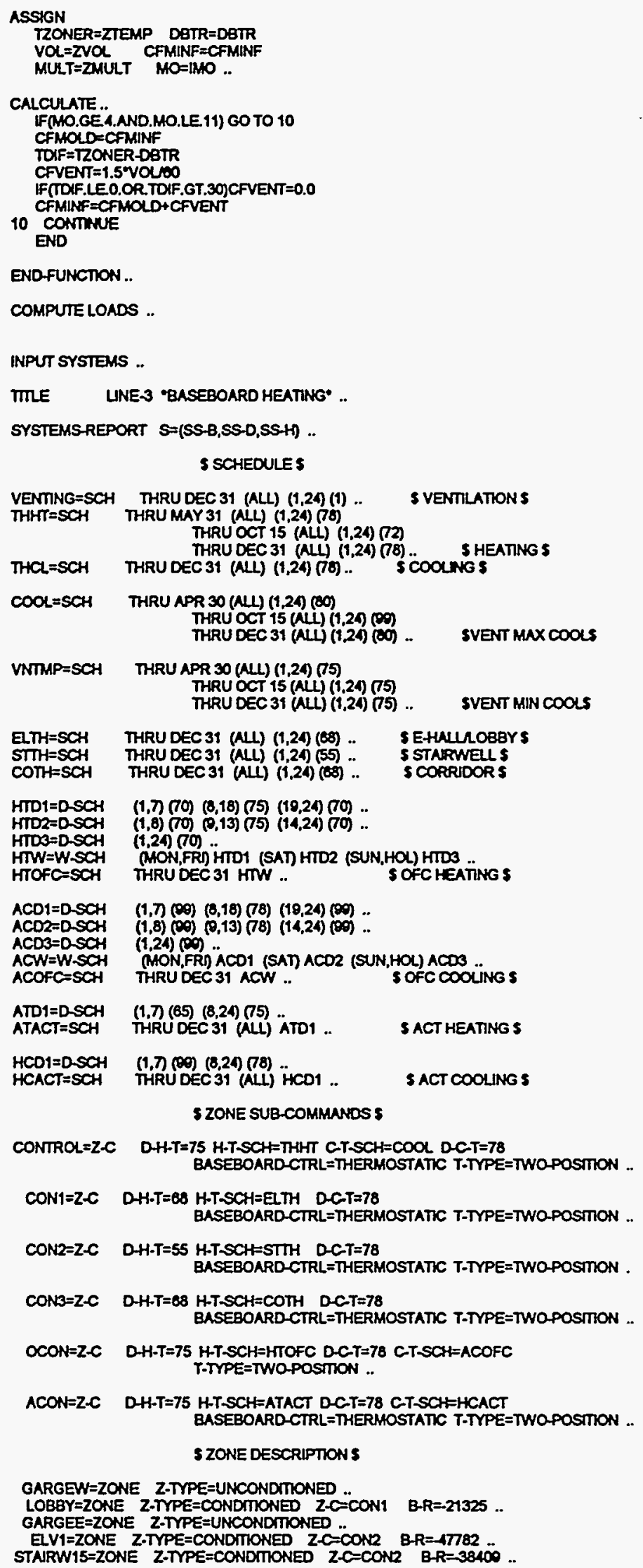




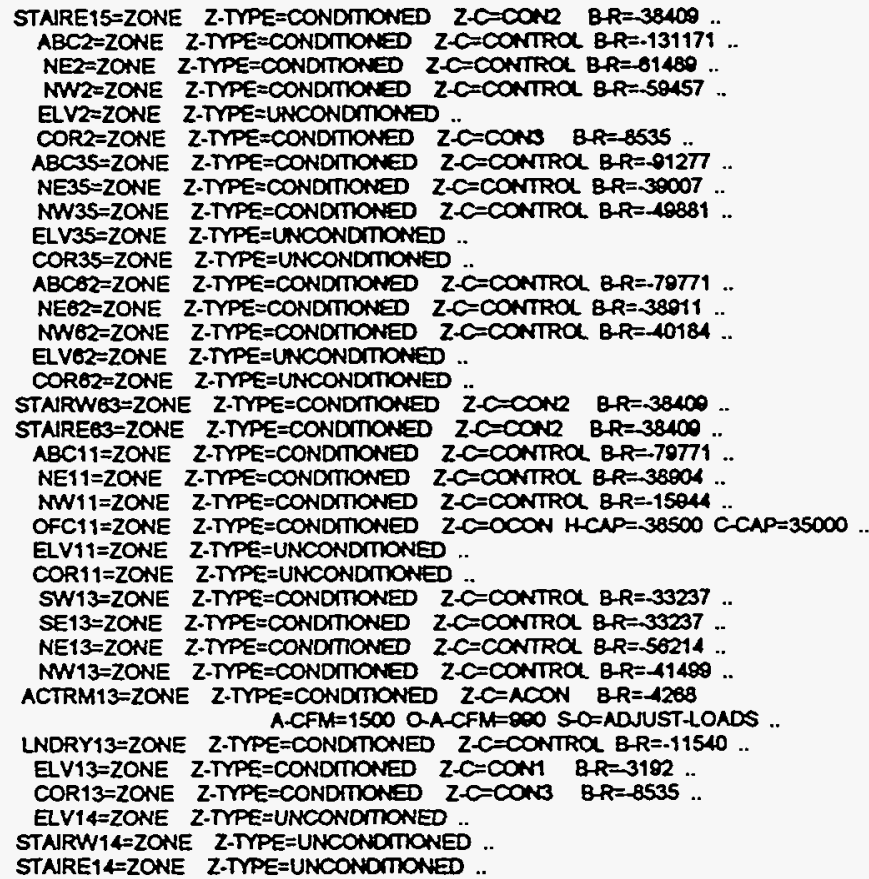

S SYSTEM SUB-COMMUNOS S

S-CTRL=S-C MNXS-T=100 MIN-S-T=55 ..

S-NR=S-A VENTHETHOD=AIR-CHUNGE VENT-TEMP-SCH=VNTMP NATURAL-VENT-AC=A MATURAL-VENT-SCH=VENTING ..

S-FN=S-FANS SUP-DTT=0.0 S-KW $=0.0$..

SEQPT $=S-E Q \quad C-C A P=0.0$ COOLSHCAP $=0.0$ HCAP $=0.0 \mathrm{CH}=00 \mathrm{~F} \cdot A=00$..

S SYSTEMS DESCRIPTION S

SYS-LBY=SYSTEM S-TYPE=RESYS S-C-S-CTRL S-A=SAR S-FANS=SPN S-EQ=S-EOPT HEATS=EECTRIC BASEBS=EECTRIC ZONE-NAMES=ROBBY,GNRGEW.GARGEE .

SYS-SWI=SYSTEM S-TYPE=RESYS S-C=S-CTRL S-A=S-AR S-FANS=S-FN S-EQ=S-EQPT HEATS=ELCTRIC BASEBSS=EECTRIC ZONE-NAMES=(STAIRW15) ..

SYS-SE1=SYSTEM S-TYPE=RESYS S-C=S-CTRL S-A=S-AR S-FANS=SFN S-EQ=S-EOPT HEATS=EECTRIC BASEBS=ELCTRIC ZONE-NAMES=(STAIRE15)

SYS-AC2=SYSTEM S-TYPEE=RESYS S-C=S-CTRL S-A=S-NR S-FANS=S-FN S-EQ=S-EQPT HEATS=EECTRIC BASEBS=EECTRIC ZONENAMES=(ABC2)

SYS-NE2=SYSTEM S-TYPE=RESYS S-C=S-CTRL S-A=SNR S-FANS=SFN S-EQ=S-ECPT HEATS=EECTRIC BASEB-S=EECTRIC ZONE-NAMES=(NE2)..

SYS-E01=SYSTEM S-TYPE=RESYS S-CES-CTRL S-A=S-AR S-FANS=S-FN S-EC=S-EQPT HEAT-S=EECTRIC BASEB-S=EECTRIC ZONE-NAMES=(EIV1,ELVZ) .

SYS-CO2=SYSTEM S-TYPE=RESYS S-C=S-CTRL S-A=S-AR S-FANS=SFN S-EQ=S-EOPT HEATS=EECTRIC BASEBS=EECTRIC ZOWE-NAMES=(COR2).

SYS-NW2=SYSTEM S-TYPE=RESYS S-C=S-CTRL S-A=S-NR S-FANS=SFN S-EQ=S-EOPT HEAT-S=ELECTRIC BASEB-S=ELCTRIC ZONE-NAMES=(NWZ) ..

SYS-ACZS=SYSTEM S-TYPE=RESYS S-C=S-CTRL S-A=S-AR S-FANS=S-FN S-EQ=S-EOPT HEAT-S=ELECTRIC BASEB-S=EECTRLC ZONE-NAMES $=$ (ABC35,EY35,COR35) .

SYS-NE35=SYSTEM S-TYPE=RESYS S-C=S-CTRL S-A=S-NR S-FANS=S-FN S-EQ=S-EQPT HEAT-S=ELECTRIC BASEBS=EECTRIC ZONE-NAMES=(NE35)

SYS-NW3S=SYSTEM S-TYPE=RESYS S-C=S-CTRL S-A=S-AR SFANS=S-FN S-EQ=S-EQPT HEATS=ELCTRIC BASEBS=EECTRIC ZONE-NAMES=(NW35) ..

SYS-ACE2=SYSTEM S-TYPE=RESYS S-C=S-CTRL S-A=S-NR S-FANS=S-FN S-EQ=S-EOPT HEAT-S=ELECTRK BASEBS=EECTRKC ZONE-NAMES $=(A B C O 2$, EQV 62 OOR62) ..

SYS-SW63=SYSTEM S-TYPE=RESYS S-C=S-CTRL S-A=S-NR S-FANS=SFN S-EO=S-EOPT HEAT SIEECTRIC BASEB $=$ EECTRIC ZONE-NAMES=(STARWE3).. 
SYS-SEE3=SYSTEM S-TYPE=RESYS S-C=S-CTRL S-A=S-AR S-FANS=SFN S-EQ=S.EOPT HEAT-S=ELECTRIC BASEB-S=ELCTRIC ZONE-NUMES=(STAREQ3) .

SYS-NEB2=SYSTEM S-TYPE=RESYS S-C=S-CTRL S-A=S-AR S-FANS=SFN S-EQ=S-EQPT HEATS=ELECTRKC BASEB-S=EECTRIC ZONE-NAMES=(NEO2) ..

SYS-NWO2=SYSTEM S-TYPE=RESYS S-C=S-CTRL S-A=S-AR S-FANS=SFN S-EO=S-EQPT HEATS=ELECTRIC BASEB-S=ELCTRKC ZONENAMES=(NWOZ) ..

SYS-AC11=SYSTEM S-TYPE=RESYS S-COS-CTRL S-A=S-AR S-FANS=S-FN S-EQ=S-EQPT HEAT-S=ELECTRIC BUSEB-S=EECTRIC ZONE-NAMES=(ABC11,EVV11,COR11) ..

SYS-NE11=SYSTEM S-TYPE=RESYS S-C=S-CTRL S-A=S-AR S-FANS=S-FN SEEO=S-EOPT HEAT-S=ELECTRIC BASEBSS=ELCTRIC ZONE-MUMES=(NE11) ..

SYS-MW11=SYSTEM S-TYPE=RESYS S-C=S-CTRL S-A=S-AR S-FMNS=SFN S-EO=S-EOPT HEAT S=ELECTRIC BASEB-S=EECTRK ZONE-NAMES=(NW11) ..

SYS-OF11=SYSTEM S-TYPE=PTAC MAX-S.T=100 MIN-S.T=55 HSCTHTHOFC C SCH =ACOFC HEAT-SOURCE=ELECTRIC BASEBS-ELECTRIC ZONE-NAMES $=($ OFC11) ..

SYS-SW13=SYSTEM S-TYPE=RESYS S-C=S-CTRL S-A=S-AR S-FANS=S-FN S-EQ=S-EQPT HEATS=ELECTRIC BASEB-S=ELECTRIC ZONENAMES=(SW13) .

SYS-E13=SYSTEM S-TYPE=RESYS S-C=S-CTRL S-A=S-NR SFANS=S-FN S-EQ=S-EOPT BASEBS=ELECTRIC HEAT SOURCE=ELECTRIC ZONE-NAMES=(ELV13) ..

SYS-C13=SYSTEM S-TYPE=RESYS SCC=SCTRL S-A=S-AR S-FANS=S-FN S-EO=S-EOPT HEATS=ELECTRIC BASEB-S=ELECTRLC ZONE-NAMES=(COR13).

SYS-SE13=SYSTEM S-TYPE=RESYS S-C=S-CTRL S-A=S.AIR S-FANS=S-PN S-EQ=S-EQPT HEAT-S=ELECTRIC BASEB-S=ELECTRIC ZONE-NAMES=(SE13,ELV14,STNRW14,STARE14) .

SYS-NE13=SYSTEM S-TYPE=RESYS S-C=S-CTRL S-A=S-AR S-FNAS-SFN S-EQ=S-EOPT HEAT-S=ELECTRIC BASEB-S=ELECTRKC ZONE-NUMES=(NE13) .

SYS-NW13=SYSTEM S-TYPE=RESYS S-C=S-CTRL S-A=S-ARR S-FANS=SFN SEEO=S-EOPT HEATS=ELECTRIC BASEBS=ELECTRIC ZONE-NAMES=(NW13) ..

SYS-AT13=SYSTEM S-TYPE=PTAC MAX-S.T=100 MIN-S-T=55 HSCHFATACT CSCH=HCACT HEAT-SOURCE=ELECTRKC BASEBSSELLECTRIC ZONE-NAMES=(ACTRM13) ..

SYSLL13=SYSTEM S-TYPE=RESYS S-C=S-CTRL S-A=S-AR SFANS=SFN SEO=S-EQPT HEATS=ELECTRIC BASEBSSELECTRIC ZONE-NAMES=(LNDRY13) ..

END

COMPUTE SYSTEMS ..

INPUT PLANT .

PLANT-REPORT $S=(P S-A, P S-B)$..

WHR=P.E TYPE $=E L E C D H W-H E A T E R$ SZEE $=.368$..

SRPTSCH=SCH THRU DEC 31 (ALL) $(1,24)$ (1) ..

SOUT-I=R-B V-T=PLANT Y.L=(10)

SHR.RPT $=H \cdot R$ R-SCH $=$ RPTSCH R-B $=(O U T-1)$

END .

COMPÜTE PLANT .

STOP.. 

APPENDIX B: DOE-2.1D Post-Retrofit Input File 
NPUT LOADS ..

S Post-Retrofie Modd $\$$

TILE

UNE-1 MARGOLIS APARTMENT BLDGPOST

UNE-2 'CHELSEA, MASSACHUSETI' ..

DAMNOSTIC=CAUTIONS ..

ABORT=ERRORS .

LOADS-REPORT S=(LS-C,LS-D,LSF) ..

RUNPERIOD JAN 011803 THRU DEC 311903

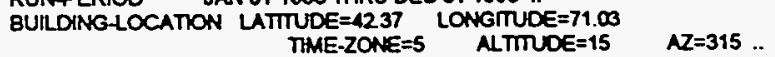

$\$$ SCHEDURES \$

$O C 1=0-S C H$

OC2=D-SCH

$\alpha C 3=D-S C H$

OCA=D-SCH

OC5=DSCH

$O C O=D S C H$

$O C 7=D S C H$

CC8 $=$ DSCH

OCCUP1=SCH

OCCUP2=SCH

OCCUP $3=S C H$

OCCUP $=S C H$

OCCUPS=SCH

LG1S=0-SCH

LGIW=DSCH

LG2=DSCH

LG3 $=0-5 C H$

LGA $=0 . S C H$

LGS=D-SCH

LGO=DSCH

LG7=D-SCH

LGHTS1 $=$ SCH

LIGHTS2=SCH

UGHTS3=SCH

UGHTS4=SCH

UGHTS5= $5 \mathrm{CH}$

LVGHTSS=SCH

LIGHTS7 $=S C H$

AP1 $=0-5 C H$

$A P 2=D S C H$

$A P 3=D-S C H$

AP4 $=D-S C H$

APS $=D S C H$

$A P Q=D S C H$

AP7 $=0 \mathrm{SCH}$

APPL $1=S C H$

APPL $2=S C H$

APPL5=SCH

APPL $6=S C H$

$\mathrm{DH} 1=\mathrm{DSCH}$

$\mathrm{OH} 2=\mathrm{O}-\mathrm{SCH}$

$\mathrm{DHW}=\mathrm{SCH}$

$E L 1=\mathrm{D}-\mathrm{SCH}$

EL2 $=D-S C H$

$\mathrm{EL3}=\mathrm{OSCH}$

ELEV $=S C H$

$(1.7)(.85)(8.8)(.8)(10,16)(.65)(17.21)(.8 .8 .26$, $85.85)(22,24)(85)$

$(1,8)(.85)(8,10)(.8)(11,18)(.7)(19,24)(89)$

$(1,7)(.85)(8,10)(.9,0.0)(11,16)(.7)(17.19)(8)$ $(20,24)(\$)$

$(1,7)(0)(8,12)(.05)(43)(.05)(14,17)(.85)(18.24)(.01)$..

(1.24)(.01)

$(1,7)(.01)(8,20)(.1)(21,24)(.01)$

$(1,7)(.01)(8,18)(.79)(19,24)(.01)$

$(1,7)(0)(8,17)(85)(18,22)(.45)(33,29)(1)$

THRU DEC 31 MD) OC1 (SAT) OC2 (SUN,HOL) OC3

THRU DEC 31 MD) OCA (SAT OCS (SUN,HOL) OCS

THRU DEC 31 MD) OCS (SAT) OCS (SUN,HOL) OCB

THRU DEC 31 (WO) OC6 (SAT) OC6 (SUN,HOL) OC8 ..

THRU DEC 31 WO) OC7 (SAT) OC7 (SUN,HOL) OC7 ..

THRU DEC 31 (WD) OCS (SAT) OCS (SUN,HOL) OCB .

(1.5)(.13) $(6,11)(.15,2,25,3,25, .24$

$(12,14)(.21)(15,21)(.22,25,28,20,25,2,2)$

$(22,24)(15,13,13)$

$(1,5)(.13)(6,91)(15,22,28,32,27,24)$

$(12,14)(.23)(15,21)(.24, .27,3,3,27,22, .22)$ $(22,24)(.17, .15, .15)$

$(1.6)(.05)(7.9)(.15, .25, .25)(10,17)(.35)(18.22)(.6)$

$(23,24)(.5,25)$

$(1,7)(.01)(8,17)(.85)(18,21)(.25)(22,24)(.01)$..

$(1,24)(.01)$

$(1.7)(1.0)(8,1)(0)(18,20)(1.0)$.

$(1,24)(1.0)$

$(1,7)(1.0)(8.17)(0)(18,24)(1.0)$

THRU MAR 31 (NLI) LGIW THRU SEP 30 (ALL) LG1S THRU DEC 31 (AL) LGIW

THRU DEC 31 MO) LG3 (SAT LGÄ (STN,HOL) LGA ..

THRU DEC 31 MO) LGS (SAT) LGS (SLN,HOL) LGS ..

THRU DEC 31 MD) LGO (SAT) LGO (SUN,HOL) LGO .

THRU DEC 31 MD) LG6 (SAT) LG6 (SUN,HOL) LG8

THRU DEC 31 MDO LG3 (SATT LG3 (SNHOL)LG3.

THRU DEC 31 MD) LG7 (SAT) LG7 (SUN,HOL) LG7 ..

$(1,7)(.1)(8,18)(.25)(19,24)(.1)$

$(1,7)(.39)(8.9)(55.55)(10.16)(.51)$

$(17,18)(62.59)(19,24)(51,51,51,47,45,4)$

$(1, J)(0)(8,12)(.85)(13)(.65)(14,17)(85)(18,24)(01)$.

$(1.24)(.01)$

$(1.7)(.01)(8,18)(.4)(19,24)(.02)$

$(1,8)(.01)(0,17)(.75)(18,24)(.02)$.

$(1,7)(.2)(8,20)(.5)(21,24)(.2)$.

THRU DEC 31 (AI) AP2 .

THRU DEC 31 (WD) AP3 (SAT) AP4 (SUN,HOL) AP4 ..

THRU DEC 31 (WD) APS (SAT) APS (SUN,HOL) APS ..

THRU DEC 31 (AL) APT ..

$(1,24)(.08,05, .02,02,00,28, .38,47, .47, .52,52,47, .45$,

$39,38,38,42,47,47,47,38,20,09,09)$

$(1,24) 14,07,03,03,14,42,50,70,70, \pi, 77,70$

$67, .58,56, .56, .62,70,70.70, .50 .42,14, .14)$

THRU MAR 31 (ALI) DIR

THRU OCT 31 (ALL) DH

THRU DEC 31 (ALL) DH2.

$(1,6)(.06)(7,24)(.2,4, .5,35, .4,35,35,3,3,3,3,4$

$$
.45,5,4,35,25,1,05
$$

(1, 6) (05) $(7.24)(1,25,45,55,5,4,45,45,4,4$

$5, .45,5,45,3,3,25, .15$

$(1,6)(.05)(7,24)(1,2,3,4,5,4,45,4,4,4,5$.

$4,5,45,3,25,15,05$

THRU OEC 31 (ND) EI (SAT) E2 (SUNHOL) EL3 ..

SHADE-SCH=SCH THRU DEC 31 (AU) $(1,8)(1.0)(0,18)(.29)$

$(19,20)(1.0)$

S MATERULLS NOT IN DOE-2 LBRARY S

EARTH $=$ MAT

$T H=2.50$ COND $=0.50$ DENS $=120 S H=0.20$.. 
S CONSTRUCTIONS

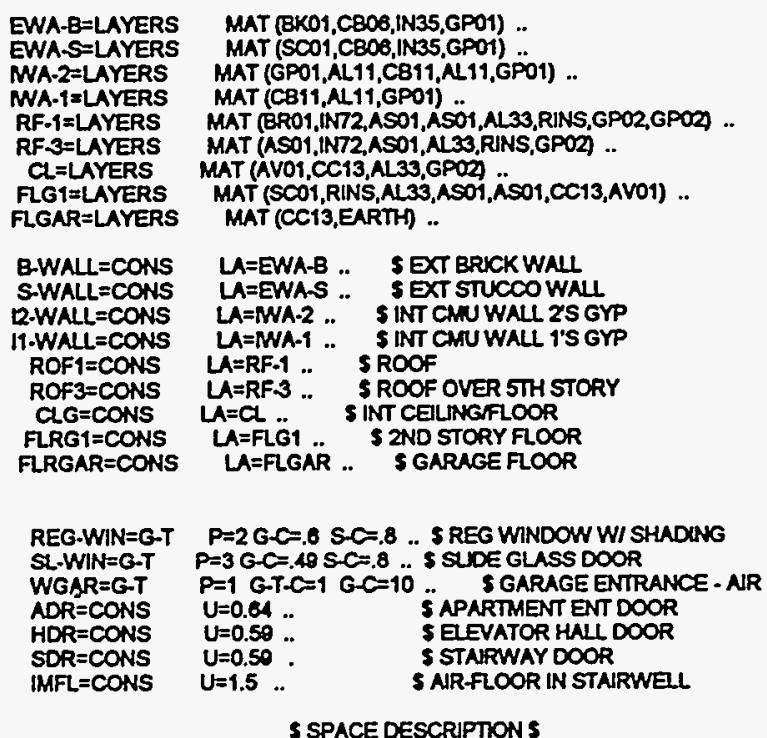

APTMT=SPACE-CONDIIONS

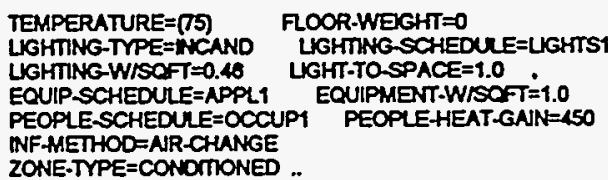

OFFICE=SPACE-CONDTIONS

TEMPERATURE=(75) FLOR.WEGHT=0

UGHTING-TYPE=RACAND UGHTIKG-SCHEDULE=LKGHTS LGHING-WISOFT $=1.5$ UGHT-TO-SPACE $=1.0$

EQUIP-SCHEDUIE=APPL2 EQUIPMENT-WISOFT $=3.0$ PEOPLESCHEOULE=OCCUP2 PEOPLEHEAT-GAIN=450

WF-METHOD=NR-CHANGE

ZONE-TYPE=CONOTONED

STAR=SPACE-CONOTONS

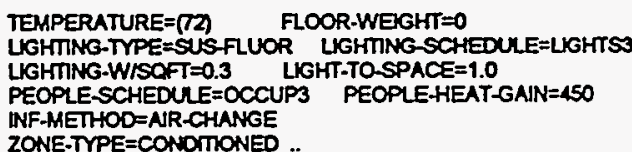

EHAL1=SPACE-CONDTIONS

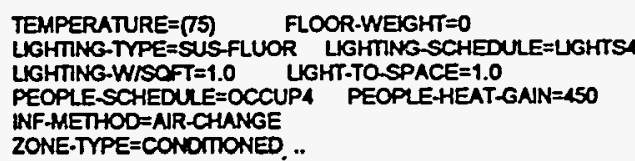

EHAL2=SPACE-CONOTIONS

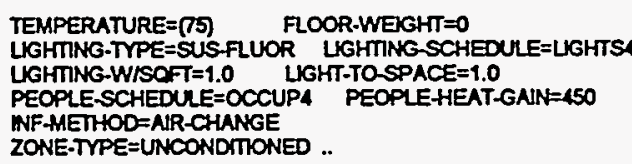

LAUND=SPACE-CONOINONS

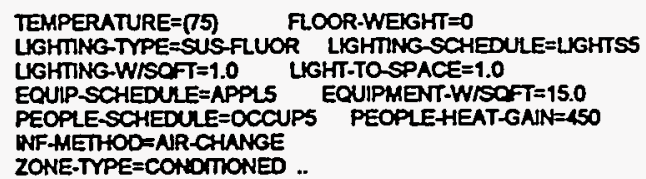


ACTIVTY=SPACE-CONDTIONS

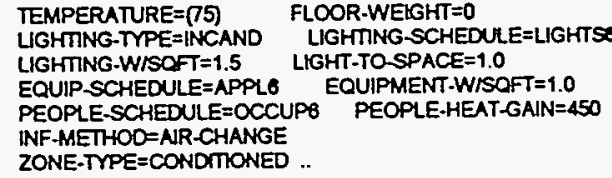

GARAGE=SPACE-CONDTIONS

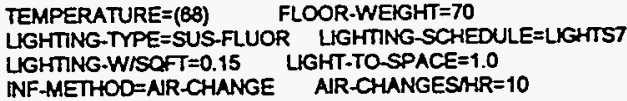

BUILDING-RESOURCE VERT-TRANS-KW $=30$ VERT-TRANS-SCH=ELEV HOT-WATER=184000 HW SCHEDULE=DHW $E+K W=3.2$ ESCHELLGHTS7 .

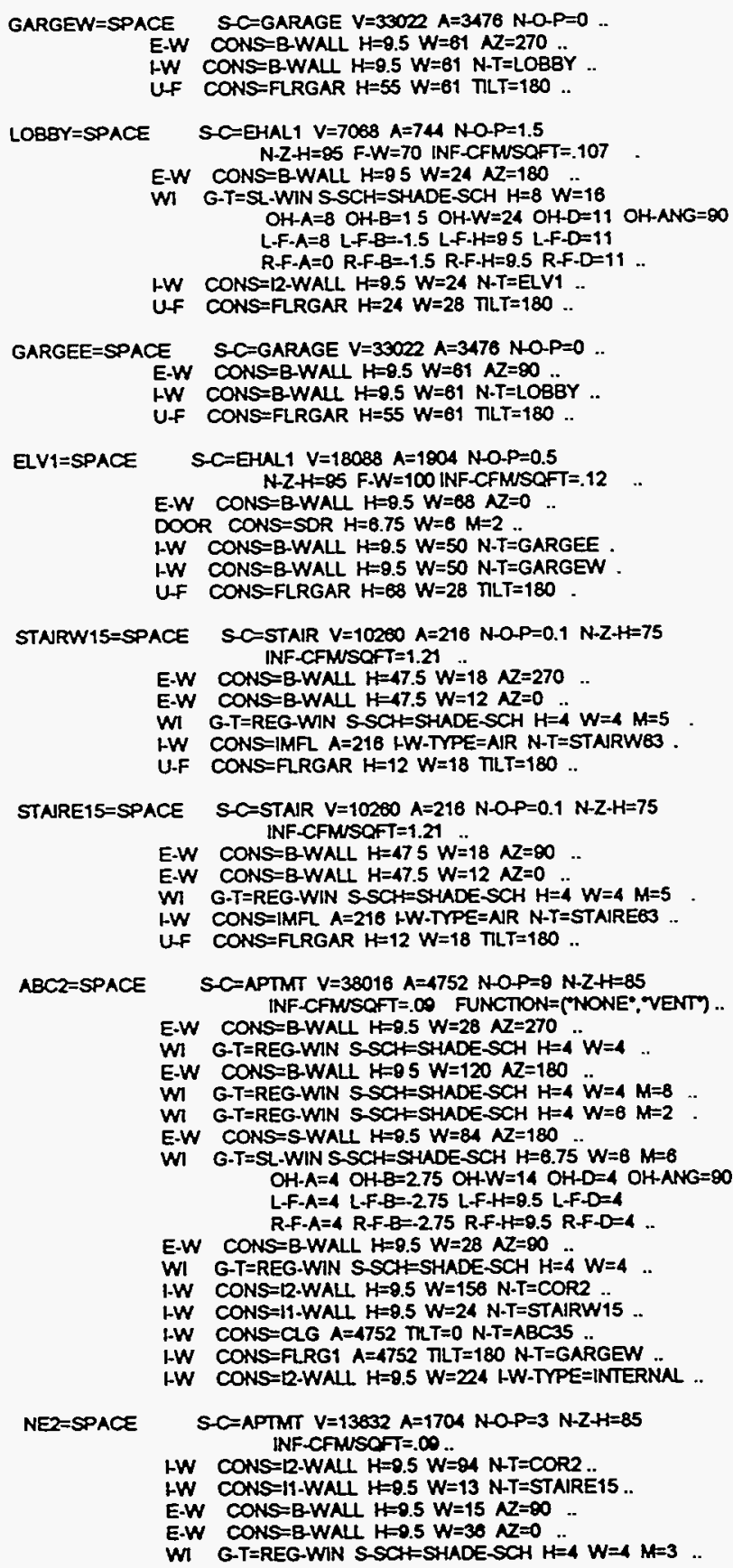


E.W CONS=S-WALL $H=0.5 \quad W=42 \quad A Z=0$

W.W G-T=ST.WN SSCH=SHADESCH H=0.75 $W=6 \quad M=3$ OH $A=1$ OH-B=275 OH.W=14 OH-D=4 OH-ANG $=20$ LF-A=A LF-B=-2.75 LFH=9.5 LF-D=A RF-A=A R-F-B=-2.75 RFH=9.5 RF-D=4.

HW CONSFCLG A=1704 TLT $=0$ NTT=NE35

I.W CONS=FLRG1 A=1704 TLT=160 N-T=GARGEE

HW CONS=ID.WALL $H=9.5 W=S 6$ HW-TYPE=INTERNAL .

$M W 2=S P A C E$

$S-C=A P T M T V=13832$ A=1704 $N-O P=3 \quad N-H=85$ NF-CFMSOFT $=.00$

E.W CONS=B-WALL $K=9.5 W=15 \quad A Z=270$

HW CONS=I1-WALL $H=0.5 W=13$ NT=STAIRW15 ..

HW CONS=D.WALL $H=0.5 W=\infty$ N.T=COF2 ..

IW CONS=12.WALL H=9.5 W=28 N-T=ELV2

$E \cdot W$ CONS=8.WALL $H=9.5 W=36 \quad \wedge Z=0$

WI G.T=REG-WIN S-SCH $=S H A D E S C H \quad H=4 W=4 \quad M=3$

E-W CONS=S.WALL $H=9.5 \quad W=42 \quad A Z=0$

WI G-T $=S L-W I N S$ SCHESHADESCH $H=0.75 \mathrm{~W}=6 \mathrm{M}=3$ OH $A=4$ OH- $8=275$ OHW $=14$ OH-D=1 OH-ANG $=9$ LF.A $A=4$ LF $B=275$ LF $H=9.5$ LF-D=4 RF-A=4 R-F $B=-2.75$ RF $+6=9.5$ RF $D=4$.

HW CONS=CLG $A=1704$ TLTT=0 $N$ T $=N W 35$

HW CONS=FLRGI A=1704 TILT=180 N-T=GARGEW

HW COAS=LW.WALL $H=0.5 W=56$ HW.TYPE=INTERNAL..

ELV2=SPACE

$S-C=E$ WN 2 V=6384 $A=872$ NOP=0.5

$F \cdot W=100 \quad \mathrm{~N}-Z \mathrm{ZH}=85$ WF-CFMSOFT $=.29 \quad$.. I.W CONS=R-WAII $H=9.5 W=24 \quad N-T=C O P 2$.

$E \cdot W$ CONS=E-WALL $H=9.5 W=24 \quad A Z=0$

HW CONS=CLG $A=512$ TLTT=0 N.T=ELV35

HW CONS=FLRG1 A=512 TLT=180 NT=ELV1.

COR2=SPACE

$S-C=$ EHALA $V=8240$ A $=780$ NOP $=0.5$

NF-CFMSOFT $=.028$

HW CONS=11-WALL H=0.5 W=5 NT=STARW15

HW CONS= 11 -WALL $H=9.5 W=5$ N-T=STARE15 ..

IW CONS=CLG $A=780$ TKT $=0 \quad N T=C O R 35$.

IW CONS=FLRGI $A=780$ TLT=180 NT=GARGEE.

ABC35=SPACE S-C=NTTMT $V=38016$ A $=4752$ NOPP=9 N-ZH=65 $F-M=3$ INF-CFMVOFT $=\infty 0$ FUNCTION=

E.W CONSERWALL H=9.5 W=28 $A 7=270$

WI G-T=REG-WIN S-SCHESHADESCH H=1 $W=4$

E.W CONS=B-WALL $H=9.5 \quad W=120 \quad A Z=180$

WI G-T=REG-WIN S-SCH=SHADESCH H=4 $W=4 M=8$

WI G-T=REG-WIN SSCH=SHADESCH H=4 W=6 $M=2$...

E.W CONS=S-WALL $H=9.5 W=84 \quad A Z=180$

WI G-T =SL.WIN S-SCH=SHADESCH $H=6.75 \quad W=6 \quad M=6$ $O H A=4$ OH $B=2.75$ OHW $=14$ OH-D=4 OH-ANG $=90$

$L F-A=4$ LF $B=-275$ LFH $=0.5$ L $F-D=4$ RF.A $=4$ RF $B=2.75$ RFH $H=9.5$ RF $D=4$..

E.W CONS=B-WALI $H=0.5 W=28 \quad N Z=\infty$

WI G-T=REG-WIN S-SOHESHADESCH $H=4$ I $W=4$

HW CONS=12.WALL $H=9.5 W=156 \quad N-T=C O R 35$

I.W CONS=11.WALL $H=0.5 W=24 \quad N-T=S T A R W 15$

H.W CONS=CLG $A=4752$ TLLT=0 HW-TYPE=ADUABATC .

HW CONS=L-WALL $H=9.5 W=224$ HW-TYPE=INTERNAL .

NE35 $=S P A C E$

$S-C=A P T M T V=13632 \quad A=1704 N-O P=3 N-2+H=65$

$F+M=3$ INF-CFM $M O F T=\infty$

HW CONS=12-WALL $H=9.5 W=24 \quad N T=C O R 35$

HW CONS $=11-W A L L ~ H=0.5 W=13 \quad N T=S T A R E 15$.

E.W CONS=BWALL $H=9.5 W=15 \quad N Z=80$

E.W CONS=B-WALL $H=0.5 W=36 \quad \Lambda Z=0$

WI G-T=REG.WIN S-SCH=SHADESCH H=4 W=4 $M=3$..

E.W CONS=S.WALI $H=0.5 \quad W=42 \quad N Z=0$

WI GTSSLWIN SSCHESHADESCH $H=6.75 W=6 \quad M=3$ OH $A=4$ OHE $=2.75$ OH+W $=14$ OH $O=4$ OH.ANG $=90$ $O H A=4$ OHE=2.75 LF-A $=4$ L $F-B=-2.75$ LFH $=9.5$ L-F-D=A
R-F-A $=4$ R.F- $B=275$ RFH=9.5 R-F-D=4

W CONS=CLG A=1704 TLTT=0 HW.TYPE=ADUBATIC.

I.W CONS=12-WALL $H=9.5 W=50$ HW-TMPE=INTERNAL

NW35=SPACE S-C=APTMT $V=13032 \quad A=1704 N-O P=3 \quad N-Z H=0 S$ F-A $=3$ NF-CFMSOFT $=00$

E.W CONS=8-WALL $H=9.5 W=15 \quad N=270$

HW CONS=11-WALL $H=0.5 W=13$ N.T=STARW15 .

HW COAS=D.WALL H=0.5 W=94 N-T=COR35

E.W CONSEQWALL $H=0.5 W=36 \quad N Z=0$.

$W 1$ G.T=REG.WIN SSCH=SHADESCH $H=4 W=4 M=3$..

E.W CONS=S-WALL $H=0.5 \quad W=42 \quad A Z=0$

WI G.T=SL-WIN S SCH=SHADE-SCH $H=6.75 \mathrm{~W}=6 \mathrm{M}=3$ $O H-A=4$ OH-B $=2.75$ OH-W $=14$ OH-D $=4$ OH-ANG $=80$ LF.A=4 L.F. $B=2.275$ L.F.H $=0.5$ L.F.D $=4$ R.F.A=4 R.F-B=275 R.F.H=9.5 R-F-D=A

IW CONS=CLG $A=1704$ TIT=0 LW-TYPE=ADUBATIC

I.W CONS=12.WALL $H=0.5 W=56$ HW-TMPE=INTERNAL

E.V35=SPACE

S.C-EHAL2 $V=6384 A=072$ NOP $=0.5$ F.W $=100$

$N-Z+H=65$ F-H $=3$ INF-CFWSOFT $=27$

HW CONS=D.WALL $H=9.5 W=24 N$ NT=COR35

$E \cdot W$ CONS=B-WALL $H=0.5 W=24 \quad A Z=0$. 
LW CONS=11.WALL H=95 W=S N-T=STARW15

HW CONS=11-WALL $H=9.5 W=5$ NTI=STAPE15

IW CONS=CLG $A=780 \mathrm{TKT}=0$ HW-TYPE $=$ NOABATC

$A B C O 2=S P A C E$

$S-C=A P T M T V=34944 A=368 \mathrm{NOP}=\mathrm{N}-Z+1=18.33$

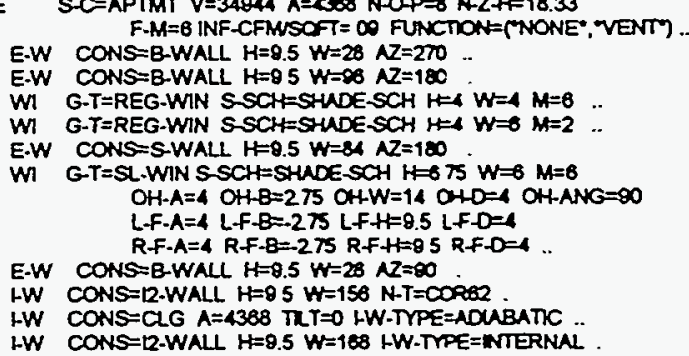

ELV62=SPACE

$S-C=E H A L 2 \quad V=0384 \quad A=672$ NOP=OS F.W $=100$ $N-Z H=18.33$ FH $=6$ NF-CFMSOTT $=.19$

I- $W$ CONS 12 .WALL $H=9.5 W=24 \mathrm{~N} T=C O R=2$

$E-W$ CONS=B-WALL $H=0.5 \quad W=24 \quad N Z=0$

I.W CONSECLG $A=512 \mathrm{NLT}=0 \mathrm{HW}$-MPPE=ADIABATKC

COR62=SPACE S-C=EHAL2 $V=6240 \quad A=700 \mathrm{NO}=05$ INF-CFMISOFT $=000 \mathrm{FHA}=6$.

LW CONS=I1-WALL $H=9.5 W=5$ N-T=STARWES

IW CONS 19 -WALL $H=95 W=5 N T=5 T A R E S 3$.

I-W CONS=CLG $A=780$ TLT=0 HW-TYPE=NDUBÄTC

STAIRWE3=SPACE S-C=STAR $V=18410 \mathrm{~A}=216 \mathrm{NOP=0}, \mathrm{NZZH=10}$ INF-CFUSOFT $=1.01$

E.W CONS=BWALL $\quad K=76 \quad W=16 \quad N Z=270$

E-W CONS=B-WALL $K=76 \quad W=18 \quad N Z=270$

$E-W$ CONS=B-WALL $K=76$ W=12 $N Z=100$

$E-W$ CONS=B-WALL $K=76 \quad W=12 \quad A Z=0$

$W I$ G-T=REG-WIN S-SCH-SHNDESCH $H=4 W=4 M=8$

IW CONS $=$ IMFL $A=216$ HW.TMPE=AIR N-T=STARW14

STAIRE63=SPACE SC=STAR $V=16416 \quad A=216 \mathrm{NOP}=0, \mathrm{~N} Z H=10$ INF-CFUSOFT $=1.01$

$E-W$ CONS=8-WALL $K=76 \quad W=12 \quad N Z=1 \infty 0$

$E-W$ CONS=B-WALL $K=76 \quad W=18 \quad A Z=\infty$.

E-W CONS=BWALL $K=76 \quad W=12 \quad N Z=0$

E-W CONS=B-WAL $H=76 \quad W=12 \quad N=0 \quad$ GST $W=4 M=8$

WI G-T=REG-WIN S-SCHESHDE-SCH HEA W=A $M=8$
HW CONS=IMFL A=216 HW-TMPE=AR NTISTARE14 ..

ABC11=SPACE S-C=APTMT $V=34944 \mathrm{~A}=1300 \mathrm{NOP}=7 \mathrm{NZ}+t=5$

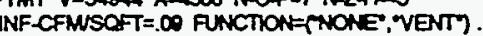

$E \cdot W$ CONS=B-WALL $H=9.5 W=28 \quad N Z=270$

$E$-W CONS=B-WALL $H=0.5 W=\infty \quad N Z=100$

w G-T=REG-WIN S-SCH=SWDE-SCH $H=1 \mathrm{~W}=4 \mathrm{~N}=6$

WI G-T=REG-WIN SSCH=SWDE-SCH $H=1 \quad W=6 \quad M=2$

WI G-T=REG-WN S-SCH=SHDESCH $K=4$

in G-T=SL-WIN S-SCTHSTHDESCH H $=75$ " $W=0$ $O H A=4$ OH $B=275$ OHW $W=14$ OHD $=4$ OHANG $=\infty$ 


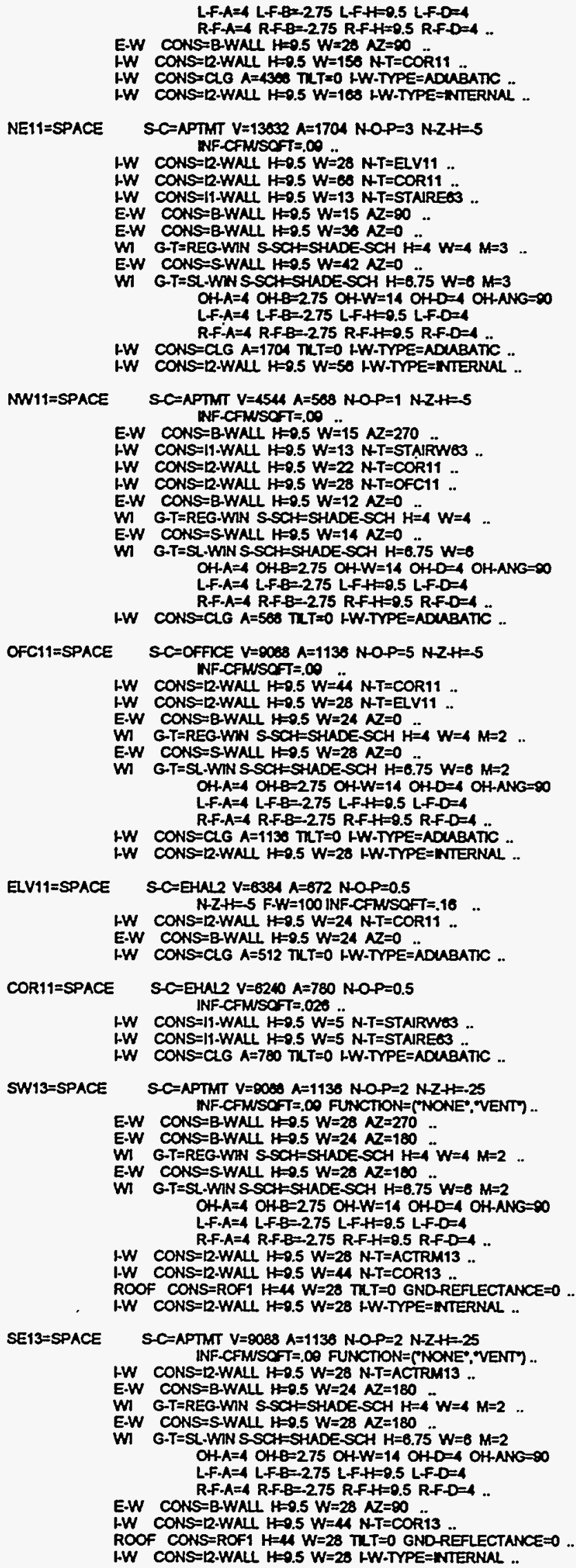




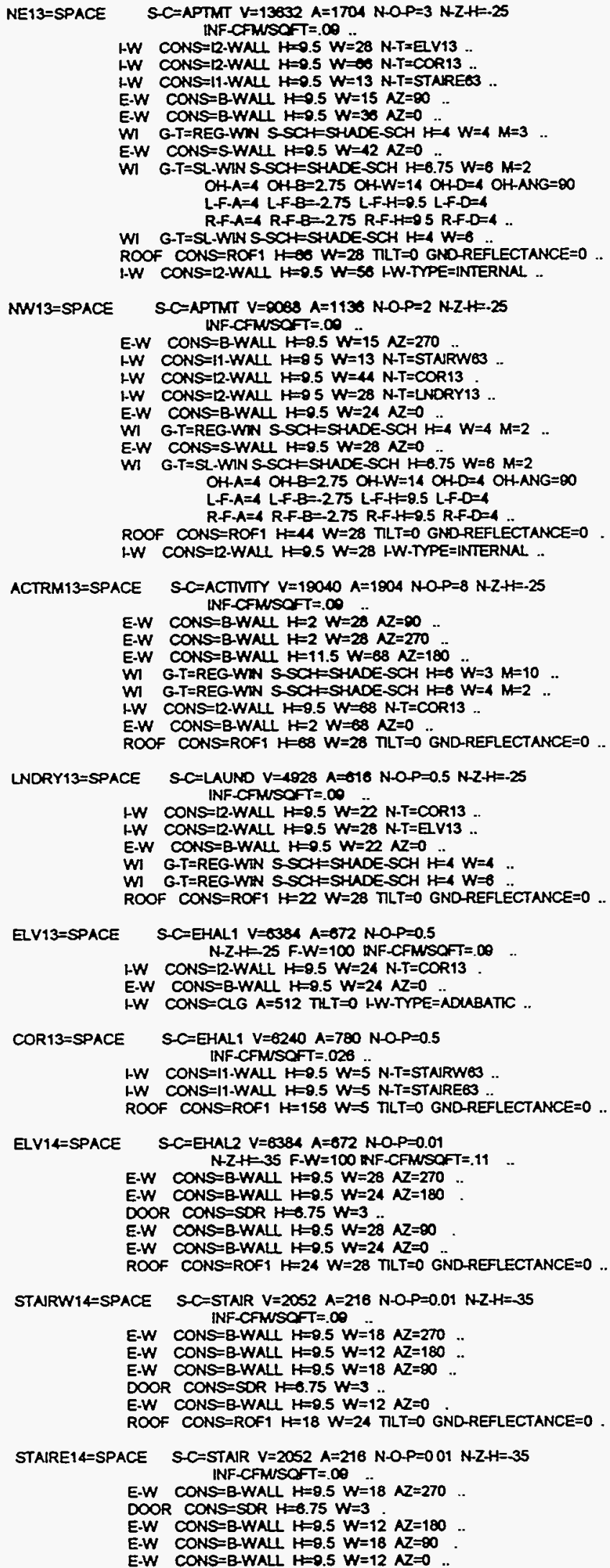

NW13=SPACE

$S-C=A P T M T V=0083 \quad A=1136 \quad N-O P=2 N Z H=25$ INF-CFNSOFT $=. \infty$..

E-W CONS=B-WMALCFT $=.00 \quad W=9.5 \quad W=15 \quad A Z=270$

IW CONS $=11-W A L L$ H=9 5 W=13 NT=STNRWE3 ..

HW CONS=12-WALL $H=0.5 W=44 \quad N-T=C O R 13$

I.W CONS=12-WALL $H=95$ W=28 N-T=LNDRY13.

E.W CONS=B-WNL $H=0.5 \quad W=24 \quad A Z=0$

$W I$ G-T=REG-WW S-SCH=SHADE-SCH $H=4 W=4 \quad M=2$..

$E-W$ CONS=S-WALL $H=9.5 W=28 \quad A Z=0$

WI G-T $=S L$-WIN SSCH=SHNDESCH H=0.75 W=8 $M=2$ OH.A $=4$ OH $B=2.75$ OH.W $=14$ OH-O=4 OH.ANG $=0$ LF.A $=4$ LF $B=-275$ LF-H=9.5 LF-D $=4$ R-F-A=A R-F-B=-275 R-F-H=9.5 R-F-D=4 ROOF CONS $=R O F 1 \quad H=4 N \quad W=28$ TLT $=0$ GNDREFLECTANCE=0. IW CONS $=12$-WNLL $H=0.5 W=28$ IW-TYPE=INTERNAL..

ACTRM13=SPACE $S-C=A C T V T V \quad V=19040 A=1904 \mathrm{NOOP}=8 \mathrm{~N}-Z H=-25$ INF-CFWSOFT $=.00$

E-W CONS=B-WAL $H=2 \quad W=20 \quad A Z=\infty 0$.

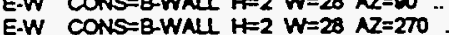

$E-W$ CONSEB-WALL $H=2 \quad W=28 \quad A Z=270 \quad .-$

E-W CONS=B-WAL $H=11.5 \quad W=88 \quad M Z=180$.

WI G-T=REG-WWN SSCHESHAOESCH $H=0 \quad W=3 \quad M=10$

WI G-T=REG-WW S-SCH=SHMOESCH H=6 $W=4 \quad M=2$..

IW CONS $=12$-WALL $H=9.5 W=68 N T=C O R 13$.

$E-W$ CONS=B-WALL $H=2 \quad W=68 \quad N Z=0$

ROOF CONS=ROFI $H=68 W=28$ TLLT=0 GND-REFLECTANCE $=0$.

LNDRY13=SPACE S-C=LAUND $V=4928 A=016 \mathrm{NOP}=0.5 \mathrm{~N}-2-H=-25$

INF-CFNISOFT $=.00$

LW CONST12-WAU H=0.5 $W=\ddot{2}$ N-T=COR13

IW CONS $=12$-WALL $H=9.5 W=28$ N-T=EV13 .

E-W CONS=B-WALL $H=0.5 \quad W=22 \quad N Z=0$.

WI G-T=REG-WIN S SOH=SHWDESCH H=4 W=4

WI G-T=REG-WN SSCH=SHADESCH $H=4 W=6$

ROOF CONS=ROF1 $H=22 W=28$ IITT=0 GNOREFLECTANCE=0 .

ELV13=SPACE

$S-C=E H A L 1$ V $=0384 \quad A=672$ NOP $=0.5$

$N-Z-H=25$ F.W $=100$ NNF-CFMSOFT $=\infty$.

HW CONS $=12-W A L L ~ H=9.5 W=24 \quad \mathrm{~N}-\mathrm{T}=$ COR13

E-W CONS=B-WALL $H=9.5 \quad W=24 \quad A Z=0$.

$\mathrm{HW}$ CONSCLG $A=512$ TLT=0 HW-TVPE=AOABATIC.

COR13=SPACE $S-C=E H A L 1 V=6240$ A=780 N-OP=0.5 INF-CFMSOFT $=.026$

IW CONS=I1.WALL $H=9.5 W=5$ N-T=STARWE3

I.W CONS $=11$-WALI $H=9.5 W=5$ N-T=STANRE 3 .

ROOF CONS=ROF1 $H=158 W=5$ TLT=0 GNDREFLECTANCE=0 .

ELV14=SPACE $S-C=E H A L 2 ~ V=6384 A=672 \mathrm{NO} P=0.01$ N-ZHE 35 F-W $W=100$ NF.CFWUSOFT $=.11$

$E-W$ CONS=B-WALL $H=8.5 \quad W=28 \quad A Z=270$.

$E-W$ CONS=B-WAL $H=0.5 \quad W=24 \quad N Z=180$

DOOR CONS $=S O R H=6.75 W=3$.

$E-W$ CONS=B-WALL $H=0.5 \quad W=28 \quad A Z=\infty$

$E-W$ CONS=B-WALL $H=0.5 W=24 \quad A Z=0$

ROOF CONS=ROFI $t=24 \quad W=28$ TILT=0 GNDREFLCTANCE $=0$.

STARW14=SPACE $S-C=S T A R \quad V=2052$ A=216 N-OP=0.01 N-Z-H=-35 INF-CPMISOFT $=.00$

$E-W$ CONS=B-WALI $H=9.5 W=18 \quad N Z=270$.

$E-W$ CONS $=B-W A L L ~ H=9.5 \quad W=12 \quad A Z=180$

$E-W$ CONS=B-WALL $H=9.5 W=18 \quad A Z=80$

DOOR CONS=SDR $H=6.75 W=3$

$E-W$ CONS=B-WALI $H=0.5 \quad W=12 \quad N Z=0$

ROOF CONS=ROF1 $H=18 \quad W=24 \quad \pi L T=0$ GNDREFLECTANCE $=0$.

STAIRE14=SPACE S-C=STAIR $V=2052 A=216 \mathrm{~N}-0 . P=001 \mathrm{~N} \cdot \mathrm{Z}+\mathrm{H}=-35$ INF-CFMSOFT $=. \infty 0$

E-W CONS=B-WALL $H=9.5 \quad W=18 \quad N Z=270$

DOOR CONS=SOR $\mathrm{H}=6.75 \mathrm{~W}=3$

$E-W$ CONS=B-WALL $\quad H=9.5 \quad W=12 \quad A Z=180$

E.W CONS=BWALU $H=0.5 W=18 \quad A Z=90$

E-W CONS=BWALL

ROOF CONS=ROF1 $H=18 W=24$ TLTT=0 GNDREFLCTANCE $=0$

END 
SYS-NEOZZSYSTEM S-TYPE=RESYS S-C-S-CIRL SALS-AR S-FANS=S-FN S-EO=S-EOPT HEATS=EECTRKC BUSEBS=ELCTRIC ZONE-NAMES=(NEOZ) ..

SYS-NW62=SYSTEM S-TYPE=RESYS S-C=S-CTRL SA=S-ARR SFANS=S-FN S-EC=S-EOPT HEAT S=ELCTRIC BASEB-S=ELECTRIC ZONE-NAMES=(NWOZ) ..

SYS-AC11=SYSTEM S-TYPE=RESYS S-C=S-CTRL S-A=S-AR S-FANS=S-FN S-EQ=S-EOPT HEATS $=E L C T R K$ BASEBS=ELCTRIC ZONEALAMES=(ABC11,EIV11,COR11) .

SYS-NE11=SYSTEM S-TYPE=RESYS SC-S-CTRL S-A=S-AIR S-FANS=S-FN S-EQ=S-EOPT HEAT-S=ELECTRIC BASEB-S=EECTRIC ZONE-NAMES=(NE11) ..

SYS-NW11=SYSTEM S-TYPE=RESYS S-C=S-CTRL S-A=S-NR S-FANS=S-FN S-EO=SEOPT HEATS=ELECTRIC BASEBS=EECTRKC ZONE-NAMES=(MW11) ..

SYS-OF11=SYSTEM S-TYPE=PTAC MAXS-T=100 MINS-T=55 HSCH=HTOFC CSCH=ACOFC HEATSOURCE=EECTRL BASEB-S=ELECTRIC ZONENAMES=(OFC11) ..

SYS-SW13=SYSTEM S-TYPE=RESYS S-C=S-CTRL S-A=S-NR S-FANS=SFN S-ECES-ECPT HEATS=ELECTRIC BASEB-S=ELECTRK ZONE-NAMES=(SW13) ..

SYS-E13=SYSTEM S-TYPE=RESYS S-C=S-CTRA S-A=SAR SFANS=S-FN S-EO=S-EOPT BASEBS=ELCTRIC HEATSOURCE=ELECTRIC ZONE-NAMES=(ELV13) ..

SYS-C13=SYSTEM S-TYPE=RESYS S-C=S-CTRL S-A=S-NR S-FANS=SFN S-EO=S-EOPT HEATS=ELECTRIC BASEBS=ELECTRKC ZONE-NAMES=(COR13) ..

SYS-SE13=SYSTEM S-TYPE=RESYS S-C=S-CTRL S-A=S-AR S-FANS=SFN S-EO=S-EOPT HEATS=ELECTRIC BASEBSS=ELECTRIC ZONE-NAMES=(SE13,EV14,STARW14,STNRE14) ..

SYS-NE13=SYSTEM S-TYPE=RESYS S-C=S-CTRL S-A=S-NR S-FANS=S-FN S-EQ=S-EOPT HEATS=ELECTRIC BUSEB-S=ELECTRIC ZONE-NAMES=(NE13) ..

SYS-AW13=SYSTEM S-TYPE=RESYS S-C=S-CTRL S-A=S-AR SFANS=S-FN S-EO=S-EOPT HEATSSELCTRIC BASEBS=ELCTRIC ZONE-NAMES=(NW13) ..

SYS-AT13=SYSTEM S-TYPE=PTAC MAXS-T=100 MIN-ST=55 HSCH=ATACT CSCHFHCACT HEAT-SOURCE=ELECTRIC BASEB-S=ELECTRIC ZONE-NAMES=(ACTRM13) ..

SYS-LD13=SYSTEM S-TYPE=RESYS S-CES-CTRL S-A=S-ARR S-FANS=SFN S-EO=S-EOPT HEATS=ELCTRK QASEBSEEECTRIC ZONE-NAMES=(LNDRY13) ..

END.

COMPÜTE SYSTEMS ..

INPUT PLANT .

PLANT-REPORT SS=(PS-A.PSE)..

WHR=P.E TYPE=ELEC-DHWHEATER SZE=.388

SRPTSCH=SCH THRU DEC 31 (NLL) (1,24) (1) ..

SOUT-1=R-B V.T=PLANT VLL=(10)

SHR RPT=H-R R-SCHERPTSCH R-B=(OUT-1) ..

END .

COMPÜTE PLANT .

STOP.. 


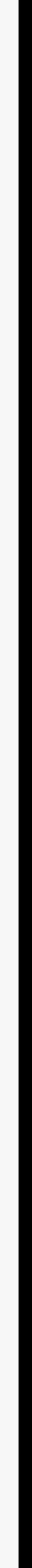


APPENDIX C: Margolis Building COMIS Results 
Margolis Building Air Flows

All cfm on a per Apartment basis

Average Apartment Volume $=6160 \mathrm{ft}^{`} 3$

Windward

\begin{tabular}{|c|c|c|c|}
\hline Floor & $\begin{array}{c}|c| \\
\text { (kg/hr) }\end{array}$ & (cfm) & \\
\hline 2 & 0 & 0 & \\
\hline 3 & 0 & 0 & \\
\hline 4 & 0 & 0 & \\
\hline 5 & 0 & 0 & \\
\hline 6 & 0 & 0 & \\
\hline 7 & 0 & 0 & \\
\hline 8 & 0 & 0 & \\
\hline 9 & 0 & 0 & \\
\hline 10 & 0 & 0 & \\
\hline 11 & 0 & 0 & \\
\hline 12 & 0 & 0 & \\
\hline 13 & 0 & 0 & \\
\hline
\end{tabular}

delta $T(k): \quad 0$

delta $T(F): \quad 0$

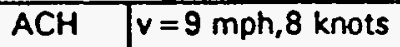
ACH (ach) (kg/hr)

\begin{tabular}{l|l}
50 & 24.5 \\
\hline
\end{tabular}

24.5

22.0

24.0

26.9

55

66

68

73.5

74

75

75

73.5

32.3

33.3

36.0

36.3

36.7

36.7

36.3

36.0
OAT (F): $\quad 75$

\begin{tabular}{|c|c|c|c|}
\hline $\begin{array}{l}\mathrm{ACH} \\
\text { (ach) }\end{array}$ & $\begin{array}{r}v=18 \mathrm{mpl} \\
(\mathrm{kg} / \mathrm{hr})\end{array}$ & $\begin{array}{l}5 \mathrm{knots} \\
(\mathrm{cfm})\end{array}$ & $\begin{array}{l}\mathrm{ACH} \\
\text { (ach) }\end{array}$ \\
\hline 0.2 & 120 & 58.8 & 0.6 \\
\hline 0.2 & 198 & 57.8 & 0.6 \\
\hline 0.2 & 120 & 58.8 & 0.6 \\
\hline 0.3 & 126 & 61.7 & 0.6 \\
\hline 0.3 & 137 & 67.1 & 0.7 \\
\hline 0.3 & 152 & 74.5 & 0.7 \\
\hline 0.4 & 160 & 78.4 & 0.8 \\
\hline 0.4 & 170 & 83.3 & 0.8 \\
\hline 0.4 & 180 & 88.2 & 0.9 \\
\hline 0.4 & 185 & 90.6 & 0.9 \\
\hline 0.4 & 170 & 83.3 & 0.8 \\
\hline 0.4 & 158 & 77.4 & 0.8 \\
\hline
\end{tabular}

Leeward

\begin{tabular}{|c|c|c|c|c|}
\hline Floor & $\begin{array}{c}v=\text { Omph,0 knots } \\
(\mathrm{kg} / \mathrm{hr})\end{array}$ & $\begin{array}{c}\text { ACH } \\
(\mathrm{cfm})\end{array}$ & $v=$ \\
\hline 2 & 0 & 0 & 0 & \\
\hline 3 & 0 & 0 & 0 & \\
\hline 4 & 0 & 0 & 0 & \\
\hline 5 & 0 & 0 & 0 & \\
\hline 6 & 0 & 0 & 0 & \\
\hline 7 & 0 & 0 & 0 & \\
\hline 8 & 0 & 0 & 0 & \\
\hline 9 & 0 & 0 & 0 & \\
\hline 10 & 0 & 0 & 0 & \\
\hline 11 & 0 & 0 & 0 & \\
\hline 12 & 0 & 0 & 0 & \\
\hline 13 & 0 & 0 & 0 & \\
\hline
\end{tabular}

detta $T(k): \quad 0$

detta T (F): $0 \quad$ OAT (F): $\quad 75$

\begin{tabular}{|l|l|l|l}
\hline$v=9$ mph, 8 knots & ACH & $v=18 \mathrm{mph}, 15.5 \mathrm{knots}$ & ACH
\end{tabular} (kg/h) (cfm) (ach) $(\mathrm{kg} / \mathrm{hr})$ (cfm) (ach)

\begin{tabular}{|c|c|c|c|c|c|}
\hline 0 & 0 & 0 & 0 & 0 & 0 \\
\hline 0 & 0 & 0 & 0 & 0 & 0 \\
\hline 0 & 0 & 0 & 0 & 0 & 0 \\
\hline 0 & 0 & 0 & 0 & 0 & 0 \\
\hline 0 & 0 & 0 & 0 & 0 & 0 \\
\hline 0 & 0 & 0 & 0 & 0 & 0 \\
\hline 0 & 0 & 0 & 0 & 0 & 0 \\
\hline 0 & 0 & 0 & 0 & 0 & 0 \\
\hline 0 & 0 & 0 & 0 & 0 & 0 \\
\hline 0 & 0 & 0 & 0 & 0 & 0 \\
\hline 0 & 0 & 0 & 0 & 0 & 0 \\
\hline 0 & 0 & 0 & 0 & 0 & 0 \\
\hline
\end{tabular}


Margolis Building Air Flows

All clm on a per Apartment basis

Average Apartment Volume $=6160 \mathrm{ft}^{\star} 3$

Windward

delta T(k): 20

delta T (F): 36

\begin{tabular}{|c|c|c|c|c|c|c|c|c|c|}
\hline \multirow{3}{*}{$\begin{array}{c}\text { Floor } \\
2 \\
\end{array}$} & \multirow{2}{*}{\multicolumn{2}{|c|}{$\begin{array}{c}v=0 \mathrm{mph}, 0 \mathrm{knots} \\
(\mathrm{ko} / \mathrm{hr}) \quad(\mathrm{cfm})\end{array}$}} & \multirow{3}{*}{$\begin{array}{c}\mathrm{ACH} \\
\text { (ach) } \\
0.5\end{array}$} & delta T If & 36 & \multirow[b]{2}{*}{$\begin{array}{l}\mathrm{ACH} \\
\text { (ach) }\end{array}$} & \multicolumn{2}{|c|}{ OAT (F): } & \multirow[b]{2}{*}{$\begin{array}{l}\mathrm{ACH} \\
\text { (ach) } \\
\end{array}$} \\
\hline & & & & \multicolumn{2}{|c|}{$\begin{array}{c}v=9 \mathrm{mph}, 8 \mathrm{knots} \\
(\mathrm{kg} / \mathrm{hr}) \quad \text { (cfm) }\end{array}$} & & $\begin{array}{r}v=18 \mathrm{mp} \\
(\mathrm{kg} / \mathrm{hr})\end{array}$ & $\begin{array}{l}5 \text { knots } \\
(\mathrm{ctm})\end{array}$ & \\
\hline & 100 & 49.0 & & 117 & 57.3 & 0.6 & 170 & 83.3 & 0.8 \\
\hline 3 & 92 & 45.1 & 0.4 & 111 & 54.4 & 0.5 & 163 & 79.9 & 0.8 \\
\hline 4 & 83 & 40.7 & 0.4 & 105 & 51.4 & 0.5 & 162 & 79.4 & 0.8 \\
\hline 5 & 80 & 39.2 & 0.4 & 104 & 50.9 & 0.5 & 168 & 82.3 & 0.8 \\
\hline 6 & 68 & 33.3 & 0.3 & 100 & 49.0 & 0.5 & 172 & 84.3 & 0.8 \\
\hline 7 & 56 & 27.4 & 0.3 & 97 & 47.5 & 0.5 & 175 & 85.7 & 0.8 \\
\hline 8 & 46 & 22.5 & 0.2 & 93 & 45.6 & 0.4 & 181 & 88.7 & 0.9 \\
\hline 9 & 37 & 18.1 & 0.2 & 90 & 44.1 & 0.4 & 183 & 89.7 & 0.9 \\
\hline 10 & 18 & 8.8 & 0.1 & 84 & 41.2 & 0.4 & 186 & 91.1 & 0.9 \\
\hline 11 & 0 & 0.0 & 0.0 & 80 & 39.2 & 0.4 & 183 & 89.7 & 0.9 \\
\hline 12 & 0 & 0.0 & 0.0 & 60 & 29.4 & 0.3 & 168 & 82.3 & 0.8 \\
\hline 13 & 0 & 0.0 & 0.0 & 43 & 21.1 & 0.2 & 156 & 76.4 & 0.7 \\
\hline
\end{tabular}

Leeward

\begin{tabular}{|c|c|c|c|}
\hline Floor & \multicolumn{2}{|c|}{$v=0 \mathrm{mph}, 0 \mathrm{knots}$} & $\begin{array}{l}\mathrm{ACl} \\
\text { lach }\end{array}$ \\
\hline 2 & 106 & 51.9 & 0.5 \\
\hline 3 & 100 & 49.0 & 0.5 \\
\hline 4 & 94 & 46.1 & 0.4 \\
\hline 5 & 88 & 43.1 & 0.4 \\
\hline 6 & 75 & 36.7 & 0.4 \\
\hline 7 & 66 & 32.3 & 0.3 \\
\hline 8 & 56 & 27.4 & 0.3 \\
\hline 9 & 43 & 21.1 & 0.2 \\
\hline 10 & 25 & 12.2 & 0.1 \\
\hline 11 & 0 & 0.0 & 0.0 \\
\hline 12 & 0 & 0.0 & 0.0 \\
\hline 13 & 0 & 0.0 & 0.0 \\
\hline
\end{tabular}

delta $T(k): \quad 20$

delta T (F): $\quad 36$

$v=9 \mathrm{mph}, 8 \mathrm{knots}$
OAT (F):

39

\begin{tabular}{|c|c|c|c|c|c|}
\hline \multicolumn{2}{|c|}{$v=9$ mph,8 knots } & $\begin{array}{l}\mathrm{ACH} \\
\text { (ach) }\end{array}$ & \multicolumn{2}{|c|}{$v=18 \mathrm{mph}, 15.5$ knots } & $\begin{array}{l}\mathrm{ACH} \\
\text { (ach) }\end{array}$ \\
\hline 94 & 46.1 & 0.4 & 61 & 29.9 & 0.3 \\
\hline 88 & 43.1 & 0.4 & 52 & 25.5 & 0.2 \\
\hline 80 & 39.2 & 0.4 & 30 & 14.7 & 0.1 \\
\hline 90 & 44.1 & 0.4 & 18 & 8.8 & 0.1 \\
\hline 56 & 27.4 & 0.3 & 4 & 2.0 & 0.0 \\
\hline 44 & 21.6 & 0.2 & 0 & 0.0 & 0.0 \\
\hline 37 & 18.1 & 0.2 & 0 & 0.0 & 0.0 \\
\hline 6 & 2.9 & 0.0 & 0 & 0.0 & 0.0 \\
\hline 0 & 0.0 & 0.0 & 0 & 0.0 & 0.0 \\
\hline 0 & 0.0 & 0.0 & 0 & 0.0 & 0.0 \\
\hline 0 & 0.0 & 0.0 & 0 & 0.0 & 0.0 \\
\hline 0 & 0.0 & 0.0 & 0 & 0.0 & 0.0 \\
\hline
\end{tabular}


Margolis Building Air Flows

All cfm on a per Apartment basis

Average Apartment Volume $=6160 \mathrm{ft}^{-3}$

Windward

Floor $v=0 \mathrm{mph}, 0 \mathrm{knots}$

\begin{tabular}{|c|c|c|}
\hline Floor & $\begin{array}{c}v=0 \mathrm{mph}, 0 \mathrm{kno} \\
(\mathrm{kg} / \mathrm{mr})\end{array}$ \\
\hline 2 & 153 & \\
\hline 3 & 146 & \\
\hline 4 & 137 & \\
\hline 5 & 120 & \\
\hline 6 & 108 & \\
\hline 7 & 93 & \\
\hline 8 & 81 & \\
\hline 9 & 56 & \\
\hline 10 & 31 & \\
\hline 11 & 0 & \\
\hline 12 & 0 & \\
\hline 13 & 0 & \\
\hline
\end{tabular}

delta T(k): $\quad 40$

delta T (F): 72
OAT (F): $\quad 3$ ACH $\quad v=18 \mathrm{mph}, 15.5$ knots (ach) ( $\mathrm{kg} / \mathrm{hr}) \quad$ (cfm) \begin{tabular}{|l|l|l|l}
\hline .8 & 218 & 106.8 & (ach) \\
\hline
\end{tabular} (cm) ACH (cfm) (ach) \begin{tabular}{l|l}
\hline 76.7 & 0.8 \\
\hline 76.4 & 0.7 \\
\hline 74.5 & 0.7
\end{tabular}

\begin{tabular}{l|l|l|l}
71.5 & 0.7 & 156 & 76.4 \\
\hline 671 & 0.7 & 152 & 74.5
\end{tabular}

\begin{tabular}{l|l}
\hline 58.8 & 0.6
\end{tabular}

52.9

45.6

39.7

\begin{tabular}{l|l}
37.4 & 0.4
\end{tabular}

15.2

0.0

0.0

0.0

0.6

\begin{tabular}{l|l}
0.6 & 147 \\
\hline 0.5 & 137 \\
\hline
\end{tabular}

147

125

72.0

67.1

57.8

51.9

106

0.1

91

44.6

39.7

\begin{tabular}{l|l|l}
\hline 0.0 & 46 & 22.5 \\
\hline
\end{tabular}

22.5

0.0

6

2.9

0.7

0.7

0.7

0.7

0.6

0.6

208

204

206

204

204

203

101.9

99.4

99.9 100.9

99.9

99.9

99.4

99.0

95.0

\begin{tabular}{l|l|l}
\hline 0.2 & 160 & 78.4 \\
\hline 0.0 & 144 & 70.5 \\
\hline
\end{tabular}

0.5

0.7

Leeward

delta T(k): $\quad 40$

delta T (F): 72

\begin{tabular}{|c|c|c|c|c|c|c|c|c|c|}
\hline & \multicolumn{2}{|c|}{ delta $T(F): \quad 72$} & \multicolumn{4}{|c|}{ OAT (F): $\quad 3$} \\
\hline Floor & $\begin{array}{r}v=0 \mathrm{mph} \\
(\mathrm{kg} / \mathrm{hr})\end{array}$ & $\begin{array}{l}\text { ots } \\
(\mathrm{cfm})\end{array}$ & $\begin{array}{l}\mathrm{ACH} \\
(\mathrm{ach})\end{array}$ & $\begin{array}{r}v=9 \mathrm{mph} \\
(\mathrm{kg} / \mathrm{mr})\end{array}$ & $\begin{array}{l}\text { ots } \\
\text { (cfm) }\end{array}$ & $\begin{array}{l}\mathrm{ACH} \\
\text { (ach) }\end{array}$ & $\begin{array}{r}v=18 \mathrm{mp} \\
(\mathrm{kg} / \mathrm{hr})\end{array}$ & $\begin{array}{l}5 \text { knots } \\
(\mathrm{cfm})\end{array}$ & $\begin{array}{l}\mathrm{ACH} \\
\text { (ach) } \\
\end{array}$ \\
\hline 2 & 168 & 82.3 & 0.8 & 156 & 76.4 & 0.7 & 129 & 63.2 & 0.6 \\
\hline 3 & 156 & 76.4 & 0.7 & 140 & 68.6 & 0.7 & 114 & 55.8 & 0.5 \\
\hline 4 & 180 & 88.2 & 0.9 & 135 & 66.1 & 0.6 & 106 & 51.9 & 0.5 \\
\hline 5 & 135 & 66.1 & 0.6 & 120 & 58.8 & 0.6 & 81 & 39.7 & 0.4 \\
\hline 6 & 112 & 54.9 & 0.5 & 102 & 50.0 & 0.5 & 56 & 27.4 & 0.3 \\
\hline 7 & 102 & 50.0 & 0.5 & 81 & 39.7 & 0.4 & 24 & 11.8 & 0.1 \\
\hline 8 & 80 & 39.2 & 0.4 & 62 & 30.4 & 0.3 & 0 & 0.0 & 0.0 \\
\hline 9 & 60 & 29.4 & 0.3 & 30 & 14.7 & 0.1 & 0 & 0.0 & 0.0 \\
\hline 10 & 30 & 14.7 & 0.1 & 0 & 0.0 & 0.0 & 0 & 0.0 & 0.0 \\
\hline 11 & 0 & 0.0 & 0.0 & 0 & 0.0 & 0.0 & 0 & 0.0 & 0.0 \\
\hline 12 & 0 & 0.0 & 0.0 & 0 & 0.0 & 0.0 & 0 & 0.0 & 0.0 \\
\hline 13 & 0 & 0.0 & 0.0 & 0 & 0.0 & 0.0 & 0 & 0.0 & 0.0 \\
\hline
\end{tabular}



$a b c . c 0 \varepsilon$
xos oot
$422,09: 321993$
1
columne:
1) storoy
2) all flow into shafts (not divided by 13)
3) all flow out of shafts (not divided by 13)
4) supply alf flow (not divided by 13)
5) lacade wind ward side for one wind ward unit
6) corrldor door for one wind ward unit
7) exhaust obaft for ono wind ward unit
8) facado 100 ward olde
9) corrldor door
10) exhaust shaft

Zero might mean flow is in oppocite direction, for llows please cee the drawing supplled with the original set of grapho.

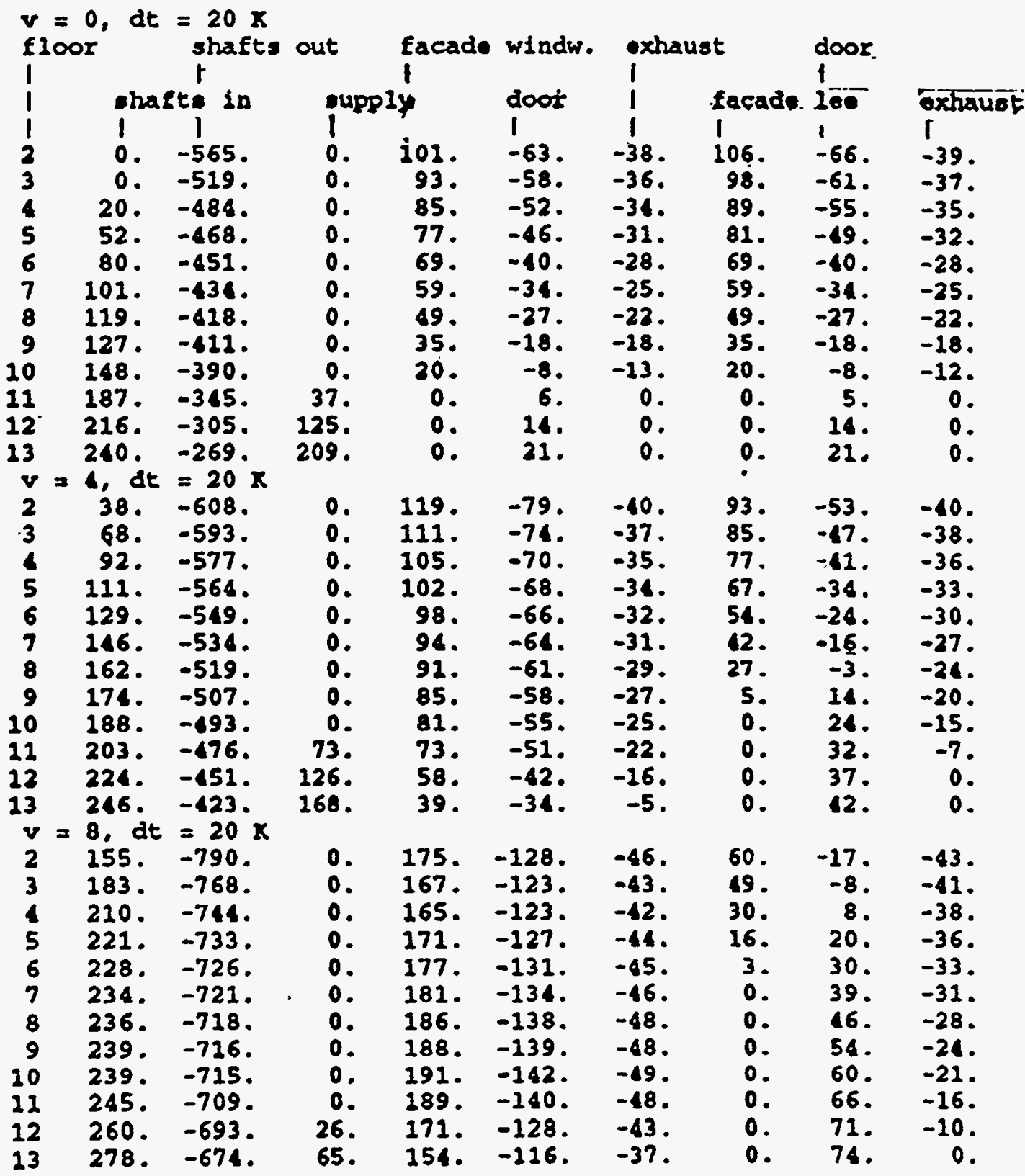



$D=1$

APPENDIX D: Margolis Building BECo Utility Costs 


\begin{tabular}{|c|c|c|c|c|c|c|c|c|c|c|c|c|c|c|c|c|c|c|c|}
\hline 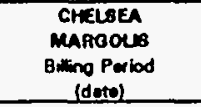 & $\begin{array}{l}\text { No. of } \\
\text { aiveno } \\
\text { Dere }\end{array}$ & 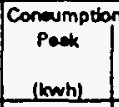 & $\begin{array}{c}\text { Ott.Pock } \\
\text { (nown) }\end{array}$ & $\begin{array}{l}\text { Demend } \\
\text { Pook } \\
\text { (tw })\end{array}$ & $\begin{array}{c}\text { Coneovrede } \\
\text { Post } \\
\text { (1) }\end{array}$ & $\begin{array}{l}\text { Cheroo } \\
\text { Ott Peok } \\
\text { Ifl }\end{array}$ & 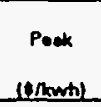 & 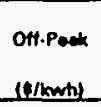 & $\begin{array}{c}\text { Beno } \\
\text { Chenos } \\
\text { (1) }\end{array}$ & 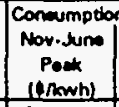 & 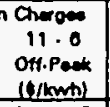 & 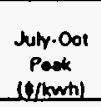 & 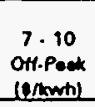 & $\begin{array}{c}\text { Dewnend Cher } \\
\text { Nov.June } \\
\text { Conswn }\end{array}$ & $\begin{array}{l}\text { July. Oot } \\
0,1 / k m\end{array}$ & $\begin{array}{c}\text { Fued } \\
\text { Cheroo } \\
\text { (e/knth) }\end{array}$ & $\begin{array}{c}\text { PF } \\
\text { (LW/XVA) } \\
\end{array}$ & $\begin{array}{l}\text { PF } \\
\text { cheroo } \\
\text { (2) }\end{array}$ & $\begin{array}{c}\text { Toded } \\
\text { cheow } \\
\text { (w/o pF) } \\
\text { (1) }\end{array}$ \\
\hline $12 / 13 / 90 \cdot 1 / 10 / 81$ & 35 & 130,544 & 185,310 & 580.4 & 0 & 0 & 0 & 0 & 20.07 & 0.02820 & 0.00005 & & & 8.329997 & & 0.04007 & 0 & 0 & $23,328.97$ \\
\hline $1 / 10 / 91$ - 2/12/81 & 28 & 83,222 & 141,384 & $\infty 01$ & 0 & 0 & 0 & 0 & 20.07 & 0.02820 & 0.00805 & & & 8.33 & & 0.03524 & 0 & 0 & $17,008.11$ \\
\hline $2 / 12 / 91 \cdot 3 / 13 / 81$ & 30 & 103,011 & 153,402 & 550.6 & 0 & 0 & 0 & 0 & 20.07 & 0.02820 & 0.00005 & & & 9.329993 & & 0.02057 & 0 & 0 & $10,120.58$ \\
\hline $3 / 13 / 91$. 4/111/81 & 30 & 78,000 & 115,147 & 418.5 & 0 & 0 & 0 & 0 & 20.07 & 0.02820 & 0.00805 & & & 0.330012 & & 0.02037 & 0 & 0 & 12.221 .31 \\
\hline $4 / 11 / 81 \cdot 5 / 13 / 91$ & 33 & 05,343 & 90,404 & 330.9 & 0 & 0 & 0 & 0 & 20.07 & 0.02820 & 0.00005 & & & 9.330009 & & 733 & 0 & 0 & $11,059.70$ \\
\hline $5 / 13 / 91 \cdot 0 / 13 / 91$ & 32 & 42,213 & 53,354 & 201.4 & 0 & 0 & 0 & 0 & 20.07 & 0.02820 & 0.00805 & & & 9.32999 & & 753 & 0 & 0 & 7.100 .00 \\
\hline a/13/9t - 7/15/81 & 33 & 30,989 & 59.154 & 182 & : & $\circ$ & 0 & 0 & 20.08 & & & 0.02804 & 0.00019 & & 18.87 & $\because 1$ & 0.0037 & $\stackrel{0}{10}-1-1$ & 0.47 \\
\hline $7 / 15 / 89$. 6/95/81 & 32 & 38,444 & 45,492 & 103.1 & 0 & 0 & 0 & 0 & 20.08 & & & 0.02904 & 0.00019 & & 18.870012 & 0.03590 & 0.8717 & 100 & .514 .73 \\
\hline $8 / 15 / 91$ - g/10/91 & 33 & 30,587 & 50,412 & 170.1 & 0 & 0 & 0 & 0 & 20.08 & & & 0.02004 & 0.00019 & & 18.070012 & 0.03500 & 0.8777 & Bo & $7,730,40$ \\
\hline $9 / 10 / 91$. 10/15/91 & 30 & 44,174 & 03,420 & 207.3 & 0 & 0 & 0 & 0 & 20.08 & & & 0.02804 & 0.00019 & & 18.87 & 0.03590 & 0.0500 & 0 & $10,005.10$ \\
\hline 10/15/9j . 11/13/91 & 30 & 07,483 & 88,944 & 397.2 & 0 & 0 & 0 & 0 & 20.08 & 0.02820 & 0.00805 & & & 8.33001 & & 0.03798 & 0.9700 & 0 & $12,199.05$ \\
\hline $11 / 13 / 91$ - $12 / 12 / 91$ & 30 & 82,285 & 113,456 & 473.0 & 0 & 0 & 0 & 0 & 20.08 & 0.02820 & 0.00005 & & & 9.330004 & & 0.03799 & 0.9648 & 0 & $15,114.27$ \\
\hline $12 / 12 / 91 \cdot 1 / 14 / 92$ & 34 & 120,334 & 177,348 & 550.7 & 0 & 0 & 0 & 0 & 20.0 & 0.02820 & 0.00005 & & & 9.329998 & & 0.03799 & 0.8081 & 0 & $21,351.92$ \\
\hline $1 / 14 / 82-2 / 12 / 92$ & 30 & 123,252 & 185.750 & 399.4 & 0 & 0 & 0 & 0 & 20.08 & 0.02820 & 0,00005 & & & 9.329997 & & 0.03314 & 0.9917 & 0 & $20,031.00$ \\
\hline $2 / 12 / 92 \cdot 3 / 13 / 92$ & 31 & 105.187 & 151.724 & 585.1 & 0 & 0 & 0 & 0 & 20.00 & 0.02020 & 0.00005 & & & 9.329995 & & 0.03314 & 0.8903 & 0 & $10,280.95$ \\
\hline $3 / 13 / 82 \cdot 4 / 13 / 92$ & 32 & 24,375 & 159.013 & 502.7 & 0 & 0 & 0 & 0 & 20.08 & 0.02820 & 0.00005 & & & 9.329998 & & 2477 & 0.9876 & 0 & $14,934.38$ \\
\hline $4 / 13 / 92 \cdot 5 / 13 / 82$ & 31 & 74,077 & 104,302 & 383.4 & 0 & 0 & 0 & 0 & 20.08 & 0.02820 & 0.00005 & & & 9.329995 & & 0.03793 & 0.8854 & 0 & $13,339.24$ \\
\hline $5 / 13 / 92 \cdot 0 / 11 / 92$ & 30 & 40,404 & 00,480 & 253.3 & $\circ$ & 0 & 0 & 0 & 20.68 & 0.02820 & 0.00005 & & & 8.33 & & & 0.8568 & 0 & $8,242.00$ \\
\hline $0 / 11 / 92 \cdot 7 / 14 / 92$ & 34 & 30,603 & 40,207 & 177.7 & 0 & 0 & 0 & 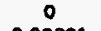 & 20.67 & & & 0.02004 & 0.00019 & & 10.870000 & 0.03703 & 0.0407 & 0 & $\bullet, 219.10$ \\
\hline $7 / 14 / 82 \cdot 0 / 13 / 82$ & m & 30.191 & 43,734 & 103.0 & 101.7 & 122.89 & 0.00281 & 0.00201 & 20.07 & & & 0.02804 & 0.00019 & & 18.009988 & 0.03341 & 0.8000 & 0 & 7.324 .39 \\
\hline $8 / 13 / 92 \cdot 9 / 14 / 92$ & 33 & 38.720 & 54,028 & 103.9 & 108.0 & 151.82 & 0.00281 & 0.00281 & 20.07 & & & 0.02804 & 0.00019 & & 18.809905 & 0.03341 & 0.9273 & 0 & $0,497.73$ \\
\hline $8 / 14 / 92 \cdot 10 / 14 / 92$ & 31 & & 00,1 & 204.0 & 140.43 & 185.90 & 0.00281 & 0.00 & 20.07 & & & 0.02004 & 0.00019 & & 18.070014 & 0.03341 & 0.2078 & 0 & $11,780.80$ \\
\hline $10 / 14 / 92 \cdot 11 / 13 / 92$ & 31 & 73,015 & 104,427 & 397.4 & 205.17 & 293.44 & 0.00281 & 0.00281 & $\theta 1.98$ & 0.028403 & 0.011205 & & & 10.248600 & & 0.03678 & 0.8048 & 0 & $14,438.95$ \\
\hline $11 / 13 / 92$. $12 / 15 / 82$ & 33 & 00,948 & 134,890 & 453.0 & 227.40 & 378.34 & 0.00281 & 0.00281 & 105.25 & 0.02859 & 0.01547 & & & 11.45 & & 0.03078 & 0.8825 & 0 & $10,330.88$ \\
\hline 12/15/92 . 1/14/93 & 31 & 88,828 & 132.950 & 422.0 & 248.01 & 373.61 & 0.00281 & 0.00281 & 165.25 & 0.02059 & 0.01547 & & & 11.45 & & 0.03248 & 0.8844 & 0 & $7,447.21$ \\
\hline $1 / 14 / 93 \cdot 2 / 11 / 93$ & 28 & 88,553 & 144,093 & 513.5 & 199.27 & 792.92 & 0.00548 & $0.0054 \theta$ & 105.25 & 0.02859 & 0.01547 & & & 11,45 & & 0.03137 & 0.2855 & 0 & 19.432 .07 \\
\hline $2 / 11 / 93 \cdot 3 / 15 / 93$ & 33 & 93,917 & 103,009 & 484.0 & 514.07 & 893.28 & 0.00548 & 0.00548 & 185.25 & 0.02859 & 0.01547 & & & 11,45 & & 0.03137 & 0 & 0 & $20,400.40$ \\
\hline $3 / 15 / 93 \cdot 4 / 13 / 93$ & 30 & 70,953 & 100,487 & 453.0 & 432.00 & 503.0 & $0.0054 \theta$ & $0.0054 \theta$ & 185.25 & 0.02859 & 0.01547 & & & 11.45 & & 0.03137 & 0.9846 & 0 & $10,117.57$ \\
\hline $4 / 13 / 93 \cdot 5 / 13 / 93$ & 31 & 47,404 & 03,730 & 259.2 & 200.1 & 348.24 & $0.0054 \theta$ & 0.00548 & 185.25 & 0.02859 & 0.01547 & & & 11.45 & & 0.03048 & 0.9032 & 0 & $0,495.03$ \\
\hline $5 / 13 / 83$. Q/1/93 & 19 & $21,07 \theta$ & 33,779 & 189.4 & 118.8 & 185.11 & $0.0054 \theta$ & 0.00548 & 104.2 & 0.02859 & 0.01547 & & & 0.440022 & & 0.03048 & 0.8415 & 0 & $4,525.59$ \\
\hline $0 / 1 / 03.0114 / 03$ & 14 & $10, \infty 1$ & 20,114 & 184 & 88.00 & 143.10 & 0.00548 & 0.0058 & 30.77 & & 0.02434 & & & & & 0.02038 & 0 & $\stackrel{0}{2}$ & 3.930 .39 \\
\hline $0 / 114 / 83 \cdot 7115 / 93$ & 32 & 25,430 & 57,192 & 182.1 & 139.39 & 313.41 & 0.00548 & $0.0034 \theta$ & 105.20 & & & 0.04077 & 0.01806 & & 20 & 0.03040 & 0.8952 & 20 & $8,915.05$ \\
\hline $\begin{array}{l}7 / 15 / 83.8 / 18 / 93 \\
8 / 10 / 93.9 / 14 / 93\end{array}$ & $\begin{array}{l}33 \\
30\end{array}$ & $\begin{array}{l}25,838 \\
23,013 \\
\end{array}$ & $\begin{array}{l}59,225 \\
55,004\end{array}$ & $\begin{array}{r}100 \\
187.5 \\
\end{array}$ & $\begin{array}{l}141.59 \\
129.4\end{array}$ & $\begin{array}{l}324.55 \\
301.75\end{array}$ & $\begin{array}{l}0.0054 \theta \\
0.0054 \theta\end{array}$ & $\begin{array}{l}0.0054 \theta \\
0.00548\end{array}$ & $\begin{array}{l}185.20 \\
185,20\end{array}$ & & & $\begin{array}{r}0.04077 \\
0.01077\end{array}$ & $\begin{array}{l}0.01880 \\
0.01880\end{array}$ & & $\begin{array}{l}20 \\
20\end{array}$ & $\begin{array}{l}0.03091 \\
0.03091\end{array}$ & $\begin{array}{l}0.8868 \\
0.8973\end{array}$ & $\begin{array}{l}50 \\
12\end{array}$ & $\begin{array}{r}8,771.10 \\
8,799.53\end{array}$ \\
\hline
\end{tabular}




\section{INTERNAL DISTRIBUTION}

$\begin{array}{llll}1 & \text { M. M. Abraham } & 15 & \text { R. L. Shelton } \\ 2 & \text { M. A. Brown } & 16 & \text { J. N. Stone } \\ 3 & \text { G. E. Courville } & 17 & \text { M. P. Ternes } \\ 4 & \text { L. S. Edwards } & 18 & \text { R.L. Wendt } \\ 5 & \text { M. B. Gettings } & 19 & \text { P. P. Wolff } \\ 6 & \text { S. G. Hildebrand } & 20-119 & \text { Energy Conservation Dist., } \\ 7 & \text { P. J. Hughes } & & \text { Building 3147, MS-6070 } \\ 8 & \text { W. P. Levins } & 120 & \text { Central Research Library } \\ 9 & \text { J. M. MacDonald } & 121 & \text { Document Reference Section } \\ 10 & \text { H. A. McLain } & 122 & \text { Laboratory Records-RC } \\ 11 & \text { D. E. Reichle } & 123-125 & \text { Laboratory Records } \\ 12 & \text { A. C. Schaffhauser } & 126 & \text { ORNL Patent Office } \\ 13 & \text { T. R. Sharp } & 127 & \text { Laboratory Protection Division } \\ 14 & \text { R. B. Shelton } & 128 & \text { ORNL Public Relations Office }\end{array}$

\section{EXTERNAL DISTRIBUTION}

129-132 R. Anderson, 1617 Cole Blvd., Solar Energy Research Institute, Golden, CO 80401

133-142 M. Bailey, U.S. Department of Energy, EE-421, 1000 Independence Ave. S.W., Washington D.C. 20585

143 W. Belgrave, DOE Kansas City Regional Support Office, 911 Walnut Suite 1411, Kansas City, MO 65106

144 D. R. Bohi, Resources for the Future, 1616 P Street, N.W., Washington, DC 20036

145 C. Byers, HUD Boston Office of Public Housing, O'Neill Federal Bldg., Boston, MA 02222

146 K. Bond, DOE Kansas City Regional Support Office, 911 Walnut Suite 1411, Kansas City, MO 65106

147 M. Burger, DOE Chicago Regional Support Office, 9800 S. Cass Ave., Argonne, IL 60439

148 M. Chamber, DOE Dallas Support Office, 1420 W. Mockingbird Ln. Suite 400, Dallas, TX 75247

149 N. Costa, DOE Philadelphia Regional Support Office, 1880 JFK Blvd. Suite 501 , Philadelphia, PA 19103

150-159 R. C. Diamond, Lawrence Berkeley Laboratory, MS-90-3074, 1 Cyciotron Rd, Berkeley, CA 94720

160 T. E. Drabek, Department of Sociology, University of Denver, Denver, CO 80208-0209

161 H. E. Fuestel, Lawrence Berkeley Laboratory, MS-90-3074, 1 Cyclotron Rd, Berkeley, CA 94720

162 R. Groberg, U.S. Department of HUD - Energy Division, 451 7th St. S.W. Room 7244, Washington D.C. 20410-7000

163 D. Hawkins, U.S. Department of Energy, EE-40, 1000 Independence Ave. S.W., Washington D.C. 20585

164 H. M. Ingram, Udall Center for Studies in Public Policy, The University of Arizona, 803/811 East First St., Tucson, AZ 85719

165 A. Jhaveri, DOE Seattle Regional Support Office, 800 Fifth Ave. Suite 3950, Seattle, WA 98104

166 R. Jones, DOE Denver Regional Support Office, 2801 Youngfield Suite 380, Golden, CO 80401-2266

167 R. Karney, U.S. Department of Energy, EE-42, 1000 Independence Ave. S.W., Washington D.C. 20585

168 P. J. King, DOE Boston Regional Support Office, One Congress St. Room 1101, Boston, MA 02114 
170 B. McDonough, Boston Edison Company, 800 Boylston St., P-301, Boston, MA 02199

171 R. McLaughlin, HUD Boston Office of Public Housing, O'Neill Federal BIdg. Room 255, Boston, MA 02222

172 T. P. Malone, U.S. Department of HUD, O'Neill Federal Bldg. Room 313, Boston, MA 02222

173 W. R. Mixon, TECH Support Services, 1018 W. Outer Dr., Oak Ridge, TN 37830

174-175 M. P. Modera, Lawrence Berkeley Laboratory, MS-90-3074, 1 Cyclotron Rd, Berkeley, CA 94720

176 Steve Morgan, EUA Citizens Conservation Services, Inc., Boott Mills South, c/o EUA Cogenex Corp., 100 Foot of John St., Lowell, MA 01852-1197

177-186 M. Myers, U.S. Department of Energy, EE-421, 1000 Independence Ave. S.W., Washington D.C. 20585

187 R. Nadar, P.O. Box 19367, Washington D.C. 20036

188 R. Nason, Chelsea Housing Authority, 54 Locke St., Chelsea, MA 02150

189 R. P. O'Brien, New England Power Service, 25 Research Dr., Westborough, MA 01582

190 J. Oliver, DOE San Francisco Regional Support Office, 1301 Clay St., Oakland, CA 94612-5219

191 R. Ovagimian, HUD Regional Office, O'Neill Federal Bidg., Boston, MA 02222

192 W. Rivers, U.S. Department of HUD, 909 1st Ave. Suite 125, Seattle, WA 98104-1000 F. Singleton, DOE Atlanta Regional Support Office, 730 Peachtree St., Atlanta, GA 30319

194 G. F. Sowers, P.E., Senior Vice President, Law Companies Group, Inc., 114 Townpark Drive, Suite 250, Kennesaw, GA 30144-5599

195 C. M. Walton, Department of Civil Engineering, College of Engineering, The University of Texas, Cockrell Hall, Austin, TX 78712 


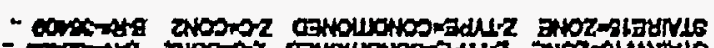

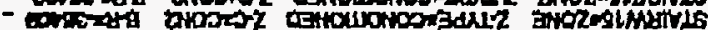

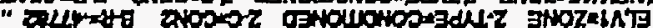

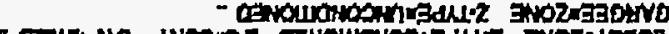

7 T:

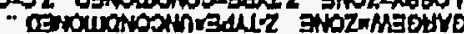

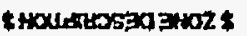

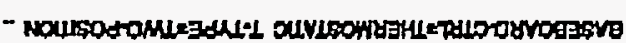

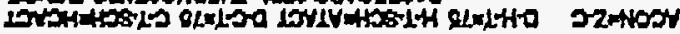

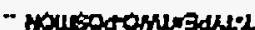

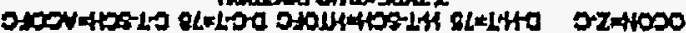

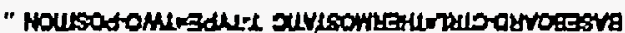

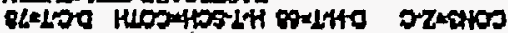

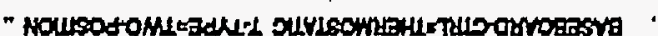

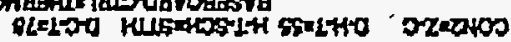

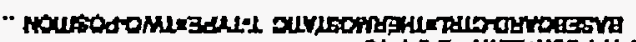

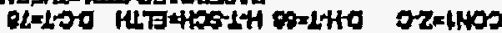

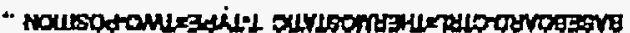

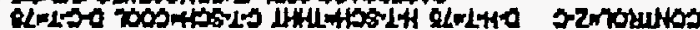

5 sanmwosegrs groz:

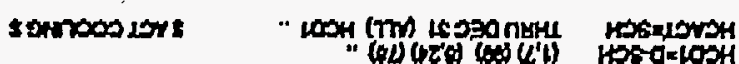

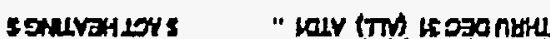

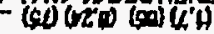

tos:cordy

Hostoraly

Exincosotos

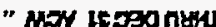

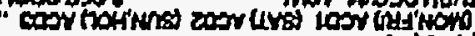

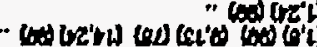

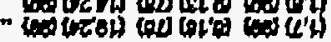

$\cos \rightarrow x+0,5$

Hos-Manisy

tostompor

tosengers $100-0 \times 100 \%$

+ Eativeraxos

"MH LF"

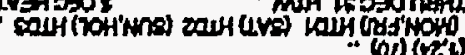

$4 \times 6 \rightarrow \infty 044$ 10smamer $0 \times 6 \times 5014$

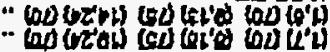
$10002 \pi 4$ tosoniols

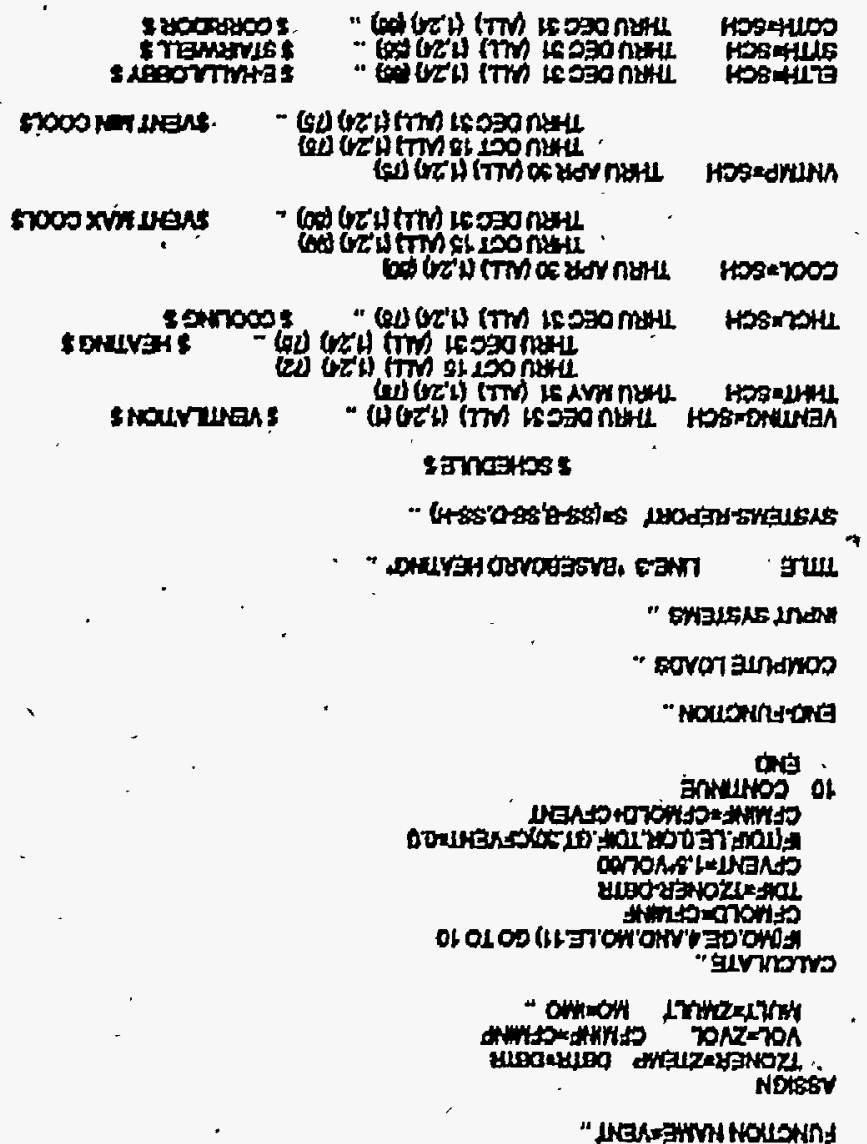





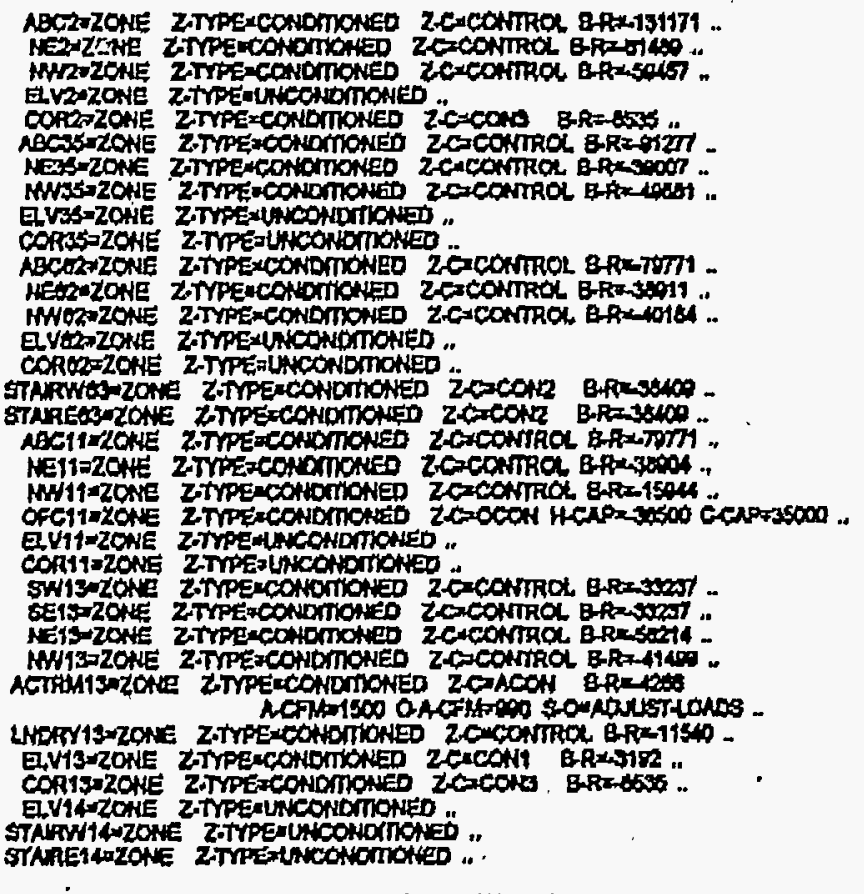

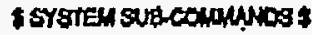

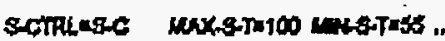

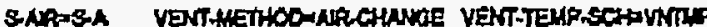

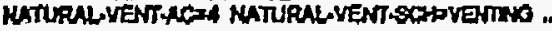

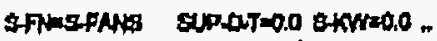

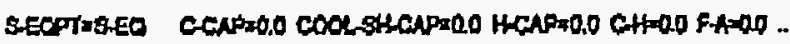
$\$$ SY\$TEUS DESCRPPIONS.

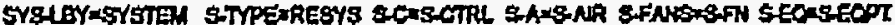

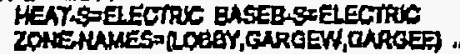

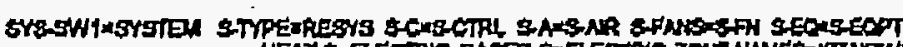

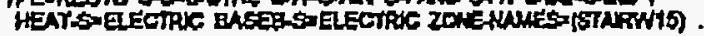

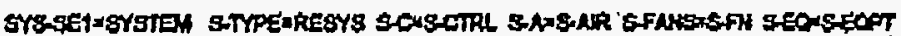

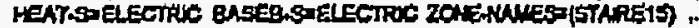

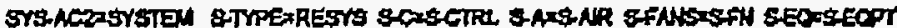

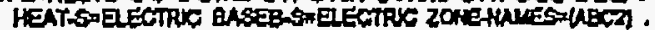

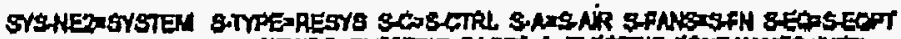

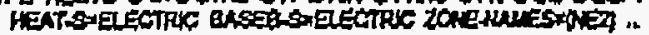

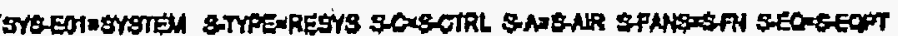

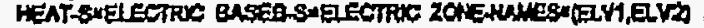

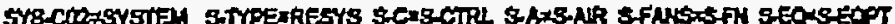

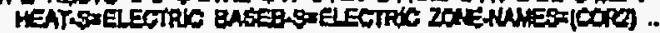

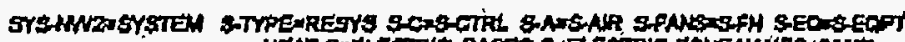

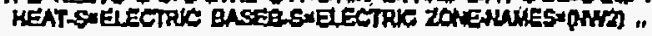

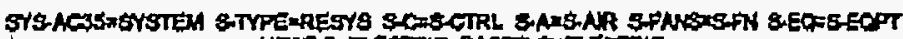

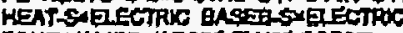

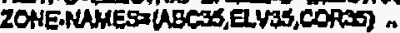

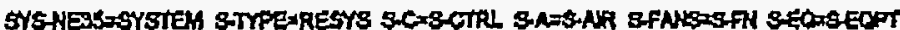

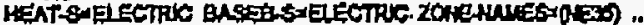

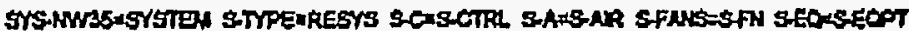

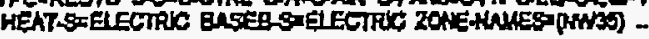

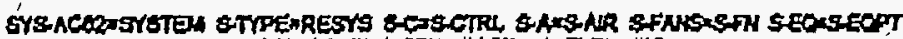

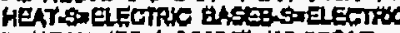

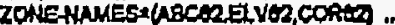

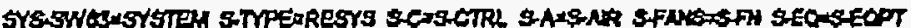

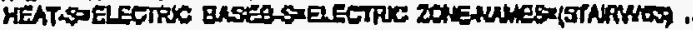

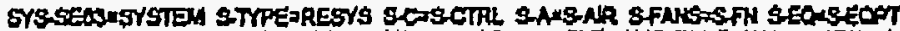

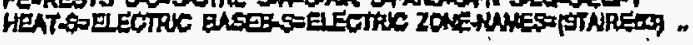


